\title{
The effect of visible skin condition on the perception of female facial age, health, and attractiveness
}

\author{
DISSERTATION \\ zur Erlangung des mathematisch-naturwissenschaftlichen Doktorgrades \\ "Doctor rerum naturalium"

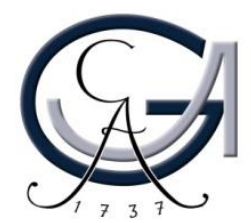 \\ der Georg-August-Universität Göttingen
}

vorgelegt von

\section{Nadine Samson}

aus Schwelm

Göttingen 2011 
First reviewer:

Second reviewer:

Date of oral examination:
Prof. Dr. Peter M. Kappeler

Dr. Bernhard Fink

June $6^{\text {th }}, 2011$ 


\section{CONTENTS}

\section{Chapter 1}

General Introduction

Part I

\section{Chapter 2}

Visible skin condition and perception of human facial appearance

\section{Part II}

\section{Chapter 3}

Visible changes of female facial skin surface topography in relation to age and attractiveness perception

\section{Chapter 4}

Interaction of skin color distribution and skin surface topography cues in the perception of female facial age and health

\section{Part III}

\section{Chapter 5}

Does a woman's skin colour indicate her fertility level? Preliminary findings.

\section{Chapter 6}

General Discussion 72

Summary 84

Zusammenfassung 85

Bibliography 87

Appendix 103

Affiliations of Co-Authors 106

Acknowledgements 107

Curriculum Vitae 109 


\title{
CHAPTER 1
}

\section{GENERAL INTRODUCTION}

\author{
"Our skin mediates the most important transactions of our lives. Skin is key to our \\ biology, our sensory experiences, our information gathering, and our relationships \\ with others."
}

(in: Nina Jablonski, 2006: Skin. A natural history)

\section{Facial attractiveness}

The perception of conspecifics' faces is of particular importance to social animals, such as humans, since it plays a significant role in inter-individual interactions (Haxby, Hoffman, \& Gobbini, 2002). At least in Western societies, the face is the most frequently exposed body part and almost permanently visible to others. It is therefore likely that the face not only serves non-verbal communication through facial expression. Evolutionary and socialisation theory suggests that facial appearance influences an individual's development (e.g., social skills, sexual experience) and his or her social interactions (reviewed in Langlois et al., 2000). For instance, physically attractive children and adults are assigned more positive personality traits than unattractive ones, and they are assumed to lead a happier and more successful life (Langlois et al., 2000; Mobius \& Rosenblat, 2006). Furthermore, attractiveness facilitates facial sex classification in adults. Identifying the sex of an individual is a fundamental event which takes place instantaneously in social interaction (Hoss et al., 2005).

Recent research has revealed that ratings of facial attractiveness are remarkably consistent, regardless of ethnicity, nationality, or age (reviewed in Langlois et al., 2000; PentonVoak \& Perrett, 2001). Thus, evolutionary psychologists propose that human preferences for certain facial beauty standards are defined neither arbitrarily nor culturally. Rather, they evolved to facilitate mate selection (Rhodes et al., 2007), since physical attractive features may provide indicators of "good genes" (Andersson, 1994). In other words, sexual selection 
may has shaped the human mind so that faces of healthy and fertile individuals are perceived as more attractive (Luxen \& Van de Vijver, 2006).

Thornhill and Gangestad (1993) proposed several underlying mechanisms that cause attractive facial features to correlate positively with phenotypic and genetic quality (see Kalick et al., 1998). Over the past 15 years, research on facial attractiveness has focused on three features: (1) facial fluctuating asymmetry, (2) facial averageness, and (3) facial sexually dimorphic traits. Fluctuating asymmetry (FA) denotes small deviations of paired traits in otherwise bilateral symmetric organisms, which are randomly assigned to the left and right side. Since the degree of asymmetry increases under environmental and genetic stress during ontogeny (Özener \& Fink, 2010), facial FA is thought to reflect an individual's ability to resist developmental perturbations (Thornhill \& Moller, 1997; Watson \& Thornhill, 1994). Investigators, who have shown attractiveness preferences for average facial shape and morphology, argued that averageness indicates genetic quality because it denotes heterozygosity (Galton, 1907; Langlois \& Roggman, 1990; Thornhill \& Gangestad, 1993). Despite this preference for averageness, the single most attractive face in a sample is not necessarily the most average one (Alley \& Cunningham, 1991), but may display distinct sexual dimorphic characteristics that signal reproductive quality of the bearer (Little et al., 2008) as well as immunecompetence as sex hormones suppress immune function (Folstad \& Karter, 1992). Because the above mentioned features are supposed to correlate with an individual's reproductive fitness, humans who mate preferentially with facially attractive individuals would have a better chance of having healthier, more fertile offspring (Gallup Jr. \& Frederick, 2010).

While there is ample evidence for the significance of certain facial characteristics in the perception of facial attractiveness and mate selection, only few studies have been concerned with the role of visible facial skin condition in mate selection. This may be surprising, since flawless skin is assumed to be the most universally desired feature in human mates (Symons, 1995). This preference may be particularly present in men. Because men and women differ in their reproductive investment, evolutionary psychology predicts sex differences in the priorities they place on the qualities desired in long-term mates (Buss \& Schmitt, 1993; Trivers, 1972). Accordingly, men have been shown to attach greater importance to physical appearance or beauty in a prospective mate than women (Buss \& Schmitt, 1993; Herz \& Inzlicht, 2002). Due to intrasexual competition among females, however, both sexes should be aware of variations in female facial skin condition. In the present thesis, I therefore focussed on the influence of visible facial skin condition on men and women's perception of female age, 
health, and attractiveness. Since actual mate choice and mating depends on various factors (e.g. Buston \& Emlen, 2003), I measured preferences and not actual mate choice.

\section{Facial skin appearance}

Facial skin in particular is continuously exposed to ever-changing environmental conditions, such as solar and thermal radiation, or biological insults (Robert \& Kupper, 1999), but is also influenced by an individual's internal homeostasis (Slominski \& Wortsman, 2000; Zouboulis, 2000). Thus, its visual appearance may reflect useful information about a putative mate. For instance, visible lesions by invading pathogenic microorganisms or ectoparasites may signal aspects of an individual's immunocompetence and current health status (Nordlund, 2009; Robert \& Kupper, 1999), while neuroimmunological skin diseases such as psoriasis and eczematous dermatitis may reflect a certain level of psychological stress (KimyaiAsadi \& Usman, 2001). Hence, people's preference for flawless skin may reflect 'good gene' selection. While parasite infections and dermatoses may be clearly visible in affected individuals, initial empirical studies in evolutionary psychology now suggest that humans are sensitive to more subtle health cues (Jones et al., 2004; Stephen et al., 2009). Moreover, there are indications that facial skin condition of women may reflect information about their fertility (Johnston et al., 2005) and, more obviously, age (Matts \& Fink, 2010; Nkengne et al., 2008).

\section{Perception of female facial age and health}

Skin colour seems to be one important cue to an individual's health. In a recent study by Stephen et al. (2009), participants were asked to manipulate the skin colour of Caucasian facial images along CIELab colour axes to enhance perceived health. Since skin chromophores differ in their absorption peak in the visible light spectrum, the authors were able to disentangle the contribution of melanin (absorption increases toward shorter wavelengths), oxyhaemoglobin $(540 \mathrm{~nm}$ and $577 \mathrm{~nm})$, and carotenoids (e.g. $\beta$-carotene: $450 \mathrm{~nm}$ ) to health perception (Parra, 2007; Stahl et al., 1998). Findings suggested that a combination of oxyhaemoglobin, high concentration of carotene, and low concentration of melanin increase a healthy looking appearance as participants increased skin redness ( $\mathrm{a}^{*}$-value, red-green axis), yellowness ( $b^{*}$-value, blue-yellow axis) and lightness ( $\mathrm{L}^{*}$-value, lightness-darkness axis). Stephen et al. (2009) argued that these results resembled the red and yellow colour cues of health displayed by many species of non-human animals (e.g. hormonal status, Czaja et al., 1977; Dixson, 1983). For instance, in various non-human primate species saturation of red 
colour indicates dominance rank (Setchell \& Dixson, 2001) and fertility status (Gauthier, 1999; Strum \& Western, 1982), which are both correlated with health. Moreover, long periods of (prenatal) stress were found to reduce melanin production in female barn owls (Tyto alba) (Roulin et al., 2008), and thus indicate reduced health. Likewise, various diseases in humans, such as congenital heart defects (Uebing et al., 2008), anemia (Lu \& Wu, 2004), or hepatic jaundice (Carter, Daly, \& Ramani, 2007), are accompanied with changes in skin colour.

Influences of changes in basal skin colour on health perception, however, have to be distinguished from changes in skin colour distribution due to premature photoageing, which have also been shown to influence health perception and, to a lesser extend, age perception. Facial skin in particular has been suggested to indicate an individual's age (Fink et al., 2008; Nkengne et al., 2008), since skin is the organ carrying the most visible age-related changes (Gunn et al., 2008). Specifically, there are age-related changes in skin surface topography (e.g., fine lines, wrinkles) and skin colour characteristics, such as melanocyte pigmentation, dermal blood vessels, and subsurface scattering by collagen (Matts et al., 2007). Particularly women exhibiting visual signs of cutaneous aging within their face were considered to be older, less healthy, and less attractive (Fink \& Matts, 2008; Fink et al., 2008), independently of facial shape (Matts et al., 2007). Studies by Fink et al. (2008) further showed a positive correlation between perceived attractiveness and youth of female faces varying in skin colour evenness and people's visual attention, such that women with less contrast in skin colour received more positive ratings and higher visual attention as measured by eye-tracking technology (Fink et al., 2008). As of yet, little is known about the impact of skin surface topography on age, health, and attractiveness perception of female faces. A study by Fink and Matts (2008) revealed that facial skin surface topography is a stronger age cue than facial colour distribution, a finding that was later confirmed by Gunn et al. (2009). Age perception does not seem to be predominantly influenced by the type of wrinkle, but rather the number of wrinkles (i.e. their quantity) and the depth of furrows (Aznar-Casanova, Torro-Alves, \& Fukusima, 2010). It is not yet known how pronounced the wrinkles must be in order to be perceived as fine lines. Moreover, it is yet unknown whether cutaneous age cues of different facial regions influence female facial age and attractiveness perception in an equal manner. Furthermore, a differential effect of facial skin colour characteristics and surface topography cues on age and health perception has been observed (Fink \& Matts, 2008), but the relative contribution of these cues on the perception of both attributes is still unknown. 


\section{Perception of female facial fertility}

Besides age, the likelihood of fertilisation and impregnation further varies with the sex hormone concentration across the female menstrual cycle, i.e. referring to a standard 28-day cycle conception probability increases with an oestrogen surge in the second week and decreases with its decline after ovulation and the increase in progesterone levels (Nelson, 2000; Wilcox, Dunson, \& Baird, 2000). Men being sensitive to sex hormone-mediated changes in female behaviour or physiology might therefore have two decisive advantages, as this would maximize their chances of successful fertilisation and reduce energetic costs associated with long courtships and multiple mating (Heistermann et al., 2001). Like in Old World monkeys (Nieuwenhuijsen, de Neef, \& Slob, 1986; Wallen, 1990) and great apes (Stanford, 1998), women possess an 'extended sexuality', i.e. their sexual behaviour is not restricted to the fertile days of the menstrual cycle (Gangestad \& Thornhill, 2008; Tarin \& Gomez-Piquer, 2002). In contrast to females of numerous primate species, however, women do not advertise their state of fertility through conspicuous visual cues, e.g. by pronounced sexual swellings (e.g. hamadryas baboons, Higham et al., 2008; bonobos, Reichert et al., 2002), or changes in paracallosal skin colour (e.g. vervet monkeys, Dixson, 1983). Therefore, women's ovulation has been considered to being concealed. Recent research now indicates that female concealment of ovulation is not perfect in humans, since men's visual (Roberts et al., 2004), olfactory (Kuukäsjarvi et al., 2004; Singh \& Bronstad, 2001), and auditory preferences (Pipitone \& Gallup, 2008) for women change with female conception probability across the menstrual cycle. Hence, evolutionary psychologists suggest a positive selection pressure on men to detect women's fertile phase, despite a sexually antagonistic selection pressure on women to conceal reliable cues of ovulation (reviewed in Gangestad \& Thornhill, 2008).

Considering the role of the face in human communication (Ekman, 2003) and its contribution to overall attractiveness perception (Peters, Rhodes, \& Simmons, 2007; Thornhill \& Grammer, 1999), it is reasonable to assume that men have adapted preferences for facial cues that signal female fertility. Until now, little is known about the facial cues that might provide information about a woman's conception probability at different days of the menstrual cycle. Fluctuating asymmetry in soft tissues (e.g., in ears) has been found to vary across the menstrual cycle and is therefore suggested to be one feature indicating conception probability (Manning et al., 1996). Findings by Law Smith et al. (2006) propose that facial skin condition might be another source of information men take into account when assessing fertility. The authors reported an effect of the menstrual cycle on men's perception of femininity, attractiveness, and health in women without make-up, but not in women using make-up. Johnston 
et al. (2005) further reported that when completing a sex-categorization task, men were faster in recognising faces of women at the time of menstruation than women at the time of ovulation / mid-cycle, regardless of whether women took hormonal contraceptives or not. Taking into account the cyclically fluctuating sex hormones, the authors argued that men's higher sensitivity to markers of menstruation (e.g. blemished skin) than to markers of ovulation (e.g. clear skin) might be due to hormone-mediated changes in female facial skin condition. This assumption converges with evidence of an influence of oestrogens and progesterone on skin structure and appearance. As a hormone target and an endocrine gland, the skin is replete with oestrogen receptors (in both dermis and epidermis) and to a lesser extent progesterone receptors (Farage, Neill, \& MacLean, 2009). Cyclically fluctuating levels of both hormones across the female menstrual cycle have been shown to influence, among other things, skin surface lipid secretion, sebum production (Thiboutot, 2001), fat deposition, dermal collagen content, skin thickness and hydration (Farage, Neill, \& MacLean, 2009; Grabmeier, Landthaler, \& Hohenleutner, 2005), as well as vasodilation (Charkoudian et al., 1999) and melanogenesis (Farage, Neill, \& MacLean, 2009). Hence, it is very likely that some of the hormone-mediated changes in female facial skin condition drive men's perception of female fertility across the menstrual cycle. Changes in facial skin colour might be most conspicuous, yet empirical evidence is lacking.

\section{Aims and outline of the thesis}

The present thesis aims to contribute to a better understanding about the importance of women's visible facial skin condition for male (and to some extend female) age, health, and attractiveness perception. Hence, in the first Part of the thesis I review the current research by linking dermatological knowledge on visible skin condition with theories of facial appearance and perception and discuss these links with reference to the evolutionary psychology framework (Chapter 2). Part II then focuses on facial skin as a cue to female age and health by investigating the noticeability of variation in facial cutaneous age cues, i.e. what is perceived and how does this influence perception (Chapter 3 and 4). More specific questions addressed in this part are:

(1) Is there a hierarchy among facial regions' skin surface topography in influencing human's age and attractiveness perception?

(2) At what magnitude of systematically smoothed facial skin colour distribution and surface topography are changes noticeable? 
(3) What are the relative contributions and interacting effects of skin surface topography and skin colour distribution in human age and health perception?

Since studies investigating the perception of female visible facial skin condition have neglected the possibility that skin condition may also indicate a woman's conception probability at different days of the menstrual cycle (e.g., Fink, Grammer, \& Matts, 2006; Fink et al., 2008) the final question has to be:

(4) Do cyclically fluctuating changes in female facial skin colour across the menstrual cycle drive men's health and attractiveness perception?

Hence, Part III deals with facial skin as a cue to female fertility (Chapter 5) (see Figure 1 for thesis outline).

\section{Skin project}

The effect of visible skin condition on the perception of female facial age, health, and attractiveness

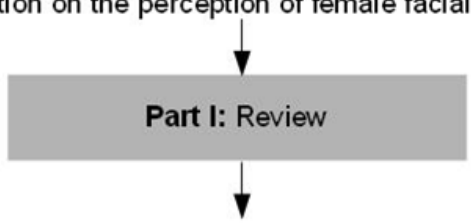

Chapter 3

Visible skin condition and perception of human facial appearance
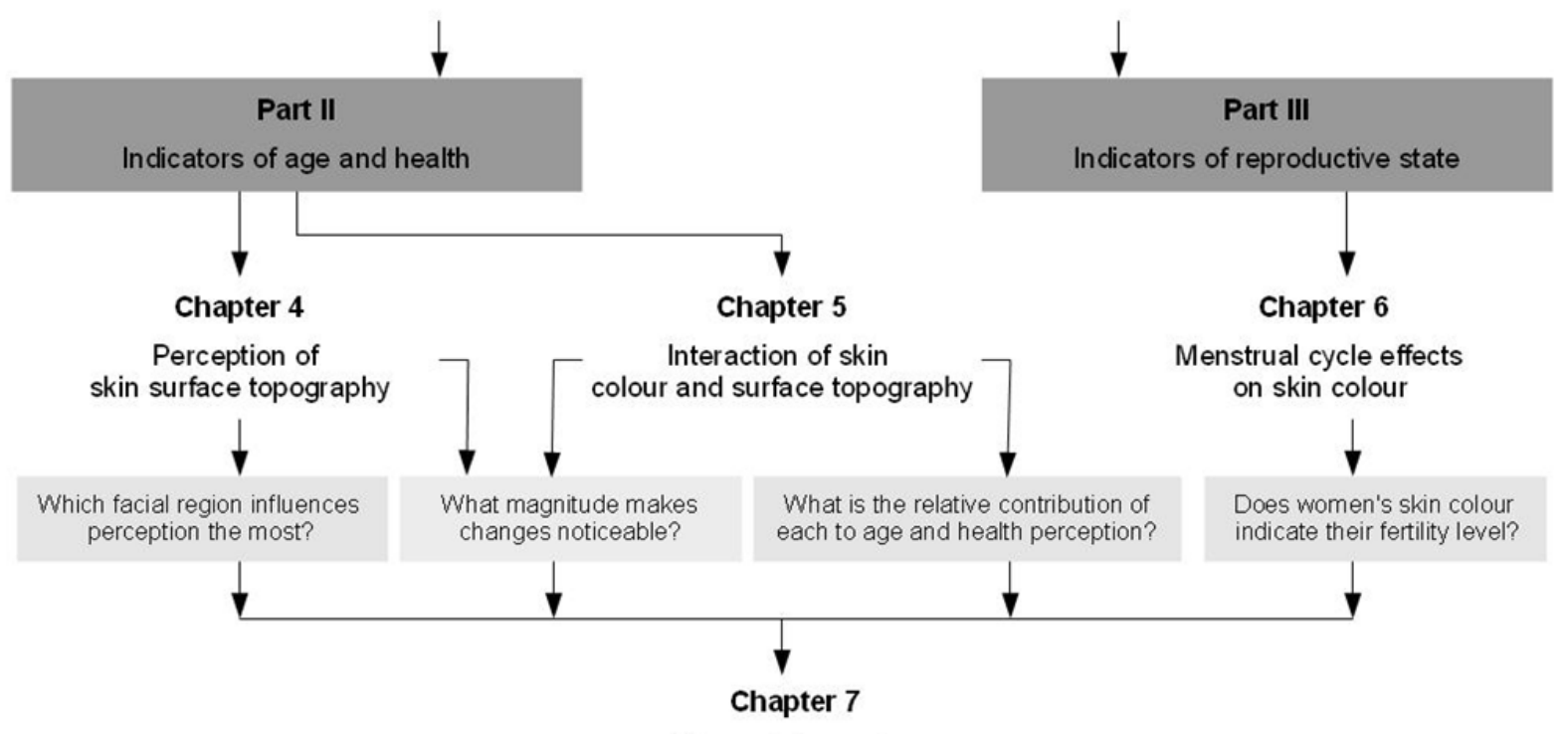

General discussion

Figure 1 Project outline of the thesis 


\section{Facial skin as an indicator of female age and health}

In collaboration with Procter \& Gamble, Fink and colleagues conducted a series of consecutive studies that combined an evolutionary psychology approach with modern dermatological measurement techniques (see for review Matts \& Fink, 2010). In doing so, they investigated human perception of cutaneous age cues of female faces and their influence on age, health, and attractiveness judgments. Part II of this thesis extends their studies, which have focussed on changes in women's skin colour distribution in relation to UV-induced premature skin aging. More specifically, Chapter 3 and 4 elaborate mainly Fink and Matts' (2008) attempt to disentangle the contribution of facial skin surface topography and skin colour characteristics to perceived health and age. The authors therefore created four sets of facial stimuli from images of British women, aged 40 - 75 years: (1) original faces, (2) faces with smoothed topography, (3) faces with smoothed colour, and finally, (4) faces with both topography and colour smoothed. A subsequent rating experiment revealed that both features differed with regard to the strength to which they influenced age and health perception, i.e. topographical cues seemed to be the stronger age cue, while colour characteristics appeared to provide more health information (Fink \& Matts, 2008). Yet, Fink and Matts (2008) neglected two important points. First, they disregarded the possibility that the removal of skin surface topography cues in some parts of the face might have stronger effects on perception than in other parts. Second, they focussed only on visible differences between the original (e.g. unmodified) facial images and those with entirely smoothed skin colour and / or surface topography. Thus, variations in the magnitude of topography and colour distribution remained unconsidered. Both issues are addressed in Chapter 3, which describes the first experiment of this thesis. Here, I investigated men and women's perception of changes in female facial skin surface topography by digitally smoothing them in certain facial regions. By systematically (i.e. in $20 \%$ increments) varying the magnitude of topography in the facial parts that showed the strongest effects on perception, I examined the noticeability of such changes. Because virtually nothing is known about human sensitivity to variations in cutaneous age cues of female faces, we decided to use images of postmenopausal women who show pronounced lines and wrinkles in multiple facial areas as well as dilated blood vessels and age spots. This will provide an important basis for future studies on the effect of facial cutaneous age cues on sexual selection.

Since participants have been shown to be highly sensitive to relatively subtle variations in surface topography, I finally investigated the relative contribution and interacting effects of skin colour homogeneity and surface topography in perceived facial age and health. This was 
realised by gradually removing both skin features in $25 \%$ increments and testing people's perception of them (Chapter 4).

\section{Facial skin as an indicator of female fertility}

Part III of the present thesis deals with the question whether a woman's facial skin condition indicates her fertility, and whether men are sensitive to changes in female's facial skin appearance due to cyclically fluctuating sex hormone concentrations in assessing peak fertility (Chapter 5). More specifically, since oestrogens and progesterone are strong melanogenic stimulants (Farage, Neill, \& MacLean, 2009) and also increase vasodilation (Charkoudian et al., 1999), Chapter 5 considers whether men's attractiveness and health perception varies across the female menstrual cycle as a result of changes in female facial skin colour.

The few existing studies investigating skin colour in relation to the menstrual cycle revealed an increase in skin pigmentation in the luteal phase and in some cases during menstruation. Within the face, changes in melanin pigmentation are most commonly seen around the eyes, followed by the forehead, the cheeks, and the eyelid (McGuiness, 1961; Snell \& Turner, 1966). Furthermore, female skin was reported to (slightly) lighten around ovulation (Buss, 2008), which might increase their attractiveness as observations by Van den Berghe and Frost (1986) lead one to assume. Based on the Human Relations Area Files, a catalogue of full-text ethnographies on nearly 400 different ethnic, cultural, religious, and natural groups worldwide (see http://www.yale.edu/hraf/index.html), the authors reported a virtually universal preference of men for females with a lighter than average skin colour of the local population (Van den Berghe \& Frost, 1986). Given that these findings were mainly based on self-reports, studies are required, in which both women's conception probability and their skin colour are quantified objectively. Snell and Turner (Snell \& Turner, 1966) have taken a first step in this direction by objectively evaluating the absorption of melanin pigmentation and haemoglobin with a Photovolt photoelectric reflection meter. Skin colour reflectance was measured by calculating the percentage of light reflected from the skin at different wavelengths of the visible spectrum by using red, green, and blue filters (reviewed in Parra, 2007). However, the authors did not investigate the perception of changes in facial skin colour and possible influences on male attractiveness judgments. Hence, experiments are needed that link the quantified colour changes with male perception to test the hypothesis that men are sensitive to the cyclically fluctuating changes in a woman's skin colour, thereby assessing her probability to conceive. 
In the experiment described in Chapter 5, I therefore objectively quantified women's facial skin colour at high (late follicular phase) and low (mid-luteal phase) fertility using spectrophotometric measurements and asked men to judge corresponding facial images taken in both sessions on attractiveness and apparent health. In contrast to the colour reflectance meter used by Snell and Turner (1966), nowadays spectrometric measurement instruments normally incorporate microcomputer hardware and software so that spectral measurements and subsequent conversion of tristimulus values to colour coordinates are integrated. Since each particular colour can be described unambiguously in terms of its Cartesian coordinates in a threedimensional CIELab colour space (Weatherall \& Coombs, 1992), spectrophotometric measurement techniques allow to objectively measure and specify the magnitude of observed differences in skin colour between the late follicular and mid-luteal phase. More specifically, each colour could be described with regard to its lightness ( $\mathrm{L}^{*}$-value), its position between red / magenta and green ( $\mathrm{a}^{*}$-value) as well as its position between yellow and blue ( $\mathrm{b}^{*}$-value) (Piérard, 1998). If female sex hormones lead to a measurable increase in melanogenesis, $\mathrm{L}^{*}$ values should decrease and $b^{*}$-values increase towards the end of the menstrual cycle. If female sex hormones increase vasodilation, $\mathrm{a}^{*}$-values should increase in the course of the menstrual cycle (cf. Stephen et al., 2009). 
Part I

Review 


\section{Chapter 2}

\section{VISIBLE SKIN CONDITION AND PERCEPTION OF HUMAN FACIAL APPEARANCE}

Nadine Samson*, Bernhard Fink* \& Paul J. Matts ${ }^{\dagger}$

* Department of Sociobiology / Anthropology, University of Goettigen, Germany

† The Procter \& Gamble Company, Rusham Park Technical Centre, Whitehall Lane, Egham, Surrey, UK KT 2HT, U.K.

International Journal of Cosmetic Science (2010) 32: 164-187 


\section{Synopsis}

Evolutionary psychology suggests that certain human beauty standards have evolved to provide reliable cues of fertility and health. Hence, preferences for some physical characteristics of the face and body are thought to reflect adaptations for the promotion of mate choice. Studies that have investigated facial attractiveness have concentrated mainly on features such as symmetry, averageness and sex-typical traits, which are developed under the influence of sex steroids. Few studies, however, have addressed the effect of human skin condition on perceptions of facial appearance in this context, and possible implications for sexual selection. There is now accumulating evidence that skin pigmentation and skin surface topography cues, particularly in women, have a significant influence on attractiveness judgements, as they seem primarily to signal aspects of age and health. This article (i) reviews briefly some of the main determinants of visible skin condition, (ii) presents recent evidence on its signalling value in face perception, and (iii) suggests areas for future research with reference to an evolutionary psychology framework.

Keywords: attractiveness, humans, perception, skin colour, skin surface topography

\section{Résumé}

La psychologie évolutive suggère que certaines normes de beauté de l'homme ont évolué pour fournir des indices fiables de la fécondité et la santé. Par conséquent, les préférences pour certaines caractéristiques physiques du visage et du corps sont censées refléter les adaptations pour la promotion de ce choix. Les études portant sur l'attractivité du visage se sont essentiellement concentre'es sur des fonctionnalités telles que la symétrie, l'aspect d'ensemble et le sexe, éléments typiques développés dans le cadre de l'influence des stéroïdes sexuels. Mais peu d'études ont porté sur l'effet de l'état de la peau humaine sur la perception de l'apparence du visage, et ses implications possibles sur la sélection sexuelle. Il y a maintenant un faisceau de preuves montrant que la pigmentation de la peau et l'aspect de surface comme repères topographiques, notamment des femmes, ont une influence significative sur l'attractivité, car ils apparaissent comme des signaux de l'âge et de la santé. Cet article (i) passe brièvement en revue certains des déterminants principaux de l'état cutané visible, (ii) présente les dernières preuves de leur valeur de signalisation dans la perception du visage, et (iii) propose des domaines de recherché future comme reference-cadre de la psychologie évolutive. 


\section{Introduction}

Variability in visible skin appearance is an important signal and moderator in human social interaction. For example, flushing because of increased blood flow when embarrassed (Crozier, 2007) or from sexual arousal (Mah \& Binik, 2001) facilitates non-verbal communication, as it reflects an individual's emotional state. Moreover, deliberate modifications of the skin, such as scarification, tattoos and piercing, are used for personal expression, rite of passage, or fashion trends (e.g., Dubose \& Pratt, 2004; Schildkrout, 2004; Stirn, 2003). The significance of the appearance of the skin is also evident in dermatological disorders, which can have a major impact on patients' daily activities, self-esteem, mental well being, and social relationships, because of their conspicuous visibility (Barankin \& DeKoven, 2002; Beattie \& Lewis-Jones, 2006). Interestingly, a study of patients from different social and ethnic groups in South Africa revealed that women were more likely than men to report the effects of skin disease on self-esteem, clothing choice, treatment problems, and anxiety (Jobanputra \& Bachmann, 2000). Because of the existence of an attractiveness stereotype (Dion, Berscheid, $\&$ Walster, 1972), public responses to skin diseases such as psoriasis, atopic dermatitis, and acne, often results in prejudice and stigmatization. The origins of such response are thought to be rooted firmly in history and culture, because skin disease has long been associated with disgrace and danger in several cultures (Jobling \& Naldi, 2006). Hence, it has been reported that the prevalence of psychiatric and psychosocial co-morbidity, including depressive illness, obsessive-compulsive disorder, social phobia, and body dysmorphic disorder in dermatological patients ranges from $25 \%$ to $43 \%$ (Hong, Koo, \& Koo, 2008). Moreover, in a study by Gupta et al. (1993), 6\% of patients suffering from psoriasis reported suicidal thoughts.

The cosmetic industry has often conveyed the image that youthful and healthy looking skin, free of blemishes and hair, is most desirable, primarily for women (Cotterill, 1988). As the face is of particular importance in human social communication (Haxby, Hoffman, \& Gobbini, 2000, 2002) and body image (Cotterill \& Cunliffe, 1997), even minor imperfections can have an often disproportionately major impact on mental health and quality of life (QoL). Hence, it is now known that women with facial skin complaints may be particularly prone to depression and an increased risk of suicide (Cotterill \& Cunliffe, 1997). In accordance with previous studies, make-up was found to improve significantly the QoL in women with disfiguring skin disorders (Boehncke et al., 2002; Hayashi et al., 2005). For example, Hayashi et al. (2005) reported a significant decrease in the score on the "General Health Questionnaire 30" (GHQ 30) in female acne sufferers after receiving advice on the appropriate use of make-up. The GHQ 30 was originally designed to screen people for psychological or mental health care 
services, and patients who scored higher than seven were recommended for psychological counselling. Women scored on average $>9$ on the GHQ 30 before the makeup lessons, whereas afterwards the score improved to a normal level $(<5)$.

Importantly, unblemished facial skin also drives the positive perception of attractiveness in healthy women without dermatological disease. In a study by Mulhern et al. (2003) 10 female volunteers were made up by a beautician to produce five possible scenarios: (1) no make up, (2) foundation only, (3) lip make-up only, (4) eye make-up only, (5) and full facial makeup. The results revealed that faces with full make-up were judged higher on attractiveness than without make-up. Moreover, it was found that attractiveness ratings of certain facial regions were also influenced by the sex of the rater. Whereas women judged eye-make up as having the greatest impact on attractiveness, in men both eye make-up and skin foundation influenced their attractiveness ratings. In accordance with the effect of make-up on mental well being in patients with skin disorders, cosmetic usage also enhances self-esteem in healthy women, as it positively influences both self-perception and perception by others (Cash \& Cash, 1982; Cash et al., 1989; Cash, Rissi, \& Chapman, 1985). Moreover, Cash et al. (1985) reported a systematic relationship between the use of cosmetics and locus of control, suggesting that cosmetic products are used to achieve an attractive appearance. Given that men seem to prefer women with facial make-up (Mulhern et al., 2003), it is likely that women may, consciously or unconsciously, use this improvement of visible skin condition to ultimately increase their mating success through the enhancement of facial attractiveness. A more recent study by Nash et al. (2006) supports the hypothesis that women can successfully employ cosmetic products to manipulate their appearance. They found that, in contrast to bare skin, Caucasian women who wore makeup were perceived as healthier and more confident, as well as having greater earning potential and more prestigious jobs. Most studies of this nature are conducted with college students or middle-aged women, although the positive effect on self-perception because of the use of facial makeup has also been validated with elderly women aged 60 to 96 years (Kligman \& Graham, 1986).

Given the importance that humans attach to skin appearance, evolutionary psychologists have proposed that skin condition, particularly that of women, may signal aspects of mate value (e.g. age and health) (Fink, Grammer, \& Thornhill, 2001). Findings that disfiguring skin disorders, such as acne vulgaris and hirsutism (male pattern of body hair in women), reflect elevated androgen levels in blood plasma (Shaw, 2002; Slayden et al., 2001) and may thus have consequences on an individual's reproductive potential (Held et al., 1984), support this hypothesis. Of note, Bunker et al. (1989) also showed that $83 \%$ of women with acne had 
polycystic ovaries. The polycystic ovary syndrome (PCOS) is the most common endocrine disorder among women of reproductive age, and is regarded as a leading cause of infertility (Boomsma, Fauser, \& Macklon, 2008; Goldenberg \& Glueck, 2008).

Evolutionary psychologists are now concerned with visible skin condition not only in an anecdotal, but also in an empirical way. Recent studies provide evidence that facial skin colour distribution and skin surface topography cues provide information about a woman's age and health (Fink \& Matts, 2008; Fink et al., 2008), both of which are linked to female fecundity (Jones, 1997; Pawlowski \& Dunbar, 1999). However, not all of the respective concepts in evolutionary psychology have been accessible, or of primary importance to other disciplines, including cosmetic science. Given the common interest in the signalling quality of visible human skin of biology, psychology, and other social and health related sciences, it seems timely to review some of the key components by which skin appearance is determined and discuss recent attempts linking the dermatological knowledge on visible skin condition with evolutionary psychology theories on facial appearance and its perception.

\section{The human skin}

Human skin accounts for one-sixth of total body weight (Farage et al., 2008), and is the largest, independent endocrine organ (Zouboulis, 2000) in the body. It consists of numerous components that give the skin a complex, multi-layered structure. Skin appearance is determined primarily by its colouration and surface topography.

\section{Skin colouration}

Human skin colouration shows remarkable variation both within and among human populations. The German anthropologist Johann Friedrich Blumenbach (1752 - 1840) was the first to propose a human classification based on skin colour variation. He distinguished five "races": (1) pale-skinned Caucasians, living in Europe, in Western Asia up to the Ganges river, and in Northern Africa; (2) yellow-brown-skinned Mongolians, living in Asian regions, which are not occupied by Europeans, and including the Finns, Laplanders, and Inuit; (3) black-skinned Ethiopians, living in all parts of Africa except from the very North; (4) coppercoloured Americans, living in South- and North-America; and (5) dark-browned Malaysians, living on Pacific islands (for full review, see Morrone, 2007). This classification of the geography of human skin colour, however, has changed over the years (Beals \& Hoijer, 1965). Moreover, the conception of race is often controversial for scientific as well as for social and political reasons, as it leads some societies not only to create myths about people with differ- 
ent skin and / or hair pigmentation (Kittles, 1995), but also to the development of racism and “colourism" (Hunter, 2002; Wagatsuma, 1967). In 1950, UNESCO issued a statement on "the race question", which suggested the use of the term "ethnic groups" rather than "races" (UNESCO, 1969).

Skin pigmentation, leading to skin colour differences among different ethnic groups, is a highly heritable trait (Rees, 2004; Sulem et al., 2007). So far, six genes have been identified in the expression of normal pigmentation, and there is evidence that several additional genes may play a role in skin, hair, and iris pigmentation (Byard, 1981; Parra, 2007; Sturm, 2006; Sulem et al., 2007). The colouration of human skin is determined by only four major pigments: carotenoids of exogenous origin (yellow) and endogenously-produced melanin (brown) in the epidermis, oxygenated haemoglobin (red) and reduced haemoglobin (red-blue) in the capillaries and the venules of the dermis (Edwards \& Duntley, 1939; Ito \& Wakamatsu, 2003; Jimbow et al., 1976). Of these, the chromophores melanin and haemoglobin are the major determinants of differences in skin colour between individuals, with melanin playing the primary role (Anderson, John, \& Parrish, 1981; Parra, 2007; Roulin et al., 2008). Interestingly, it has been reported that women differ from men in these two main components of skin colour. That is, the skin of women is generally poorer in melanin and (oxygenated) haemoglobin than that of men (Edwards \& Duntley, 1939). This appears to be a genuine biological sexual dimorphism. In women, lightness of skin colour correlates with the ratio of second finger length to fourth finger length (2D:4D), a possible biomarker for prenatal sex steroids (Manning, Bundred, \& Mather, 2004). Furthermore, women were also reported to have greater concentrations of carotene within their skin (Edwards \& Duntley, 1939). Besides the four chromophores, the structural dermal protein collagen, additionally, contributes to skin colouration by scattering light in the visible spectrum (Matts et al., 2007).

In humans, melanin can be found in two forms: eumelanin and phaeomelanin. The former chromophore is a black-brown pigment and, because of its location within the skin, hair, and eyes, it is also called "cutaneous" melanin. Phaeomelanin, however, varies in colour from yellow to reddish brown and is also found in the skin and eyes, as well as in hair, while in red hair it is found in high concentrations (Kittles, 1995). In hair, varying proportions of the two pigments produce a wide range of colours, from the original black to brown, flaxen, golden, and red. Phaeomelanin, however, is less photostable than eumelanin and also occurs in less density (Kittles, 1995; Rees, 2004). Both pigments are synthesised by melanocytes, which are dendritic cells located in the basal layer of the epidermis. This synthesis process is called melanogenesis and is catalysed by the enzyme tyrosinase (Byard, 1981). Melanocyte activity 
is influenced by a variety of stimuli, such as UV-radiation (Lee \& Lasker, 1959; Loomis, 1967), melanocyte stimulating hormones, adrenocorticotropic hormone (Gantz \& Fong, 2003), and corticosterone (Roulin et al., 2008). After melanin synthesis, melanin chromophores are transferred in discrete packages (melanosomes) along the dendritic processes of the melanocytes and delivered into surrounding keratinocytes by exo- and endocytosis. Once within keratinocytes, melanin species co-localise within membranous structures (reviewed in Jimbow et al., 1976; Kittles, 1995). Interestingly, the number of melanocytes is actually equal in human ethnic groups, so that the melanin component of skin colour is determined solely by the size and pattern of distribution of melanosomes, the eumelanin and phaeomelanin content within the melanosomes, and metabolic and tyrosinase activity within the melanocytes (Kittles, 1995; Rees, 2004).

East Asians, for instance, have a yellowish complexion because their skin has a higher proportion of phaeomelanin to eumelanin. Moreover, the clustered pigments are organized spherically rather than in an ellipsoidal fashion (Nakagawa et al., 1989). Further examples of ethnic differences in skin pigmentation are provided by Alaluf et al. (2002). These authors revealed that the most light-skinned individuals (e.g., European, Chinese, and Mexican), have approximately half the epidermal melanin as the most darkly pigmented (e.g., sub-Saharan African and Indian), but also that the size of melanosomes apparently varies progressively with ethnicity, that is, sub-Saharan African skin having the largest melanosomes followed in turn by Indian, Mexican, Chinese and European. Regardless of ethnicity, however, it should be noted that epidermal melanin fraction volume correlates positively with the average dose of surface solar UV-radiation received at the geographical location of the ethnic group in question (itself largely a function of latitude). Jablonski and Chaplin (2000) demonstrated that skin reflectance was most strongly correlated with the quantity of UV-radiation required to produce a barely perceptible reddening of lightly-pigmented skin (UVMED), but that some notable variations of UVMED relative to latitude existed, especially in extremely arid and high-altitude environments.

Standardized methods to measure skin pigmentation have been used since the early $20^{\text {th }}$ century. The first attempts were based on colour matching techniques, in which an individual's skin pigmentation was compared with a chromatic scale (e,g., von Luschan's chromatic scale, Robins, 1991). These methods were then replaced by reflectance spectrophotometry when portable instruments became available. Early models of such reflectance spectrometry measured the percentage of light reflected from the skin by using up to nine filters corresponding to the different wavelengths of the visible spectrum (Edwards \& Duntley, 1939; 
Parra, 2007). The most commonly used instrument was the E. E. L. reflectance spectrophotometer (Evans Electroselenium Ltd., currently distributed by Diffusion Systems, UK) (e.g., Hulse, 1967; Rigters-Aris, 1972), which is still used in some studies (e.g., Jablonski \& Chaplin, 2000; Madrigal \& Kelly, 2007).

Modern, objective in vivo measures of skin colour utilise spectrophotometric or colorimetric techniques and the use of derived colour coordinates such as $\mathrm{L}^{*} \mathrm{a}^{*} \mathrm{~b}^{*}$, and various digital imaging / image analysis methods (for a full review of these approaches, the reader is directed to the review by Piérard, 1998)). While these measures certainly bring objectivity to the measurement of skin colour, they still are not able to separate the individual contributions of the chromophores responsible for either the measured, integrated remittance spectrum or the final photographic image (no matter how high a quality it may be). Consequently, recent years have seen the development of the so-called "Melanin Index" and "Erythema Index" (MI and EI, respectively), to try and provide a linear, interval data scale for these chromophores (Stamatas et al., 2004; Zonios, Bykowski, \& Kollias, 2001). Instruments that derive MI and EI [for example, the Mexameter ${ }^{\mathrm{TM}}$ (Courage \& Khazaka GmbH, Cologne, Germany), the DermaSpectrometer ${ }^{\mathrm{TM}}$ (Cortex Technology, Hadsund, Denmark) and the Erythema / Melanin $\operatorname{Meter}^{\mathrm{TM}}$ (DiaStron Ltd, Andover, UK)] utilise the same basic approach, taking the log of ratios of reflectance within 2-3 selected wavebands in the visible and infrared. These approaches represent a significant step forward in the quantification of the chromophores responsible for skin colour, but are limited by (a) their limited measurement area (a maximum of approximately $10 \mathrm{~mm}$ diameter), (b) their integration over the measured area, with no resolution of spatial distribution, (c) their direct contact with the skin surface (which can lead to artefacts such as blanching through excessive applied probe pressure, etc.) and (d) the inability of the log-ratio method to completely separate contributions from the two chromophores. As a general comment, these methods fall short because they do not take into account the complex interaction of visible light with, and transport within, human skin, summarised in Figures $1 \mathrm{a}$ and $\mathrm{b}$.

To address this need, therefore, a new, non-invasive measurement technique has been developed by Cotton and Claridge (1996) and later modified by Astron Clinica (Cambridge, UK): spectrophotometry intracutaneous analysis (SIA), also called "SIAscopy". The SIAscopy was developed originally for the early diagnosis of malignant melanoma (Hall et al., 2008; Michalska, Chodorowska, \& Krasowska, 2004), but has since demonstrated great utility in the measurement of normal skin (Matts, Dykes, \& Marks, 2007). This new measurement takes into account light transport within skin, operating on the principle of "chromophore 
mapping" and determines not only the concentration and distribution of (eu)melanin and (oxy)haemoglobin in vivo (see Fig. 2), but also dermal collagen. Currently, two different SIA measures are available: a hand-held contact probe and a non-contact measure enabling larger acquisition areas (for more details, please see Matts, 2008; Matts, Dykes, \& Marks, 2007).

\section{Skin surface topography}

The surface topography of the skin is basically determined by the structure of the dermis and the mechanical forces imposed on this tissue. It is characterized by regular patterns of intersecting lines and irregular dispersed pilosebaceous follicles and eccrine pores (Piérard, Uhoda, \& Pierard-Franchimont, 2003).

The main mechanical roles of the human skin are (1) to instantly and / or permanently match dynamic changes in shape and volume of the viscera and adipose tissue, (2) to protect them against external mechanical stress, and (3) to facilitate, via palmar and plantar skin, the gripping of objects and negotiation of the surrounding environment (Agache \& Humbert, 2004). The skin is composed of three primary layers, each with varying mechanical properties: the superficial layer [stratum corneum (SC)], the epidermis, and the dermis. These three layers cover the hypodermis (also referred to as subcutaneous adipose layer or subcutis). The SC is the outermost layer of the skin and constitutes the body's waterproof, protective integument, varying in thickness from $<10 \mu \mathrm{m}$ on the face, to $10-20 \mu \mathrm{m}$ on the trunk and limbs, to $200-300 \mu \mathrm{m}$ on palmar and plantar skin (see the review by Rawlings and Matts (2005) for a more detailed discussion of skin structure and function). The SC is composed of

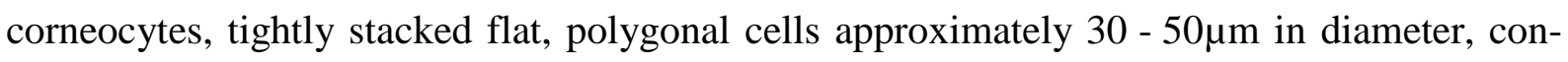
taining densely packed keratin protein filaments, surrounded by a tough involucrin-rich protein cell "envelope". The mechanics of native, dry SC are characterised by stiffness and brittleness. Dry SC, therefore, even with an abundance of excess surface area in the form of micro-topography, tends to crack and split so that its barrier function is compromised physically and chemically. Something is needed, therefore, to "plasticise" the SC, to confer suppleness and fluidity of movement. Water is the only endogenous "plasticiser" of the SC in vivo, which is why "moisturisation" (both endogenous and supplemented) of this outer layer is of such importance. 


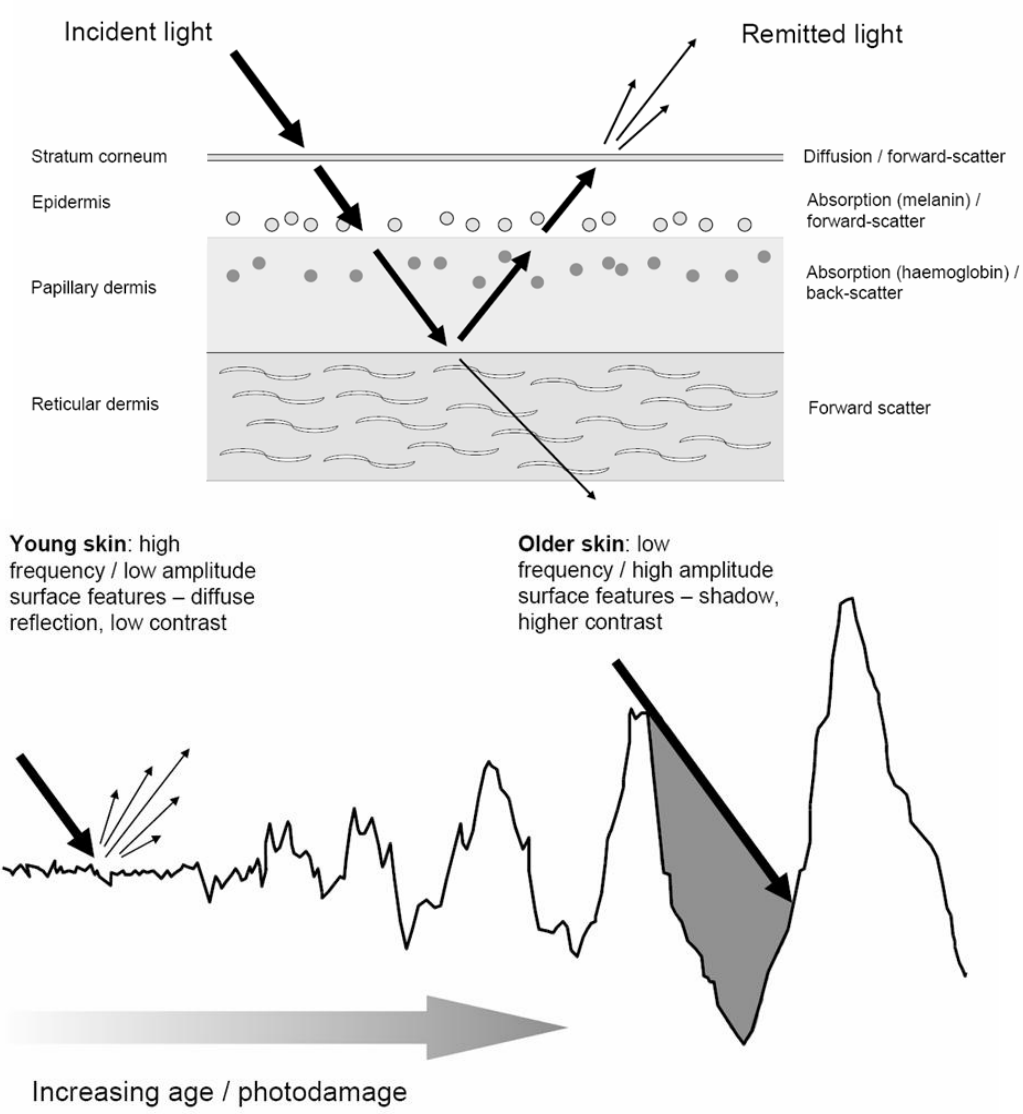

Figure 1 (a) Schematic diagram of light transport in human skin; (b) schematic representation of skin surface topography, and its interaction with light, as a 'continuum' across a human lifetime.

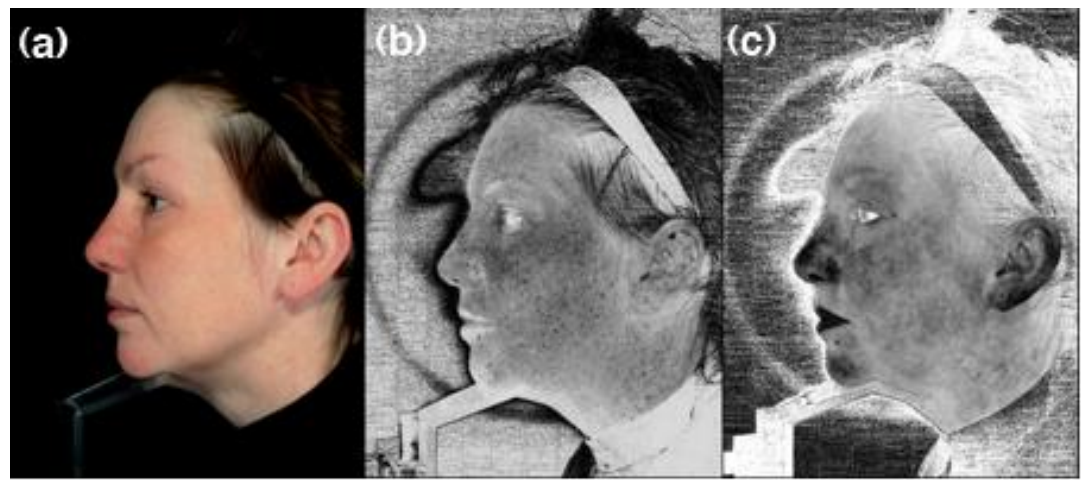

Figure 2 Non-contact SIAscopy: (a) original cross-polarised image, (b) corresponding eumelanin greyscale concentration map, (c) corresponding greyscale oxyhaemoglobin concentration map.

The less rigid 50 to $100 \mu \mathrm{m}$-thick epidermis is able to conform and flow with overlying SC (Agache \& Humbert, 2004). As it contains no blood vessels it is nourished by diffusion of oxygen and nutrients from the dermal vasculature. Keratinocytes and melanocytes form the 
majority of the cell population of the epidermis. The function of melanocytes has already been described above. Keratinocytes originate in the basal layer (stratum basale) of the epidermis and are the predominant cell type in this compartment (forming approximately $90 \%$ of the epidermal cells). Keratinocytes migrate towards the surface in a process of progressive keratinisation (differentiation), eventually undergoing a dramatic transformation into the squamous corneocyte cells of the SC. At the SC surface, "desquamation" takes place, a rolling system to replace "spent" surface corneocytes with fresh cells from beneath, equivalent approximately to a layer of surface corneocytes being exfoliated and replaced approximately every day. The exfoliation of corneocytes from the surface of the skin is facilitated by the action of specific hydrolytic enzymes in the SC.

The major mechanical component of the skin is the dermis, which can be several millimetres thick, consisting of connective tissue embedded in an amorphous extracellular matrix. This layer provides cushioning and shock protection to a variety of delicate structures, including blood and lymphatic vessels, hair follicles, sweat glands, sebaceous and apocrine glands, and a variety of mechanoreceptor / nerve endings, which endow the sense of touch and heat. The two fibrous proteins collagen and elastin provide skin with tensile and elastic strength, respectively. With aging (and particularly photoageing), the quantity and quality of both of these proteins deteriorate, resulting in a loss of tensile strength and elasticity, and, thus, formation of fine lines and wrinkles (particularly in areas of continuous or repeated flexure). The thickness of the hypodermis can range from $1 \mathrm{~mm}$ to more than $5 \mathrm{~cm}$, depending on the amount of adipocytes contained within it. Its purpose is to attach the skin to the underlying bone and muscle as well as supplying it with vasculature and innervations. The aging process causes certain areas of the face to undergo fat atrophy, while in others, adipocytes undergo increased mitosis, resulting in the characteristic fat dysmorphism of senescence (Donofrio, 2000).

In their review, Piérard et al. (2003) describe four types of wrinkles, which result from structural changes in the skin layers elucidated above. Depending on their histological aspects, pathogenesis, orientation and depth they are classified as (1) atrophic, (2) elastotic, (3) expressional, and (4) gravitational wrinkles. Atrophic wrinkles are fine, almost parallel lines, which vanish when skin is put under transversal tension. They occur because of collagen degradation both in the dermis and the hypodermis. Elastotic wrinkles, however, become progressively permanent lines, which do not lessen upon stretching. As a result an accumulation of abnormal, thickened, tangled, and non-functional fibres of elastin in and around these wrinkles (histologically known as solar elastosis) (Battistutta et al., 2006; Bennett et al., 
2008), the skin takes on a characteristic "cobblestone" appearance and becomes significantly more rigid. Expressional wrinkles gradually became permanent furrows, caused by the repeated contraction of the muscles of facial expression (the frown lines, glabellar lines and the "crow's-feet" being typical examples). Expressional wrinkles are of a lower frequency and higher amplitude than those described previously. Finally, gravitational wrinkles result from folding and sagging of the skin, which has lost its turgidity, under its own weight. The structural changes responsible for these changes are found in the hypodermis.

Numerous objective and non-invasive methods are available to quantify the severity of wrinkles. These methods range from classification according to their visual representation by the use of rating scales, to the accurate replication of skin surface topography with subsequent mechanical / laser profilometry, through to the current state of the art non-contact 3D techniques such as fringe-projection (e.g., Agache \& Humbert, 2004; Battistutta et al., 2006; Hatzis, 2004; Piérard, Uhoda, \& Pierard-Franchimont, 2003). Currently, there are three grading scales which attempt to classify the type and severity of wrinkles: Fitzpatrick's scale, Glogau's scale, and Hamilton's scale (for details see Agache \& Humbert, 2004). There is, however, no consensus about the definition of such terms as wrinkles, lines, and furrows, and choice of specific scale or measure is often left to the researcher and their particular branch of research.

\section{Skin aging}

The aging process represents a steady accumulation of cell and tissue change as the result of progressive disorder of regulatory mechanisms and an associated reduction in systemic reserves to counter stress and disease (Quiroga, 2005). The human skin undergoes an aging process in a similar manner as the viscera (at least in non sun-exposed sites) and, thus, represents a unique visible indicator of systemic age (Pawlowski \& Dunbar, 1999). Wrinkling and changes in pigmentation are obvious signs of cutaneous aging, influenced by both intrinsic and extrinsic factors (Gilchrest \& Krutman, 2006). However, as both factors interact it is often difficult to assign phenotypic consequences of the aging process to one or the other.

\section{Intrinsic aging}

Intrinsic aging processes are structural changes that occur as natural consequences of aging and are determined genetically (Farage et al., 2008). Consequently, these processes are also seen in most internal organs (Jenkins, 2002). Intrinsic aging refers, in particular, to a decrease in the gonadal production of oestrogen in females (menopause) and testosterone in 
males (andropause), the adrenal production of the androgen dehydroepiandrosterone (DHEA) and its metabolite DHEA sulfate (DHEAS), and the activity of growth hormone, as well as of the insulin-like growth factor (somatopause) (reviewed in Quiroga, 2005). Lowered secretion of these hormones is thought to be linked to decreased proliferation capacity leading to senescence and altered biosynthetic activity of the skin (Jenkins, 2002).

Although SC thickness is apparently unaffected by the menopause, deficiencies in neutral lipid neosynthesis have been found which, in turn, affects the barrier / interface function of the skin. Consequently, more time is needed to reconstitute an effective SC barrier following injuries to the skin, superficial or otherwise (Ghadially et al., 1995; Yaar, 2006). Furthermore, lowered oestrogen levels lead to an overall decrease in skin strength and elasticity, because of degenerative changes in collagen and elastin and a progressive atrophy in cutaneous blood supply. In association with this, hyperpigmentation, wrinkling and pallor of the skin may be seen, although at lower intensities compared with skin alterations caused by cumulative photodamage. Alongside these findings in women, lowered testosterone levels result in a decrease of elasticity, extensibility and turgor in male skin. Moreover, appendages such as hair follicles, and apocrine and endocrine glands are apparently decreased in number (Quiroga, 2005; Zouboulis, 2003). Somatopause leads to an uneven distribution of adipose tissue, where certain areas of the face undergo fat atrophy while others experience a hypertrophy of fat. A decrease in the amount of adipocytes is found primarily in the periorbital, buccal, temporal, and perioral areas, as well as on the forehead, whereas an increase in adipocytes is seen in the jowl, lateral nasolabial fold, lateral labiomental crease, and lateral malar areas (Donofrio, 2000; Yaar, 2006).

\section{Extrinsic aging}

Extrinsic aging is driven by environmental factors, including exposure to solar UVradiation (e.g., Fisher et al., 1997; Krutman, 2003; Leung \& Harvey, 2002), IR-radiation (Schieke, 2003), smoking (e.g., Aizen \& Gilhar, 2001; Ernster et al., 1995; Leung \& Harvey, 2002), ozone (Krutman, 2003; Yaar, Eller, \& Gilchrest, 2002), and dust (Krutman, 2003), and involves changes in cellular biosynthetic activity and a progressive disorganization of the dermal matrix (Jenkins, 2002; Krutman, 2003; Yaar, Eller, \& Gilchrest, 2002). Among these environmental factors, casual exposure to solar UV-radiation is the most potent and prominent driver of so-called "premature skin aging" (Jenkins, 2002), causing the production of free radicals or "reactive oxygen species" (ROS) which, by nature, damage virtually every class of cell component, including protein, lipid and nucleic acid (Taylor, 2005). For instance, 
it is now believed that free radicals can damage the guanine residues that make up $50 \%$ of the telomere overhang structure, accelerating telomere shortening and, thus, speeding up premature aging (e.g., Krutman \& Gilchrest, 2006; Taylor, 2005). These reactive species have also been shown to stimulate the degeneration of dermal matrix components, e.g., collagen and elastin, leading to an accumulation of compromised, so-called "elastotic" tissue (Krutman, 2003) and associated mechanical failure. ROS are also known to drive a variety of pigmentation disorders, resulting in selective over- (e.g., lentigos, diffuse hyperpigmentation) and under- (e.g., guttate idiopathic hypomelanosis) expression of melanin, causing a progressive visible heterogeneity in melanin distribution (reviewed in Ortonne \& Bissett, 2008).

Because of variation in epidermal melanin content and melanosome distribution, pigmentary alterations vary in their severity and manifestation among different ethnic groups (reviewed in Taylor, 2005; Tschachler \& Morizot, 2006). Consequently, the lifetime protection from solar UVR afforded by melanin accounts for smaller differences between sunexposed sites and sun-protected sites in sub-Saharan African versus Caucasian skin. Additionally, these darker skin types appear to express certain wrinkle types with less severity and at a greater age than fairer skin (Farage et al., 2008; Shirakabe, Suzuki, \& Lam, 2003; Tschachler \& Morizot, 2006). Elastotic wrinkles, for instance, are apparently less prominent in people with darker skin than in Caucasians (Farage et al., 2008). Somewhat in contrast to Caucasian skin, it has been proposed that East Asian facial skin tends to age with more emphasis on weaker skeletal support, heavier soft tissue, larger amounts of malar fat, thicker skin, and a weaker chin, driving downward gravitational migration of facial skin tissue (Shirakabe, Suzuki, \& Lam, 2003).

In general, it is thought that the other environmental noxa such as IR-radiation, smoking, ozone, and airborne pollution, act via mechanisms similar to those identified for UVradiation (see Krutman, 2003). Interestingly, environmental factors, such as pollution and smoking, seem to produce skin wrinkling but not pigmentary abnormalities (Yaar, 2006).

\section{The effect of human skin condition on face perception}

Evolutionary and socialisation theory suggests that human facial appearance, and attractiveness in particular, influences the perception of others in social interactions, as well as development of certain behaviours (e.g., social skills, dating and sexual experience) and traits (e.g., mental and physical health) (reviewed in Hoss et al., 2005; Langlois et al., 2000). Studies have shown that people assign more positive qualities to attractive children and adults than to unattractive ones (Langlois et al., 2000; Mobius \& Rosenblat, 2006). In addition, facial 
attractiveness correlates positively with mating success and, thus, supports the hypothesis that the attractiveness of the face is important in human mate selection (Rhodes, Simmons, \& Peters, 2005). Moreover, people's view of facial attractiveness seems to be remarkably consistent, regardless of race, nationality, or age (reviewed in Langlois et al., 2000; Penton-Voak \& Perrett, 2001). It is, therefore, hardly surprising that humans attach great importance to a beautiful, healthy, and youthful-looking skin. An improvement in facial skin appearance can be accomplished relatively easily through the use of cosmetic products (Boehncke et al., 2002; Hayashi et al., 2005; Kligman \& Graham, 1986). The visible signs of aging can also be considerably reduced via injections of Botulinum toxin, the use of dermal fillers, and chemical peels (Schürer, 2003). Despite the highly significant role which humans assign to their facial skin condition, the influence of the biology and associated appearance of skin on mate choice has so far received only little attention in evolutionary psychological research.

\section{Skin colour, natural and sexual selection}

The influence of feather and skin patch colouration on sexual attractiveness is known in a wide variety of non-human animals (Andersson, 1994). Studies in avian species particularly have shown that colouration can serve as a secondary sexual ornament, advertising individual quality in terms of physical condition and reproductive potential (e.g., Dufva \& Allander, 1995; Madsen et al., 2007). However, there are also examples in mammals, notably in nonhuman primates, indicating an honest signal function of skin (e.g., Cooper \& Hosey, 2003; Gauthier, 1999; Gerald et al., 2007; Setchell \& Dixson, 2001; Setchell, Wickings, \& Knapp, 2006; Waitt et al., 2006). Following these findings, evolutionary psychology suggests that visible skin condition, particularly those of women, may also signal aspects of an individual's mate quality in humans (Barber, 1995; Symons, 1995). Hence, skin pigmentation has been shown to influences judgments of attractiveness in a profound manner.

Geographic variation in skin colour has been attributed to adaptation via natural selection, at least in part (Frost, 1994a; Jablonski \& Chaplin, 2000; Norton et al., 2007). Given that melanin has both UV absorption and ROS scavenging capacity, dark skin is thought to likely be an adaptation to the intensity of ground-level UV-radiation at lower latitudes. Additionally, varying degrees of depigmentation are thought to evolve to permit UV-induced synthesis of previtamin $\mathrm{D}_{3}$ (Aoki, 2002; Jablonski \& Chaplin, 2000). Contradictory to the natural selection pressure for darker skin, cross-cultural studies indicate male preference for lighter-thanaverage skin colour in sexual partners (Frost, 1994b; Swami, Furnham, \& Joshi, 2008; Van den Berghe \& Frost, 1986). In addition to female menstrual cycle-dependent preferences for 
darker skin complexions in males (Frost, 1989, 1994b), both preferences lead to a sexual dichromatism in humans (Edwards \& Duntley, 1939; Jablonski \& Chaplin, 2000). The observed latitudinal gradient in skin colour seems to result from a balance between natural and sexual selection (Aoki, 2002). Sexual selection theory, however, does not presume that sexdifferences in skin pigmentation arise exclusively because of sexual selection but, rather, assigns sexual selection a secondary, facultative role. Hence, lighter skin in females is thought to have evolved originally for other reasons and only later became a mate selection criterion for men. Van den Berghe and Frost (1986) argued that lighter skin in females arose firstly by coincidence, e.g., the differing effects of male and female sex hormones on melanin production, causing female skin colouration to fluctuate slightly with the menstrual cycle and being lightest, smoothest and most free of blemishes near ovulation (Frost, 1988; Johnston et al., 2005). These authors further suggested that men might then have used this visible signal, subconsciously, to assess a female's hormonal status and thus, her reproductive potential. Other researchers have argued that lighter skin in women acts as infantile mimicry to lessen aggressiveness in men and to stimulate their provisioning instincts (Guthrie, 1970), while others assume that women first acquired a lighter skin to facilitate vitamin D synthesis and, thereby, ensure higher calcium reserves for pregnancy and lactation (Jablonski \& Chaplin, 2000). The different explanations for a preference for lighter skin in women, however, are still controversial (Madrigal \& Kelly, 2007; Robins, 1991).

There are also arguments for lighter skin being the most beautiful and desirable because of its association with power, wealth, and privilege due to the persistent effect of European colonization and slavery (Bond \& Cash, 1992; Hulse, 1967; Hunter, 2002). Bond and Cash (1992), for instance, found a distinct idealization of lightness among female African Americans. They found that, although women were generally satisfied with their skin tone, those who desired a different skin tone favoured being lighter over being darker. They also found that, in contrast to light- and dark-skinned Black women, the ideal skin tone for mediumtoned Black women was significantly lighter than their self-perceived colour. Moreover, the majority of respondents believed that Black men consider light skin most attractive. A more recent study by Hunter (2002) provides additional support for the effects of skin colour on women's perceived attractiveness. As hypothesized, skin tone was found to predict educational and income status in both African-American and Mexican-American women. Moreover, lightness of the skin correlated positively with spousal status in African-American (but not Mexican American women). 
This hypothesis is challenged by van den Bergh and Frost (1986), who stated that there seems to have been a general preference for lighter-than-average female skin in human societies, even before the area of European colonialism in regions that had never been dominated by a lighter-skinned ethnic group. Furthermore, they argued that this preference is also demonstrated in societies where higher-status individuals tend to be darker than the mass of the population. Finally, preference for skin lightness often coincides with rejection of other European physical features, as noted by Wagatsuma (1967).

\section{Skin condition as a signal in mate choice}

Studies on facial attractiveness have predominantly investigated the influence of symmetry, averageness and sex hormones on facial appearance and its perception (see for review Fink \& Neave, 2005; Fink \& Penton-Voak, 2002; Gangestad \& Scheyd, 2005; Koscinski, 2007; Peters, Rhodes, \& Simmons, 2007; Rhodes, 2006; Thornhill \& Gangestad, 1993), by suggesting that these physical characteristics indicate the underlying genetic quality of an individual (e.g., Schaefer et al., 2006; Thornhill \& Gangestad, 1993). However, only a few studies in evolutionary psychology have been concerned with facial skin as an indicator of mate value, even though findings indicate that the signal value of the skin is not solely restricted to sexual dichromatism. When presenting small skin patches (i.e., isolated fields of skin images) extracted from the left and right cheeks of male facial images, Jones et al. (2004) found a positive correlation between women's rating of apparent health and those of attractiveness, this being independent of facial shape information. Further support for an association between skin condition, genetic quality, and perceived attractiveness is provided by Roberts et al. (2005). These authors demonstrated that facial skin patches of men who where heterozygous at all three loci of the major histocompatibility complex were judged by women to be more attractive and healthier than those of men who were homozygous at one or more of these loci.

Neither study, however, investigated the relative contributions of skin colour distribution and surface topography cues to judgments of attractiveness and health. Recent research by Fink et al. $(2006 ; 2001 ; 2008)$ aimed to disentangle both determinants of visible skin condition. Using images of 170 British women aged from 11 to 76 years, they found that facial skin colour distribution alone, independent of skin topography and facial shape, significantly influenced the perception of age, with evenness in skin colouration accounting for up to twenty years of perceived age. Furthermore, the authors found a remarkably high correlation between estimated age and judgments of facial attributes, such as attractiveness, health, and 
youth (Fink, Grammer, \& Matts, 2006). Further studies showed that, although both skin colour distribution and skin surface topography cues significantly influence the perception of age and health, they convey differential information with regard to the strength of these effects. That is, skin surface topography is a greater visual cue for an individual's age, whereas skin colour distribution seems to be a stronger visual cue for health (Fink \& Matts, 2008) (see Fig. 3).

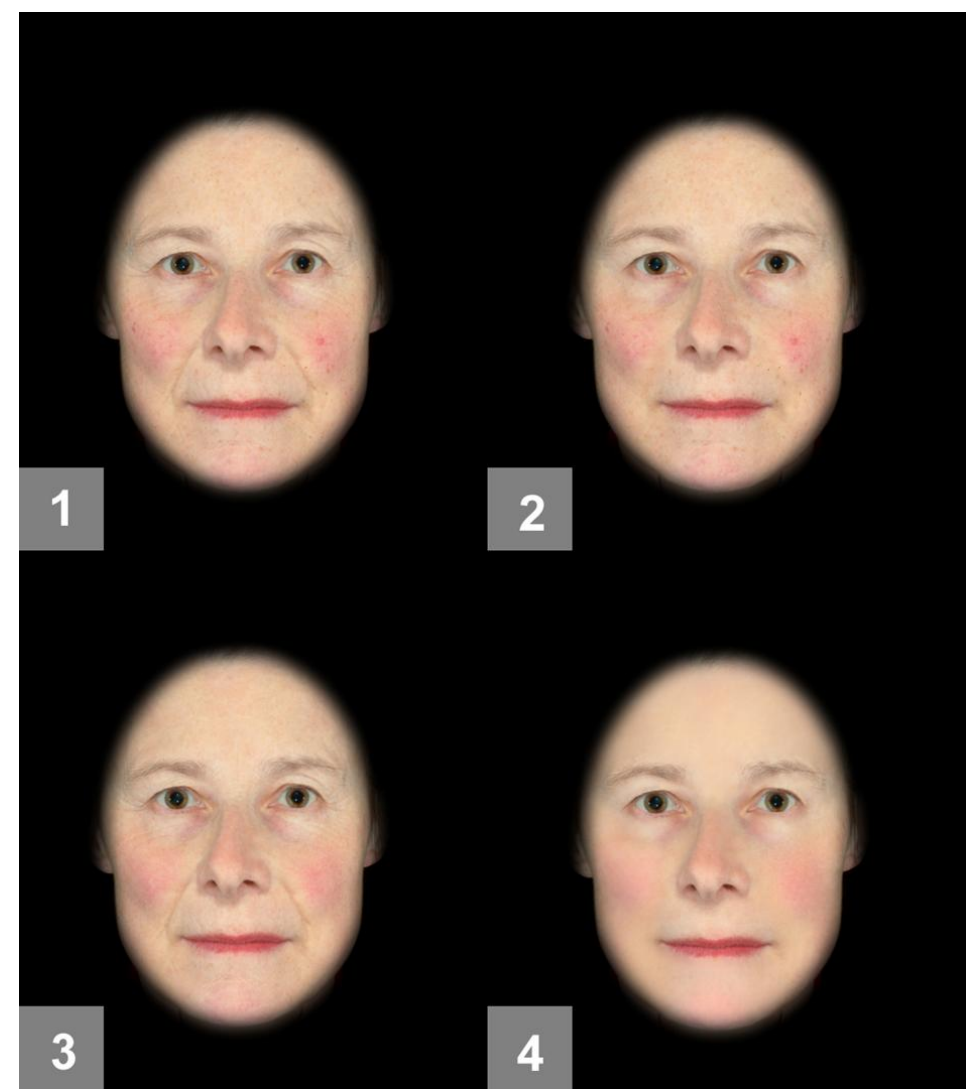

Figure 3 Examples of stimulus images from the study of Fink and Matts (2007): (1) original face; (2) topography smoothed; (3) colour smoothed; (4) topography and colour smoothed.

The processes of intrinsic and extrinsic ageing produce changes in both skin colouration and surface topography and, thus, drive perception of both age and health and provide information about an individual's mate value.

As the face provides important non-verbal information through facial expression and the display of facial form and skin condition, face perception and visual attention towards faces are critical in human social communication (Haxby, Hoffman, \& Gobbini, 2002). Studies by Langlois et al. (1991; 1987) and Maner et al. (2003) have reported a positive correlation between visual attention and perceived facial attractiveness. In accordance with these studies, 
Fink et al. (2008) were able to link visual attention to perceived age and attractiveness judgements. This study not only revealed that the number of eye fixations and dwell time were positively correlated with skin colour homogeneity, but also that they were negatively correlated with perceived age and positively so with perceived attractiveness (Fink et al., 2008).

The detrimental effects of facial aging on attractiveness ratings in women are consistent with other studies reporting that old faces are generally perceived to be less attractive than young faces (Ebner, 2008; Wernick \& Manaster, 1984). The signs of cutaneous aging, however, do not negatively influence people's judgments on facial attractiveness in an equal fashion. For instance, Perrett et al. (2002) showed that the evaluation of facial attractiveness reflects the learning of parental characteristics. When considering the attractiveness of female images for possible long-term relationships, men whose mothers were older than 30 years of age at their birth were less impressed by visual youth cues than men with younger mothers. However, maternal age did not impact upon judgements of similar images for possible shortterm relationships. In women, and in contrast to the findings in men, the age of both parents influenced preferences for men for both possible short-term and long-term relationships. Judgements on same-sex faces (i.e. the judge was the same gender as the subject) revealed decreased attractiveness with increasing age cues (Perrett et al., 2002). Furthermore, the age of the person surveyed appears to influence attractiveness rating of facial stimuli, that is, older respondents evaluated faces more positively for attractiveness than younger participants (Ebner, 2008).

It is reported that female mate value is determined principally by fertility and health, which are both correlated with age (Jones, 1997; Pawlowski \& Dunbar, 1999). Furthermore, variance in reproductive success is lower for females than for males and they also have a narrow reproductive window compared to males (Sefcek et al., 2006). Selection pressure on males to choose females on the basis of age should be much stronger than in females (Jones, 1997), whereas females should compete with each other for high quality spouses by advertising reproductive potential and exaggerating morphological indicators of youthfulness (Barber, 1995). With reference to the skin, a more unblemished, relative hairless and smooth skin indicates low androgen and high oestrogen concentrations (reviewed in Farage et al., 2008) and, thus, may signal fertility (Fink, Grammer, \& Thornhill, 2001; Johnston et al., 2005). In this view, skin wrinkling and changes in skin colour distribution are the most obvious cues that indicate a person's age. Schneider et al. (2003) propose that the quality of skin condition is important in attracting mates during the reproductive phase of a human life whereas, after menopause, it is no longer a factor in selection pressure. For instance, the loss of ovarian oes- 
trogen causes a decline in skin collagen content (Brincat et al., 1985) as well as alterations in skin pigmentation (Broniarczyk-Dyla \& Joss-Wichman, 2001).

As the face is the most frequently exposed part of the body and always visible to others, facial skin condition might be used as an honest indicator of female mate value. This hypothesis is supported by the findings of Furnham et al. (2004), who found facial age to have a more significant influence on the assessment of attributes such as youthfulness, attractiveness, fertility, healthiness, and fecundity, than other oestrogen-dependent body features such as waistto-hip ratio (WHR).

In contrast, many male characteristics, which seem to be chosen by females, are correlated positively with age (reviewed in Manning, 1985). On this basis, women should prefer men of a greater age (Bereczkei \& Csanaky, 1996). However, females do not only choose their mates on the basis of characteristics which advertise adequate parental investment in terms of resource and social status (Dixson et al., 2007), but also on physical attributes (Havlicek, Roberts, \& Flegr, 2005; Little et al., 2002), which indicate individual quality in terms of body condition and reproductive quality (Hamilton \& Zuk, 1982; Zahavi, 1975). The study by Jones et al. (2004) provides the first evidence that women may also use the condition of skin in male faces to evaluate their health and attractiveness. Both are particularly important when considering an appropriate mate to sire offspring. Although many desired male characteristics are correlated positively with age, previous findings by Adams and Huston (1975) as well as Cross and Cross (1971) did not support the hypothesis that middle-aged men are considered to be more attractive than middle-aged women (35 - 55 years). Hence, cutaneous aging also has detrimental effects on attractiveness ratings in men. Recent studies indicate that the older the putative father is, the higher the chance of passing on genetic defects to his offspring (reviewed in Thacker, 2004). Moreover, studies have shown that fertility significantly declines with age in men older than 45 (e.g., Hellstrom et al., 2006; Luna et al., 2007; Moskovtsev, Willis, \& Mullen, 2006). Given these findings, women should also derive benefit from correctly perceiving the age of a putative mate and almost certainly use signs of cutaneous aging in the male face to assess his inherent mate value.

\section{Conclusions}

Studies in evolutionary psychology investigating facial attractiveness have focused mainly on facial form. Yet, the significance of visible skin condition on the perception of human facial appearance needs to be determined. There is now evidence accumulating from recent research that visible facial skin condition influences perception and attractiveness 
judgements, and could thus also signal aspects of mate value. Preliminary results indicate that humans are highly sensitive to signs of age such as (even subtle) alterations in skin colour distribution and surface topography, which occur because of intrinsic and extrinsic aging processes. This sensitivity towards facial age cues is expressed not only through the judgments of facial attributes, such as attractiveness, health, and youth, but also through altered visual attention (Fink, Grammer, \& Matts, 2006; Fink \& Matts, 2008; Fink et al., 2008). As fertility and health are both negatively correlated with age, facial age may thus provide reliable information on an individual's mate quality. Furthermore, as female skin colouration changes slightly across the menstrual cycle (Frost, 1988), more detailed research on alterations in both melanin and haemoglobin concentration and distribution in the course of this cycle would be interesting.

As studies investigating human skin condition were conducted primarily with Caucasian women from the United Kingdom, Austria, or Germany, cross-cultural studies are needed to investigate if the putative signal value of skin condition is universal or, rather, depends on socio-ecological conditions. In consideration of ethnic differences in the cutaneous aging process, attractiveness ratings of non-Caucasians with varying skin surface topography are also needed. Furthermore, there are hardly any published data on the signal value of male skin condition. Indeed, as it has been argued that the appearance of facial skin might be more important in women than in men (because of a relatively narrow reproductive window), most of the studies investigating human skin condition are restricted to female stimuli. However, recent findings also suggest a decrease in fertility with age in men (e.g., reviewed in Thacker, 2004) and, thus, investigations into the putative impact of age signals in male faces might also be worthwhile.

So far, Jablonski and Chaplin (2000) have made significant progress in investigating the adaptive value of skin colour across the world. They conclude that the degree of melanin pigmentation in human skin is an adaptation to solar UV-radiation (see also Jablonski, 2006) but did not, however, quantify cutaneous melanin concentration (or relative concentrations of eu- vs. phaeomelanin). Furthermore, possible differences in the information content of the major chromophores haemoglobin and melanin, or even the two forms of melanin, have not been investigated yet. Studies in barn owls (Tyto alba) have shown that eumelanin-based and phaeomelanin-based traits signal different information relevant for mate choice (Roulin \& Dijkstra, 2003). Additionally, chronically elevated corticosterone levels during embryonic development result in a decrease of melanin production (Roulin et al., 2008). Similar changes 
(i.e., heterogeneous skin colour distribution from birth onwards) in melanin concentrations because of prenatal stress might also be possible in humans.

Finally, given that the aging process causes an uneven distribution in facial adipose tissue and that facial features such as symmetry and sexual dimorphism strongly influence attractiveness judgements, the interaction of skin topography and facial form deserves special attention in future studies. In closing, we believe that the determinants of skin appearance and perception identified and discussed in this review are of particular interest to the cosmetic scientist, as they are at the heart of the continuing consumer demand for better technologies to address these issues. We believe that a more complete understanding of the mechanisms of skin appearance and the psychology of perception will inevitably improve our ability to identify new and more relevant cutaneous targets and concurrent innovation of better technology.

\section{Acknowledgements}

We express our thanks to Nick Neave, who helped with improving an earlier version of the manuscript. Preparation of this article was supported by the Procter \& Gamble Company, and the German Research Foundation (Deutsche Forschungsgemeinschaft (DFG)) through the Institutional Strategy of the University of Göttingen. B.F. is currently funded by an EmmyNoether Fellowship of the DFG (FI 1450/4-1). 


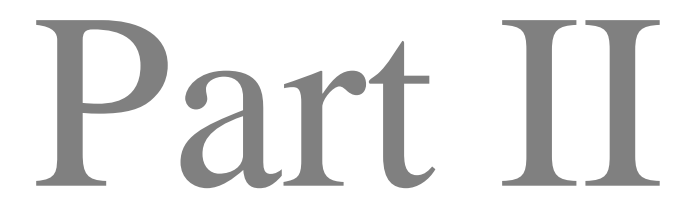

Facial skin as an indicator of female age and health 


\section{Chapter 3}

\section{VISIBLE CHANGES OF FEMALE FACIAL SKIN SURFACE TOPOGRAPHY IN RELATION TO AGE AND ATTRACTIVENESS PERCEPTION}

Nadine Samson ${ }^{1}$, Bernhard Fink ${ }^{1}$, Paul J. Matts ${ }^{2}$, Nancy C. Dawes ${ }^{3} \&$ Shannon Weitz ${ }^{3}$

${ }^{1}$ Department of Sociobiology / Anthropology, University of Goettigen, Germany

${ }^{2}$ The Procter \& Gamble Company, Rusham Park Technical Center, Whitehall Lane, Egham, Surrey, UK

${ }^{3}$ The Procter \& Gamble Company, Rusham Park Technical Center, Cincinnati, OH, USA 


\section{Summary}

Objectives Evolutionary psychology suggests that a woman's age and physical appearance are important mate choice criteria. Given that changes in female facial skin surface topography are important, prominent visible signs of aging, male perceptual sensitivity for variation in this trait may also affect preference and attractiveness judgement.

Methods Two experiments were conducted to investigate perception (Experiment 1) and noticeability (Experiment 2) of skin surface topography manipulations in facial images of six British women, aged 45 - 65 years. In Experiment 1 skin surface topography cues were completely removed on the cheeks, the "crow's feet" area adjacent to the eye, under the eyes, above the upper lip, and on the forehead while, in Experiment 2, it was removed gradually (20\% increments) on the forehead and around the eyes. In both experiments, stimuli were presented to American and German participants (total $\mathrm{N}=300$, aged 15 - 55 years) in omnibus pair-wise combinations (within-face). With each pair, respondents were asked to select that face which they considered as younger looking (Experiments 1 and 2) and more attractive (Experiment 1).

Results Faces with skin surface topography cues removed were judged significantly younger and more attractive than their original (unmodified) counterparts, with modifications on the forehead and around the eyes showing the highest differences. In these areas, participants were able to detect at least a $20 \%$ visual change in skin surface topography.

Conclusions The results support the assertion that even small changes in skin surface topography affect the perceptions of a woman's facial age and attractiveness and may, thus, also influence men's mate preferences.

Keywords: age, attractiveness, face, humans, noticeability, skin surface topography 


\section{Introduction}

Evolutionary psychologists argue that certain beauty standards have evolved because they provide reliable information about an individual's mate quality (in terms of health and fertility). In this view, preferences for facial and bodily characteristics are thought to reflect cognitive adaptations, shaped by evolutionary selection pressures, for the benefit of partner selection. Findings by Rhodes et al. (2005) support this assertion by showing a positive correlation between facial attractiveness and mating success. In humans, research on the perception of facial attractiveness has concentrated mainly on associations with features such as symmetry, phenotypic averageness, and sexually dimorphic traits (see for review Fink \& Neave, 2005; Fink \& Penton-Voak, 2002), as these physical characteristics supposedly reflect the underlying genetic quality of an individual (Schaefer et al., 2006; Thornhill \& Gangestad, 1993).

Only a few studies in evolutionary psychology have addressed the effect of human skin condition on the perception of facial appearance and possible implications for human mate preferences. However, these studies corroborate the hypothesis that skin, particularly those of females, also signals aspects of mate "quality" (Barber, 1995; Fink, Grammer, \& Thornhill, 2001), as it affects the perception of an individual's age, attractiveness and health (Fink, Grammer, \& Matts, 2006; Fink \& Matts, 2008; Fink et al., 2008; Jones et al., 2004). Jones et al. (2004) reported a positive correlation between ratings of apparent health and attractiveness, independent of facial shape, when presenting small skin patches isolated from male skin images, to female participants. Roberts et al. (2005) further support the claim of an association between skin condition, genetic quality and perceived attractiveness, by demonstrating that women judge images of isolated fields of facial skin of men who were heterozygous at all three loci of the major histocompatibility complex as more attractive and healthier than those of men who are homozygous at only one or more of these loci.

Given the close association of female age, attractiveness and health with reproductive capacity, it has been argued that men in particular have evolved a preference for female skin that signals these attributes (Barber, 1995; Symons, 1995). Age-related changes in visible skin condition are driven primarily by an increase in uneven pigmentation (derived from both melanin and haemoglobin) as well as changes in skin surface topography due to changes in skin biomechanics (Farage et al., 2008; Gilchrest \& Krutman, 2006). Recent research by Fink et al. (2006) revealed that humans are sensitive to the visible signs of cutaneous aging by demonstrating that variation in skin color distribution affects age, attractiveness, and health 
perceptions of female faces. These authors found that skin color distribution alone, independent of skin surface topography and facial shape, accounted for a span of up to 20 years of age perception (Fink, Grammer, \& Matts, 2006). In a follow-up study, the same researchers found a negative correlation between visual attention (as determined by eye tracking) towards skin color evenness and perception of female facial age, but a positive correlation of visual attention and attractiveness judgements (Fink et al., 2008). Female faces with more even skin coloration received higher visual attention and were considered younger and more attractive. An additional study (Matts et al., 2007) on the same stimulus faces revealed similar associations with age, attractiveness, and health perception, even when presenting isolated fields of skin images to participants. Moreover, Matts et al. (2007) reported significant and negative associations of measures of skin color homogeneity (through objective image analysis) with chronological and perceived age, and positive correlations with attractiveness and health judgements.

While there is accumulating evidence from the above studies that skin coloration and pigmentation cues affect the social perception and judgement of a woman's facial appearance, comparably little is known about the impact of skin surface topography cues in this context. Initial findings by Fink and Matts (2008) revealed that, although both facial skin color distribution and facial skin surface topography cues significantly affect people's perception of female's age and health, they convey differential information with regard to the strength of these effects. That is, skin surface topography seems to be a relatively greater visual cue for an individual's age, whereas skin color distribution is likely to be a relatively stronger health indicator (Fink \& Matts, 2008). These authors, however, investigated only visible differences between original (i.e., non-modified) facial images and those with skin surface topography fully removed. Moreover, they did not distinguish certain facial areas and consider the possibility that the removal of skin surface topography cues in some parts of the face might have stronger effects on perception than in others.

Thus, in the present studies we aimed to extend the data of Fink et al. (2001) by investigating perception of changes of female facial skin surface topography cues by digitally manipulating them in certain facial regions (Experiment 1), and the noticeability of such changes (in terms of the magnitude of skin surface topography removal) in those facial parts that show the strongest effects on perception (Experiment 2). 


\section{Experiment 1}

In this experiment, we hypothesized that a varying degree of expression of skin surface topography in female faces causes significant differences in perception of age and attractiveness. Because studies investigating visual attention have demonstrated differences in gaze and dwell time for different areas of the face (Hsiao \& Cottrell, 2008), it was further hypothesized that manipulations of certain facial regions have stronger effects on perception of age and attractiveness than others.

\section{Methods}

\section{Stimulus material}

Facial images of six British women aged 45 - 65 years, showing considerable predominance of lines and wrinkles in multiple facial areas, were taken using a custom digital imaging rig comprising a 6.2 - megapixel digital single-lens reflex camera fitted with a Nikkor $45 \mathrm{~mm}$ 1:2.8 P lens (Nikon Corporation, Tokyo, Japan), a multiple flash lighting system and a chinrest to ensure accurate, reproducible positioning of subjects and overall component stability. Images were captured and stored in uncompressed TIFF format at a resolution of $3277 \times 2226$ pixels and 72 dpi. Women did not use makeup and any facial adornments were removed for the photography. No color correction or spatial filtering was applied to these images.

Images were digitally manipulated, following the procedure described by Fink and Matts (2008), to remove visible high frequency / low amplitude skin surface topography (micro-texture and fine lines) as well as visible low frequency / high amplitude skin surface topography (macro-texture, i.e., wrinkles) in five areas: (i) on the cheeks, (ii) the 'crow's feet' area adjacent to the eye, (iii) under the eyes, (iv) above the upper lip, and (v) on the forehead. Thus, in addition to the original (unmodified) facial images, five conditions were created for each of the six original images.

\section{Rating study}

One hundred female participants aged $36-55$ years $(M=46.0, S D=5.6)$ from the local population of Cincinnati, OH (USA), and 100 women and 100 men aged $15-37$ years $(\mathrm{M}=$ 25.0, $\mathrm{SD}=3.9$ ) from the student population of the University of Göttingen (Germany), rated the stimulus faces on color corrected TFT monitors (LaCie 324, LaCie Inc., Portland, USA / Paris, France), set to a resolution of 1920 x 1200 pixels at 32 - bit ('true color') color depth. 
Stimuli were presented in a forced choice task in omnibus pairwise combinations ("within face condition"), in which six conditions for each face were randomised with regard to side of presentation (left, right). Moreover, the order of the six different subject faces ("between faces condition") was also randomised for each participant. For each facial pair, and in separate rating sessions, participants were asked to indicate the face which they considered, first, younger looking and, secondly, more attractive by clicking on a corresponding button on the screen below the respective face. At the end of the experiments, all participants were reimbursed with a nominal stipend and were informed upon the purpose of the study.

\section{Results}

Given that the preference data were not normally distributed (one-sample KolmogorovSmirnov goodness-of-fit test; age: all $\mathrm{Z}>2.6$, all $\mathrm{P}<0.001$; attractiveness: all $\mathrm{Z}>2.7$, all $\mathrm{P}<0.001$ ) and variances were not equal (Mauchley's test of sphericity; age: $\chi^{2}=186.8$, $\mathrm{P}<0.001$; attractiveness: $\chi^{2}=186.9, \mathrm{P}<0.001$ ), non-parametric tests were used (Dancey \& Reidy, 2004). Differences in preferences among the six facial conditions were calculated using a Friedman test (two-tailed) and a Wilcoxon signed-rank test was applied as a post hoc test. In order to address the statistical problem of obtaining significant results due to multiple testing alone, the significance level was adjusted (Bonferroni correction) to $\alpha=0.003$ (Dancey \& Reidy, 2004). Differences in preferences between American and German participants, as well as between women and men, were tested using Mann-Whitney U-test (twotailed) at $\alpha=0.05$.
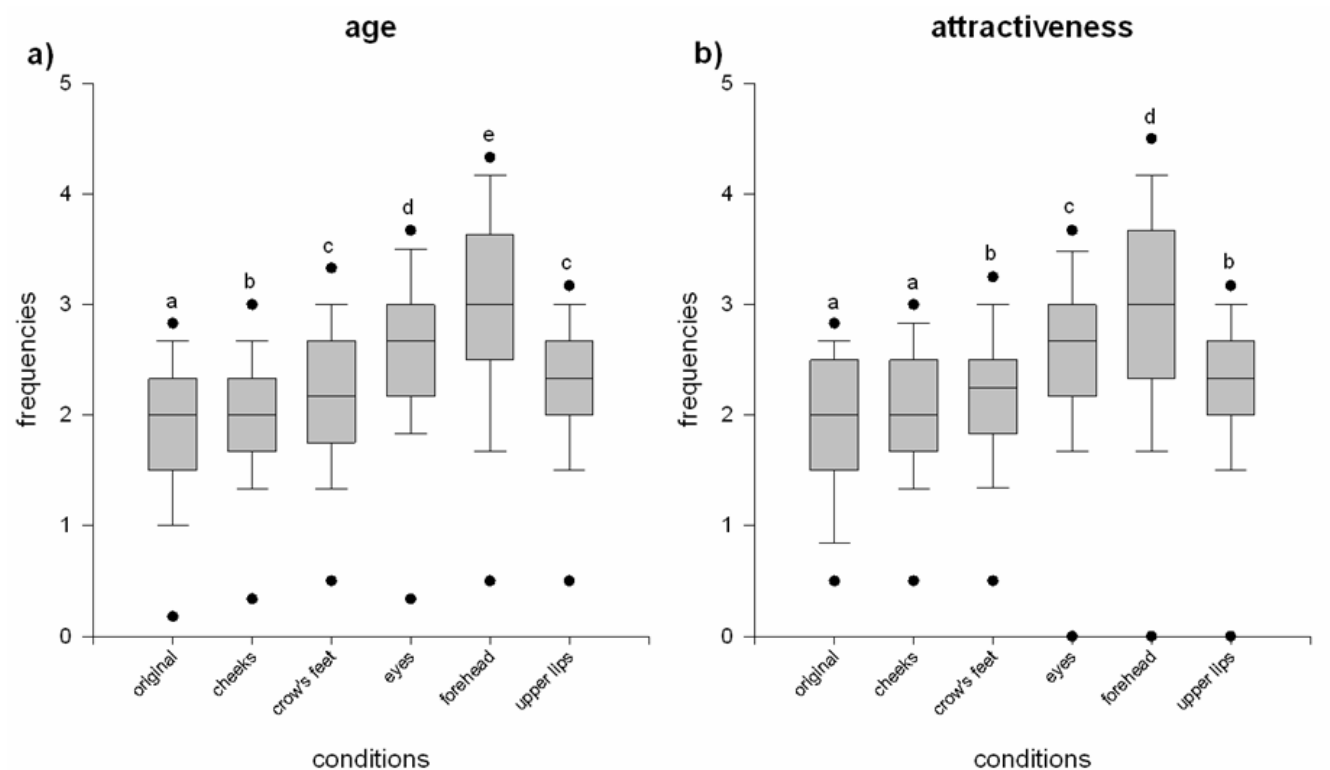

Figure 1 Frequencies of age (a) and attractiveness (b) preference. Values represent medians with their respective $5^{\text {th }} / 95^{\text {th }}$ percentiles. Box-plots with different letters differ significantly. 
Preferences of perceived age and attractiveness of female faces varying in the expression of skin surface topography cues differed significantly from each other (age: $\chi^{2}=208.1$, $\mathrm{P}<0.001$; attractiveness: $\left.\chi^{2}=327.7, \mathrm{P}<0.001\right)$. Overall, both American and German respondents preferred images with skin surface topography cues removed on specific parts of the face significantly more often than the original un-altered images (Fig. 1a,b, manipulations of the forehead, under the eyes, the crow's feet and the area above the upper lip, in descending order of preference). Removal of skin surface topography cues from the cheeks resulted in a significant improvement perception of age, but not attractiveness (Fig. 1b).

There were some differences in the perception of American and German respondents (see Table 1a). German women perceived unmodified (original) facial images significantly younger and more attractive than American respondents and found faces with skin surface topography removed on the cheeks more attractive than American women. American and German women also differed in their perception of those images in which skin surface topography was removed under the eyes. German women preferred these images significantly more often than American women when choosing the more attractive looking face, while female respondents in America preferred these stimuli significantly more often when asked to select the younger looking face.

Table 1a Age and attractiveness preferences of American and German women.

\begin{tabular}{|c|c|c|c|c|}
\hline & USA & Germany & & \\
\hline & MD & MD & $\mathrm{U}$ & $\mathrm{P}$ \\
\hline \multicolumn{5}{|l|}{ Age } \\
\hline Original & $1.5(0.3-2.8)$ & $2.1(0.0-3.2)$ & 2801.0 & $<0.001$ \\
\hline Cheeks & $2.0(1.0-3.0)$ & $2.0(0.0-4.0)$ & 4405.0 & 0.14 \\
\hline Crow's feet & $2.3(1.0-3.5)$ & $2.2(0.0-3.5)$ & 4813.0 & 0.65 \\
\hline Eyes & $2.8(1.7-4.3)$ & $2.2(0.0-3.5)$ & 3801.5 & $<0.01$ \\
\hline Forehead & $2.8(1.2-4.2)$ & $3.0(0.0-4.7)$ & 4902.0 & 0.81 \\
\hline Upper lips & $2.2(1.0-4.0)$ & $2.3(0.0-3.2)$ & 4997.0 & 0.99 \\
\hline \multicolumn{5}{|l|}{ Attractiveness } \\
\hline Original & $1.7(0.5-2.8)$ & $2.2(0.0-3.7)$ & 2618.5 & $<0.001$ \\
\hline Cheeks & $2.0(0.7-2.8)$ & $2.2(1.2-3.8)$ & 4145.5 & 0.04 \\
\hline Crow's feet & $2.3(1.0-3.5)$ & $2.2(1.2-3.5)$ & 4486.0 & 0.21 \\
\hline Eyes & $2.7(1.7-4.3)$ & $2.7(0.0-4.0)$ & 4185.5 & $<0.05$ \\
\hline Forehead & $3.0(1.0-4.0)$ & $2.8(0.0-4.7)$ & 4713.0 & 0.48 \\
\hline Upper lips & $2.2(1.0-4.0)$ & $2.3(0.0-3.3)$ & 4926.0 & 0.86 \\
\hline
\end{tabular}

Values are given as medians; numbers in parentheses give ranges.

No significant differences were found in preferences of age and attractiveness perception between German men and women, although men tended to prefer images with skin sur- 
face topography cues removed above the upper lip more often when choosing the more attractive-looking face than women $(\mathrm{P}=0.09)$ (see Table $1 \mathrm{~b}$ ).

Table 1b Age and attractiveness preferences of German women and men.

\begin{tabular}{|c|c|c|c|c|}
\hline & Women & Men & & \\
\hline & MD & MD & $\mathrm{U}$ & $\mathrm{P}$ \\
\hline \multicolumn{5}{|l|}{ Age } \\
\hline Original & $2.1(0.0-3.2)$ & $2.2(0.0-3.3)$ & 4742.0 & 0.53 \\
\hline Cheeks & $2.1(0.0-4.0)$ & $2.0(0.0-3.5)$ & 4914.0 & 0.83 \\
\hline Crow's feet & $2.2(0.0-3.5)$ & $2.2(0.2-3.8)$ & 4775.0 & 0.58 \\
\hline Eyes & $2.5(0.0-3.8)$ & $2.5(0.0-4.8)$ & 4886.5 & 0.78 \\
\hline Forehead & $3.0(0.0-4.7)$ & $3.1(0.0-4.8)$ & 4425.5 & 0.16 \\
\hline Upper lips & $2.3(0.0-3.2)$ & $2.5(0.0-4.0)$ & 4334.0 & 0.10 \\
\hline \multicolumn{5}{|l|}{ Attractiveness } \\
\hline Original & $2.3(0.0-3.7)$ & $2.2(0.2-3.3)$ & 4565.0 & 0.29 \\
\hline Cheeks & $2.2(0.2-3.7)$ & $2.0(0.0-3.5)$ & 4768.5 & 0.57 \\
\hline Crow's feet & $2.2(0.2-4.0)$ & $2.2(0.2-4.0)$ & 4843.0 & 0.70 \\
\hline Eyes & $2.7(0.0-4.0)$ & $2.5(0.0-4.2)$ & 4782.0 & 0.59 \\
\hline Forehead & $2.8(0.0-4.7)$ & $3.0(0.0-4.7)$ & 4432.5 & 0.17 \\
\hline Upper lips & $2.5(0.0-3.3)$ & $2.5(0.0-4.2)$ & 4303.5 & 0.09 \\
\hline
\end{tabular}

Values are given as medians; numbers in parentheses give ranges.

\section{Summary}

Overall, female images with skin surface topography removed on specific areas of the face were perceived both significantly younger and more attractive than the original (unmodified) images. The strength of this effect was region dependent, with modifications on the forehead and under the eyes having the strongest effects. Geographical / cross-cultural differences were found with reference to the original images and images with manipulations on the cheeks and under the eyes. Men and women did not differ significantly in their perception.

\section{Experiment 2}

In this experiment, we digitally manipulated female facial skin surface topography to determine the magnitude of removal noticeable. We concentrated on age perception, given that there was a high degree of inter-correlation between the perception of age and attractiveness in Experiment 1. Furthermore, the noticeability of skin surface topography removal was studied on the forehead and the peri-orbital area, as in Experiment 1 these regions showed the strongest visual differences compared to the original (unmodified) faces.

\section{Methods}

\section{Stimulus material}

The facial images of Experiment 1 were used to create stimuli varying in the degree of facial skin surface topography in the forehead and in then periorbital area (i.e., under the eye / 
"crow's feet"). The original (unmodified) image and its modified version with $100 \%$ of topography removed were combined into a single image as separate layers, using Adobe Photoshop CS (Adobe Systems, San Jose, CA, USA). The opacity of one layer was modified in $20 \%$ increments from 0 to $100 \%$, resulting in six categories of each face (i.e., 0 - $20-40-60$ $80-100 \%$ ) varying in the magnitude of skin surface topography cues in the respective areas. Each $20 \%$ increment overlay image was flattened (i.e., the layers were merged) and saved in (uncompressed) TIFF format at a resolution of 3277 x 2226 pixels and 72 dpi. Hence, these manipulations resulted in a set of 12 images (six conditions, two regions) with a progressive, objective and controlled removal of skin surface topography in $20 \%$ increments (see Fig. 2 and 3).

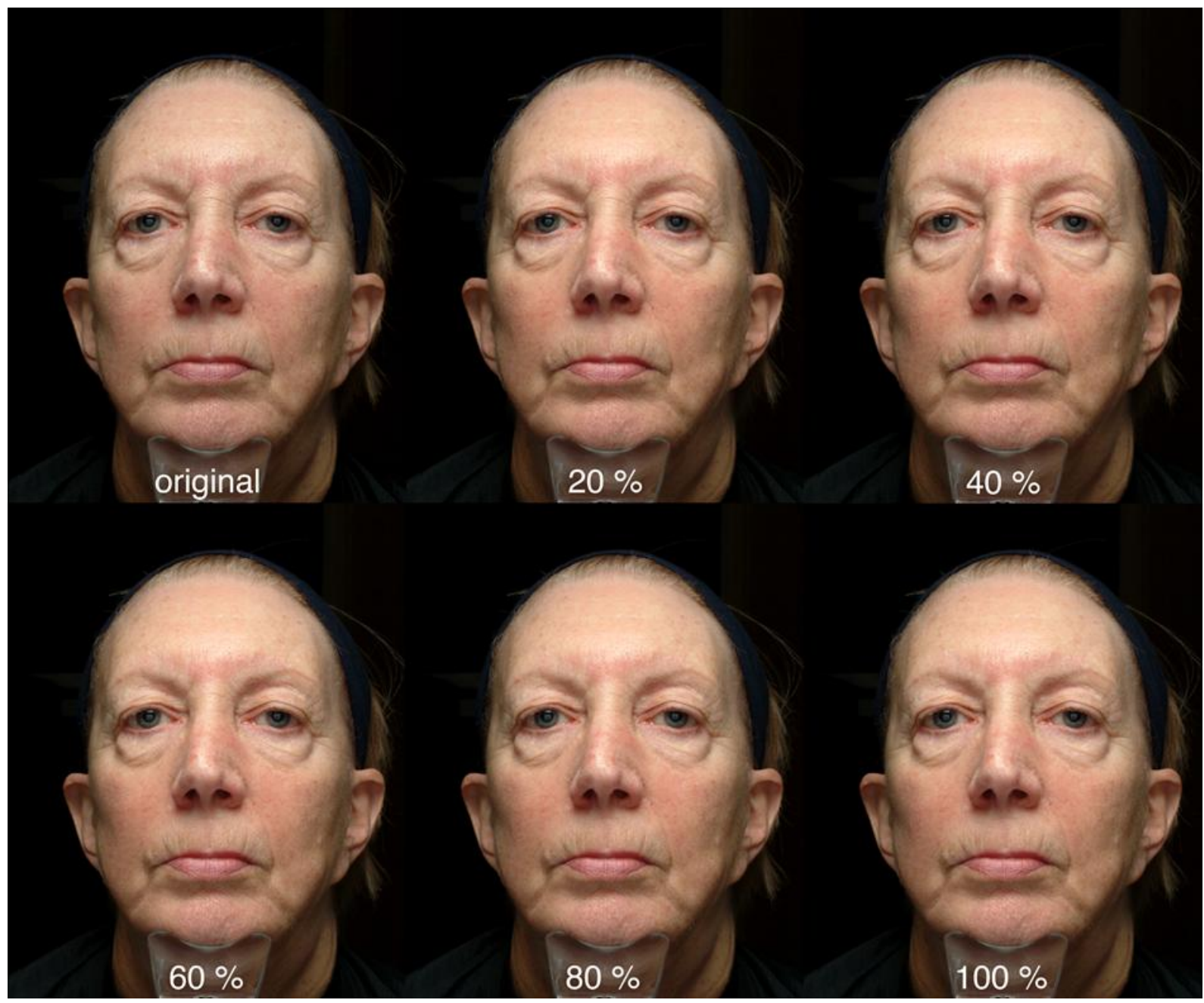

Figure 2 Progressive, objective, and controlled digital removal of skin surface topography in $20 \%$ increments on the forehead. 


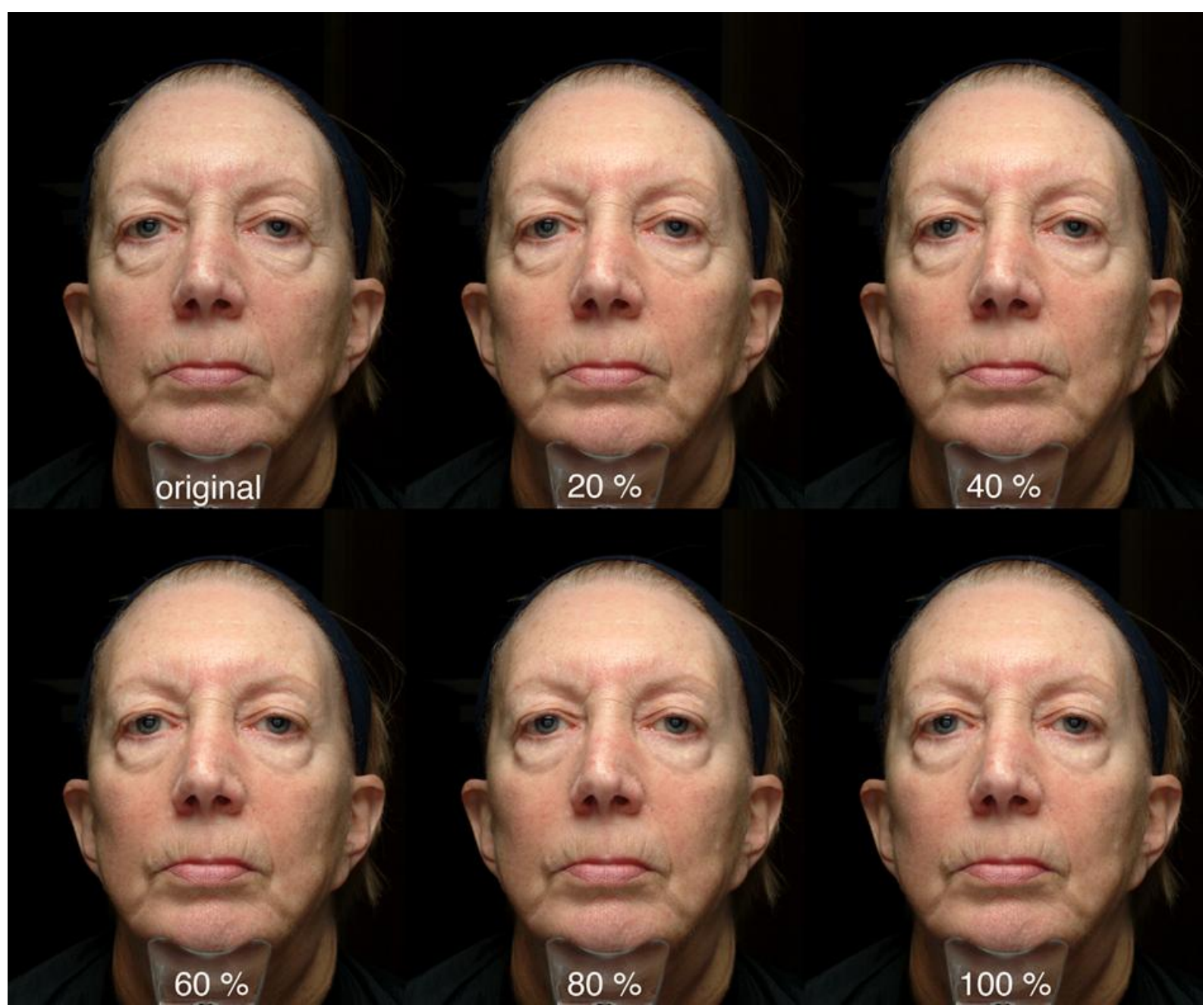

Figure 3 Progressive, objective, and controlled digital removal of skin surface topography in $20 \%$ increments in the peri-orbital area.

\section{Rating study}

One hundred female participants aged $35-55$ years $(M=44.0$ years, $\mathrm{SD}=5.9)$ from the local American population of Cincinnati, and 100 women and 100 men aged 16 - 35 years $(\mathrm{M}=22.7, \mathrm{SD}=2.9)$ from the student population of the University of Göttingen (Germany) were recruited for the rating study. The experimental setup and equipment was the same as in Experiment 1. Participants were reimbursed with a nominal stipend and were fully debriefed after they have completed all tasks.

\section{Results}

A one-sample Kolmogorov-Smirnov goodness-of-fit test indicated preference data were not normally distributed (forehead: all $\mathrm{Z}>2.7, \mathrm{P}<0.001$; eyes: all $\mathrm{Z}>2.2, \mathrm{P}<0.001$ ) and variances of stimuli were not equal (Mauchley's test of sphericity; forehead: $\chi^{2}=690.3, \mathrm{P}<$ 
0.001; eyes: $\left.\chi^{2}=739.7, \mathrm{P}<0.001\right)$, thus non-parametric tests were used, as in Experiment 1 (Dancey \& Reidy, 2004) and the significance level was adjusted to $\alpha=0.003$ (Dancey \& Reidy, 2004).

Overall, age perception differed significantly among facial skin images varying in the degree of skin surface topography cues on the forehead $\left(\chi^{2}=1219.2, \mathrm{P}<0.001\right)$ and around the eyes $\left(\chi^{2}=1117.3, \mathrm{P}<0.001\right)$. That is, the more skin topography was removed, the more frequently the facial image was preferred (see Fig. 4a and b).

A comparison of American and German respondents revealed that German women preferred the original images, as well as images with $20 \%, 40 \%, 60 \%$, and $80 \%$ removal of forehead topography cues significantly more often than American women when choosing the younger-looking facial image. This was also found with rates of preference for faces varying in the magnitude of skin surface topography in the eye region, although no significant differences were detected in preferences for images with $80 \%$ removal of skin topography $(\mathrm{P}=$ 0.21 ; see Table $2 a)$.
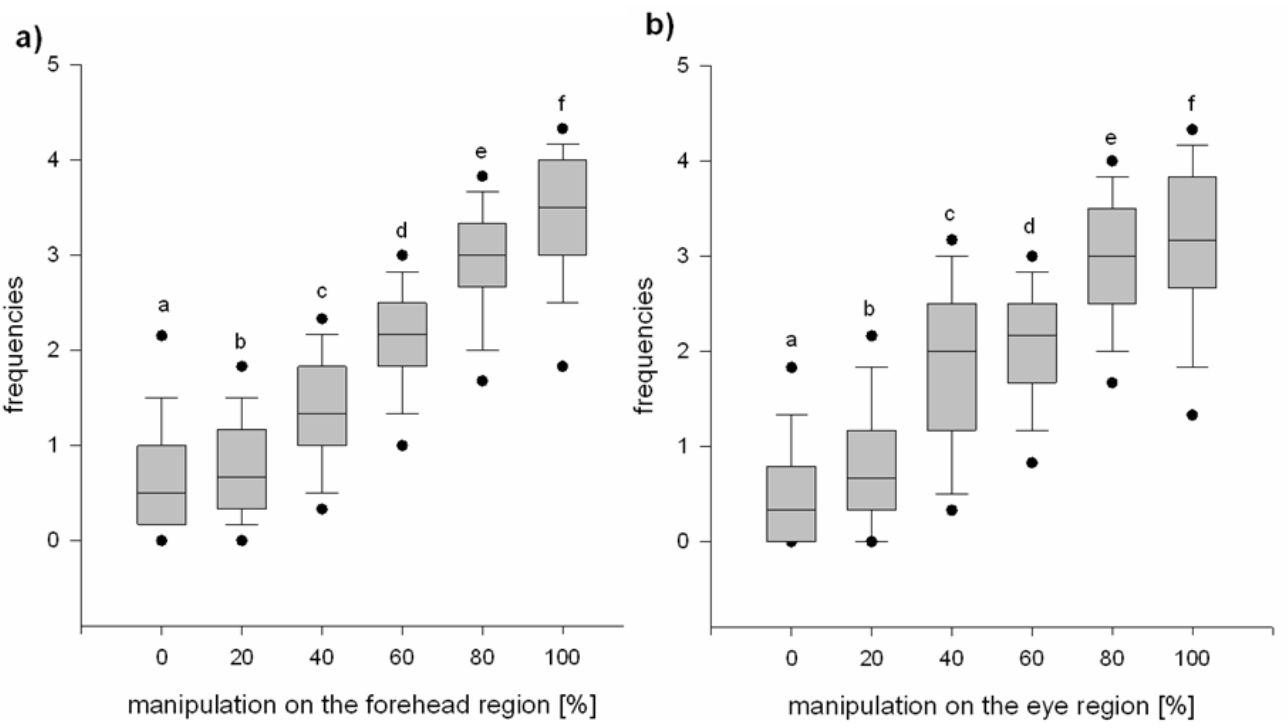

Figure 4 Frequencies of age preferences for the forehead (a) and eyes (b) region. Values represent medians with their respective $5^{\text {th }} / 95^{\text {th }}$ percentiles. Box-plots with different letters differ significantly.

Differences in preference were also found between German men and women. Men perceived unmodified facial images, images with $20 \%$ removal of skin topography on the forehead and the eyes, and facial images with $40 \%$ removal of forehead topography significantly younger than women. By contrast, when asked to indicate the younger looking facial image, women preferred images with $60 \%$ (eyes only), $80 \%$ and $100 \%$ removal of skin surface topography significantly more often than men (see Table $2 b$ ). 


\section{Summary}

Overall, participants perceived facial images as being younger when skin surface topography cues were removed and were able to notice at least a $20 \%$ change. German woman perceived images, in which skin surface topography was not completely removed, significantly younger than their American counterparts. However, the interpretation of this effect needs to be considered with caution, given that mean age of participants was different between the countries. There was also some gender difference, with German men preferring facial images with minor changes $(<40 \%)$ and German women preferring those with major changes (>60\%) in skin surface topography more frequently.

Table 2a Age preferences of American and German women for the forehead and eye region.

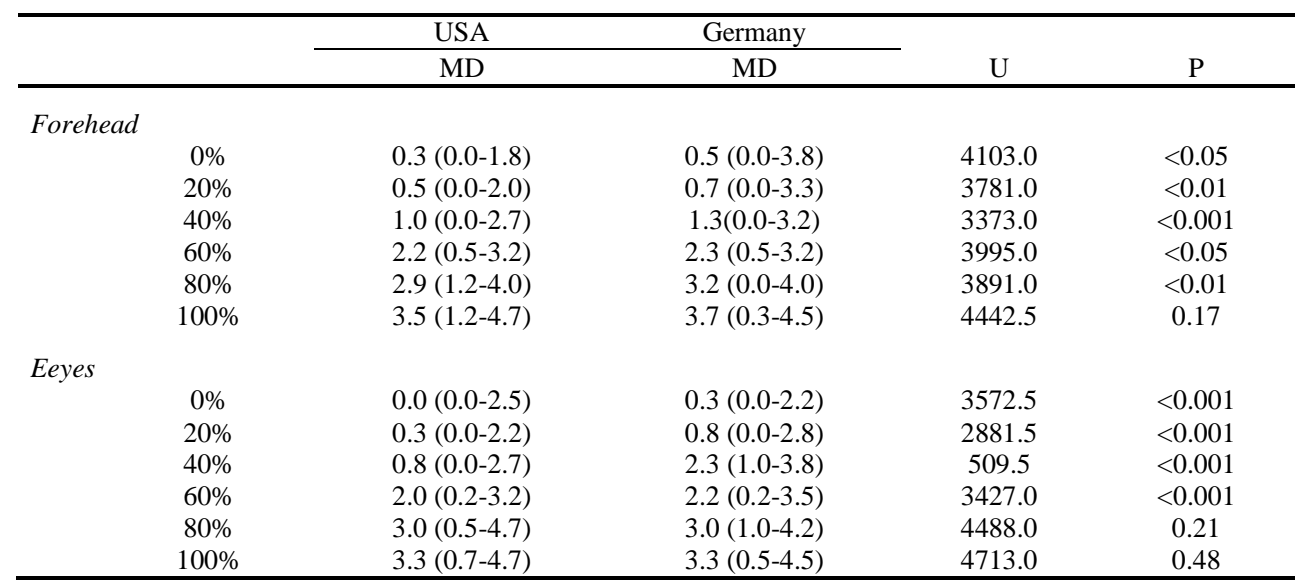

Values are given as medians; numbers in parentheses give ranges.

Table $2 \mathbf{b}$ Age preferences of German women and men for the forehead and eye region.

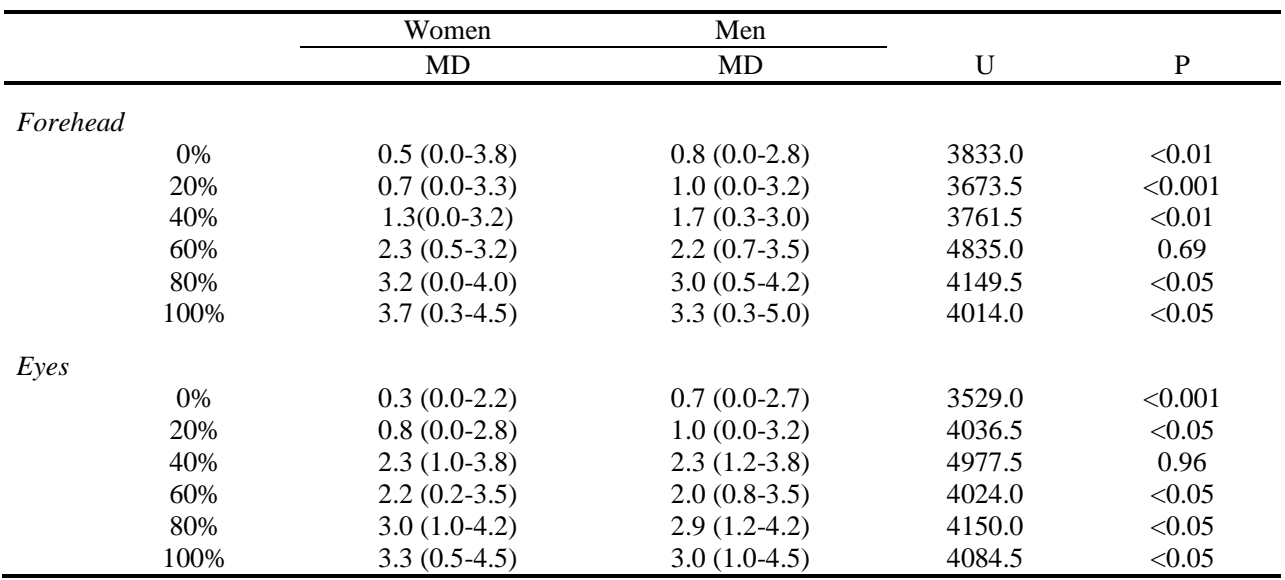

Values are given as medians; numbers in parentheses give ranges. 


\section{Discussion}

The results of the present study indicate that people are sensitive to skin surface topography cues when making judgements of female facial age and attractiveness. Images with skin surface topography removed were perceived as both younger looking and more attractive than their original (unmodified) counterparts. The removal of skin surface topography cues on the forehead and around the eyes had a stronger effect on perception than manipulations on other parts of the face (Experiment 1). Moreover, even a 20\% removal of skin surface topography in these facial regions significantly affected perception of age (Experiment 2).

Although the perception of American and German women was affected equally, i.e., the forehead and eye region had the strongest effect. Overall, German women and men did not differ significantly in their perception of altered regions of the face (Experiment 1), although men perceived facial images with minor changes in skin surface topography $(<40 \%)$ significantly younger than women, while women perceived those with major changes (> 60\%) significantly younger (Experiment 2).

How is this result important in a broader (i.e., evolutionary psychology) context? Evolutionary psychologists hypothesise that preference for certain characteristics of the face (and body) have evolved as they provide cues to one's fertility and health. From this point of view, preferences for some facial and bodily traits are thought to reflect cognitive adaptations that facilitate human mate selection. Male reproductive success is most notably determined by female biological age, thus assigning age a prominent role in human mate selection (Jones, 1997; Pawlowski \& Dunbar, 1999). Given that apparent skin condition changes with age, due to various intrinsic and extrinsic factors, we argue that skin surface topography (in addition to evenness of skin coloration) provides important information about female age that is also relevant in male mate selection (Barber, 1995; Fink, Grammer, \& Matts, 2006; Fink, Grammer, \& Thornhill, 2001). This might be especially so in the face, as it is of particular importance in human social communication (Haxby, Hoffman, \& Gobbini, 2002). The results of the present study support this suggestion, given that facial images with skin surface topography removed were perceived to be younger looking and more attractive compared to their unmodified (original) counterparts. Our results are in line with previous studies, showing that facial images of individuals aged $60+$ years are perceived as less attractive than those younger $(\mathrm{Eb}-$ ner, 2008), and that uneven skin color distribution, which increases with an individual's chronological age and cumulative sun damage (Farage et al., 2008; Gilchrest \& Krutman, 2006), is negatively correlated with perception of health and attractiveness (Fink, Grammer, \& Matts, 2006; Fink \& Matts, 2008). 
The present study further indicates that some facial parts influence people's perception more strongly than others, at least with reference to skin surface topography cues, given that we found significant differences between respective manipulations, with removal of topography on the forehead and around the eyes showing the strongest influence on perception of age and attractiveness. This is important, as researchers are still trying to understand the cause of selective visual attention towards different parts of the face in human social interaction.

The strongest preferences for images with manipulations of skin surface topography on the forehead could be explained simply by the fact that this is the largest continuous area of facial skin when seen in frontal view. Furthermore, a combination of the anatomy of the forehead in relation to the natural directionality of dermal tension ("Langer's Lines") (Farage et al., 2008), its assumed relatively high lifetime cumulative dose of solar erythemally effective UV radiation (Lock-Andersen, Drzewiecki, \& Wulf, 1998), and the relatively high degree of flex experienced by skin in this area tends to produce particularly marked, long linear wrinkles (dynamic expression lines) (Piérard, Uhoda, \& Pierard-Franchimont, 2003; Quatresooz et al., 2006) and, thus, may make the removal of these features particularly noticeable.

As the eyes receive more visual attention than any other part of the face (Hsiao \& Cottrell, 2008; Piérard, Uhoda, \& Pierard-Franchimont, 2003), thus making them particularly relevant in social communication (Mulhern et al., 2003), one is likely to be more sensitive to changes in topography cues in the peri-orbital region than others. A higher visual attention to the eye region (and the forehead) was also found in a preliminary eye-tracking study, in which we used the same stimuli as in the present study (Samson et al., unpublished data). This is also in line with a recent eye-tracking study, which investigates age- and fatigue-related markers of human faces (Nguyen, Isaacowitz, \& Rubin, 2009). The authors demonstrated preferential focus on the eye area (followed by the forehead) when assessing age, with higher frequency and longer duration of gaze than on other parts of the face, with the brow and lower lid (including the fatty parts of the lower lid / lacrimal sac) receiving most visual attention (Nguyen, Isaacowitz, \& Rubin, 2009).

Other studies have shown that the crow's feet area adjacent to the eyes and the wrinkles above the upper lip are independent parameters driving judgement of age (Dicanio et al., 2009; Nkengne et al., 2008). In the present study, however, the systematic, controlled removal of skin surface topography in these facial areas had a relatively low effect on perception of age and attractiveness. The effect of skin surface topography above the upper lip may be dependent on facial expression (Quatresooz et al., 2006). Similarly, the crow's feet area might also have more effect on perception as facial expression varies, as wrinkling in this area is 
considerably more pronounced when smiling, for example (Hillebrand \& Myamoto, 2007, September-October).The removal of skin surface topography on the cheeks had the lowest effect on age perception and had no significant effect on perceived attractiveness. This might be explained simply by the fact that skin in the cheek area expresses fewer linear topographical features relative to other parts of the face.

Possible explanations for German woman being apparently less sensitive than American women to removal of skin surface topography remain speculative as few, if any, scientific research has directly compared both geographies. One explanation could be the age difference between American and German respondents. Since the older American volunteers were nearly the same age as the women presented in the images, they may have been more concerned with signs of aging than the relatively younger participants in Germany, as persistent wrinkles tend not to be expressed before the age of 30 (Quatresooz et al., 2006).The results, therefore, might indicate a so-called "own-age bias", found also in studies investigating facial recognition, where adults and children are more likely to recognise and more accurately estimate the age of faces of their own age cohort, relative to others (Anastasi \& Rhodes, 2005, 2006).

The finding that women performed better in the recognition of minor $(<40 \%)$ modifications in skin topography cues, while men performed better in the recognition of major (>60\%) modifications, is interesting. This difference might be explained by the fact that most cosmetic products are still targeted towards women (Schlessinger, 2007), possibly causing them to be more sensitive towards the facial skin condition of other women, regardless of age. The market for male grooming products, however, is rising (Schlessinger, 2007) and may in time, if there is merit in the hypothesis above, increase male sensitivity towards smaller changes in skin condition. A higher sensitivity towards female skin condition might also be explained by female intra-sexual competition, as men have been shown to prefer women displaying morphological markers of youth (Barber, 1995). Similar sex differences in the perception of female faces were observed in a study by Nkengne et al. (2008). When estimating the facial age of female images, female participants were found to be more accurate than men. This, however, would still not account for the higher male preference rate for female facial images with major modifications in skin surface topography.

In summary, we have shown that not all facial skin topographical features are equal and have uncovered an apparent hierarchy in the perception of change in female facial skin topography. We have also shown that men and women are sensitive to at least $20 \%$ increments of change in topography around the eyes and on the forehead. 


\section{Acknowledgements}

This project was funded by The Procter \& Gamble Company, Cincinnati, USA and the German Science Foundation (DFG), grant number FI 1450-4-1, awarded to Bernhard Fink as well as through the Institutional Strategy of the University of Göttingen. 


\section{Chapter 4}

\section{INTERACTION OF SKIN COLOR DISTRIBUTION AND SKIN SURFACE TOPOGRAPHY CUES IN THE PERCEPTION OF FEMALE FACIAL AGE AND HEALTH}

Nadine Samson*, Bernhard Fink* \& Paul J. Matts ${ }^{\dagger}$

* Department of Sociobiology / Anthropology, University of Goettigen, Germany

† The Procter \& Gamble Company, Rusham Park Technical Centre, Whitehall Lane, Egham, Surrey, UK

Journal of Cosmetic Dermatology, (2011) 10 (1): 78-84 


\section{Summary}

Background Skin color distribution and skin surface topography are the predominant drivers of the variation in visible skin condition and this variation affects one's perception of age and health. Recent research, however, has shown that the strength of the impact of these features on perception differs such that skin surface topography is a stronger indicator of age, while skin color distribution is more strongly linked to health perception.

Objectives To examine further the relative contribution and interaction effects of skin color distribution and surface topography cues on perception by considering small changes of these features.

Methods Two sets of images were created by gradually smoothing uneven skin colour distribution and removing skin surface topography cues (both in 25\% increments) in the digital image of the face of a 61-year-old British woman. Omnibus pair-wise combinations of modified images were presented to a panel of 160 German men and women (aged 19 - 49 years). With each pair, they were asked to select the face they considered both youngerlooking and healthier.

Results Female facial age perception was more strongly affected by the removal of skin surface topography cues than by changes in skin color distribution, particularly so for topography removal of $50 \%$ and more. In contrast, the smoothing of uneven skin color distribution had a stronger effect on the perception of female facial health, particularly for changes of $25 \%$ and greater.

Conclusions These results support previous reports on the differential effects of visible skin color distribution and surface topography cues on the perception of female facial age and health and show that only relatively small changes are necessary to drive this differential perception.

Keywords: age, face, health, skin color distribution, skin surface topography, age, women. 


\section{Introduction}

Visible skin condition, particularly that of women, affects our perception of age, health and attractiveness. The majority of knowledge regarding these associations is derived from facial studies (e.g., Refs. Fink, Grammer, \& Matts, 2006; Fink \& Matts, 2008; but see Fink et al., 2011, for the significance of body skin). For example, it has been report reported that men judge shape-standardized female faces with even skin color distribution as younger, healthier, and more attractive than counterparts showing greater contrast (Fink, Grammer, \& Matts, 2006). Moreover, even skin color distribution, as measured via image analysis of isolated fields of high-resolution digital facial skin images, was found to be correlated positively with perception of attractiveness and health and negatively with perception of age of the same images (see also Matts et al., 2007; Nkengne et al., 2008). Furthermore, faces with even skin color distribution also attract visual attention more strongly than those with greater color contrast. In a study that employed eye-tracking technology (Fink et al., 2008) shape-standardized images of female faces varying only in the evenness of skin color distribution were presented to a sample of young men and their eye gaze tracked while viewing these images. It was found that both dwell time and fixation count were significantly higher for faces with more even skin color distribution and that these measures correlated significantly with subsequent judgements of age (negative correlation) and attractiveness (positive correlation).

In stressing an evolutionary psychology context in understanding the significance of age-related changes in visible skin condition, scholars have recently summarised the evidence from these studies and concluded that facial skin aging, with the dyschromia and decrease in bulk light reflection characteristic of chronic solar ultraviolet radiation (UVR) damage, can be perceived readily by both men and women and, in consequence, affects our judgement of others (Matts \& Fink, 2010). However, facial skin age is influenced not only by dyschromia and a decrease in bulk light reflection, but also the severity and frequency of lines and wrinkles, another consequence of chronic UVR damage (Fedok, 1996; Friedman, 2005), and a loss of hygroscopicity and hydration (Manuskiatti, Schwindt, \& Maibach, 1998). Thus, a recent study (Samson et al., 2010) investigated perception and noticeability of skin surface topography cues in facial images of six British women, aged 45 - 65 years by systematic, incremental removal of lines and wrinkles in certain facial areas (i.e., the peri-orbital area, the cheek, above the upper lip, and on the forehead). It was found that faces with skin surface topography cues removed were judged significantly younger and more attractive than their original (unmodified) counterparts, with changes on the forehead and around the eyes having the greatest noticeability and concomitant perceptual impact. In these areas, participants were 
able to detect at least a $20 \%$ change in skin surface topography. Hence, even relatively small changes in skin surface topography can affect perception of female facial age and attractiveness, with associated social consequence (in terms of mate selection).

The evidence summarized earlier, however, is derived from studying the perception of single associations of either skin color distribution or skin surface topography features - a situation not present in reality, as both characteristics are expressed simultaneously across a broad range of relative magnitude. It is important, therefore, to consider the possibility of interaction effects for these features to ensure a more ecologically valid picture of the signalling mechanisms at work. In the attempt to disentangle the relative contribution of skin color distribution and skin surface topography cues on perception of female facial age and health, scholars created different sets of digital images of female faces, i.e., unmodified (original) images, images with smoothed skin color distribution, images with skin surface topography removed, and images with both features smoothed/ removed (Fink \& Matts, 2008). It was found that, although both skin color distribution and skin surface topography both significantly affected perception of age and health, skin surface topography was a stronger predictor of female facial age, while skin color distribution was a stronger health cue. A significant limitation of this study was that it compared only images of faces that were unmodified in skin color distribution and skin surface topography with those that had these features completely smoothed / removed. In addition, considering recent research showing that we are sensitive to relatively subtle variation in these endpoints (Samson, Fink, \& Matts, 2010), it is likely that differential effects are likewise present at smaller magnitudes.

The objective of the present study, therefore, was to determine the relative contribution and interaction effects of skin color distribution and skin surface topography on the perception of female facial age and health by gradually removing these features in $25 \%$ increments. We hypothesized (i) differential effects of skin color distribution and skin surface topography on the perception of female facial age and health (as per Ref. Fink \& Matts, 2008), such that faces with smoothed / removed skin features should receive higher preference, and (ii) the presence of these effects with even relatively small changes in these facial skin cues.

\section{Methods}

\section{Stimuli}

The facial image of a 61- year- old British woman was selected from the database of a previous study (Samson et al., 2010), based on co-expression of both skin color distribution 
and skin surface topography features. This woman was photographed using a custom digital imaging rig with a 6.2-megapixel digital single-lens reflex camera fitted with a Nikkor $45 \mathrm{~mm}$ 1:2 P lens (Nikon Corporation, Tokyo, Japan), a multiple flash lighting system, and a chinrest to help ensure stability and precise positioning. The subject was asked to remove makeup as well as any jewellery and / or other facial adornments. The image was captured and stored in uncompressed TIFF format at a resolution of 3277 × 2226 pixels and 72 dpi, without any color correction or spatial filtering.

Two types of image sets were created by either smoothing skin color distribution (Set 1) or removing skin surface topography cues (Set 2) in 25\% increments. First of all, in both image sets, either uneven skin color distribution or skin surface topography features were completely smoothed / removed by precise digital image processing. Manipulation of skin color distribution was performed by adjusting the hue and saturation of affected areas so that it matched closely the color of adjacent skin. Hyperpigmented spots and dilated blood vessels were removed by replacing them with adjacent unaffected skin using the "healing" tool in Adobe Photoshop CS (Adobe Systems, San Jose, CA, USA). Similarly, for the removal of skin surface topography cues, samples of unaffected skin adjacent to the respective feature were cloned to replace them. The digital brush of the "healing" tool was set to a size of 10 pixels, and images were enlarged by at least $400 \%$ before manipulation. Secondly, the creation of a linear series of decreasing magnitudes of visible skin color distribution and skin surface topography was achieved by following the protocol reported in Samson et al. (2010). The original (unprocessed) image and its (processed) counterpart (with its respective skin features completely smoothed / removed) were combined as separate layers into a single image using Adobe PhOtoshop CS. The opacity of the processed image was increased in $25 \%$ increments, resulting in five levels of magnitude of expression of visible skin color distribution and skin surface topography (i.e., $0,25,50,75,100 \%$ ). Thirdly, the respective layers were merged and saved in uncompressed TIFF file format at a resolution of 3277 x 2226 pixels and 72 dpi. Thus, our final stimulus material comprised two sets of facial images that differed in apparent skin color distribution / skin surface topography, each set comprising faces with the respective skin feature changed in $25 \%$ increments (see Fig. 1). 
Chapter 4

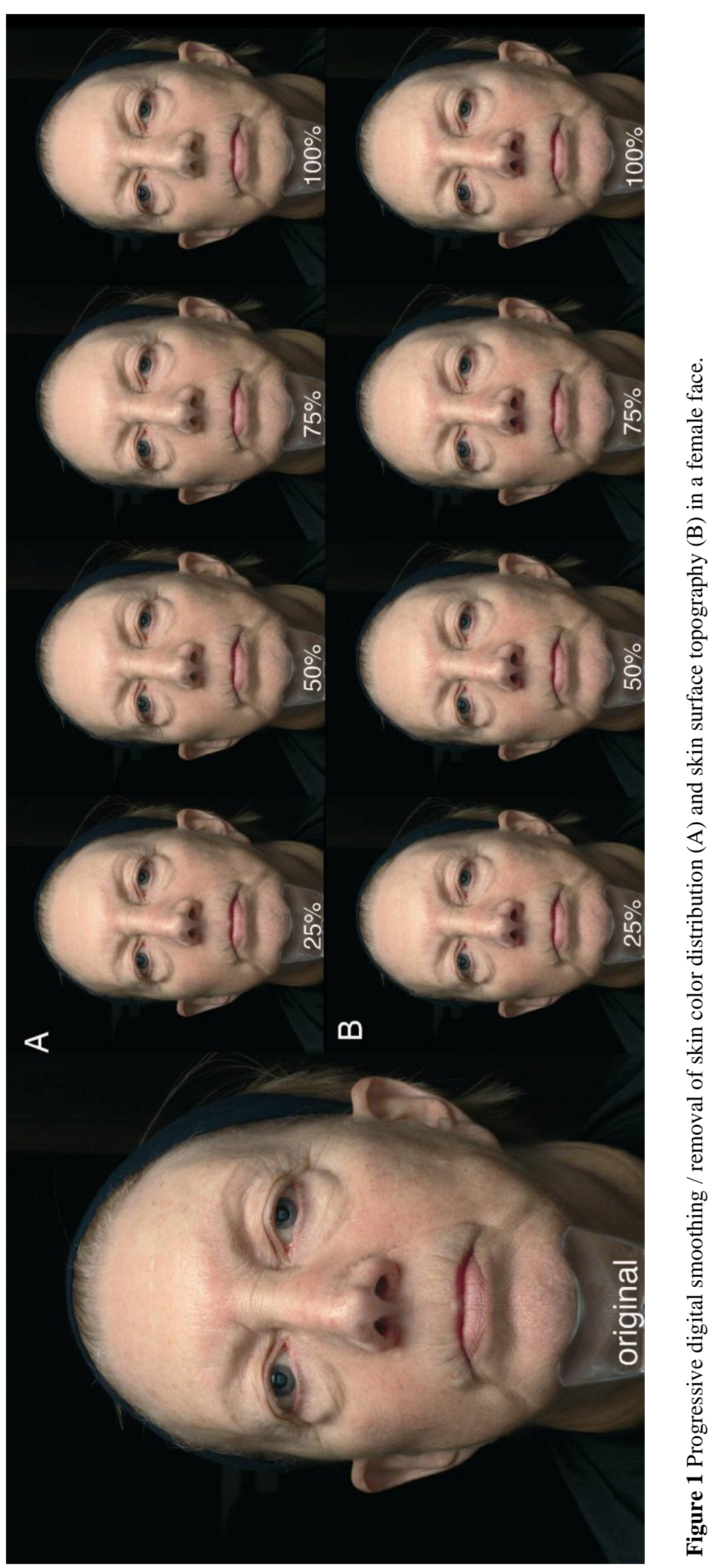




\section{Rating study}

A rating study was carried out on color-corrected TFT monitors (LaCie 324, LaCie Inc., Portland; OR, USA, Paris, France), set to a resolution of 1920 x 1200 pixels at 32-bit color depth. To ensure constant color conditions and resolution for all participants, monitors were calibrated with the LaCie Blue Eye calibrator. A total of 160 participants ( 80 men, 80 women) between the ages of 19 and 49 years (mean age $=23.73$ years, $\mathrm{SD}=3.98$ ), mainly undergraduate students from the University of Goettingen, judged the stimuli in a pairwise presentation design for perceived age and health. Omnibus combinations of face pairs were presented on slides using MEDIALAB software (Empirisoft Inc., New York, NY, USA), by selecting one face from Set 1 and one from Set 2 per slide. The sides of presentation (left / right) were counter-balanced for the two image sets, and the order of slides was randomized between the judges. Participants were requested to select the face they considered younger and, separately, healthier (in two blocks, randomised between subjects) by indicating their choice via a mouse-click. After completing all tasks, they were fully debriefed on the purpose of the experiment. In the statistical analysis, the summary of preferences for each condition (skin feature and magnitude) of all men were used.

\section{Results}

A 2 (skin feature) x 5 (magnitude of manipulation) repeated measures analysis of variance (ANOVA) was conducted to test the possibility of differences in the judges' perception (of age and health) of differing visible expressions of original skin color distribution / skin surface topography. Given that Mauchley's test of sphericity had been violated for both age $\left(\chi^{2}=76.88, \mathrm{P}<0.001\right)$ and health $\left(\chi^{2}=53.86, \mathrm{P}<0.001\right)$, Greenhouse-Geisser estimates of sphericity were applied to correct the degrees of freedom.

Age

Descriptive statistics of facial age perceptions are reported in Table 1. There was a significant main effect of each skin feature $\left(\mathrm{F}_{(1,159)}=5.52, \mathrm{P}<0.05\right)$ and the magnitude of its manipulation $\left(\mathrm{F}_{(3,487)}=156.78, \mathrm{P}<0.001\right)$ on perceived facial age. The removal of skin surface topography cues had a stronger effect on age perception than the smoothing of uneven skin color distribution, although preferences for each increased with the degree of feature smoothed / removed (Fig. 2). There was also, however, a significant interaction effect of skin feature $\mathrm{x}$ magnitude of manipulation $\left(\mathrm{F}_{(3,513)}=7.39, \mathrm{P}<0.001\right)$ on facial age perception, indi- 
cating that certain degrees of removal of skin surface topography had a stronger influence on age perception than smoothing of uneven skin color distribution. Post hoc pair-wise comparisons (Bonferroni) revealed that the removal of at least $25 \%$ and up to $50 \%$ of both skin color distribution and skin surface topography cues had the strongest effect on facial age perception although, for $50 \%$ manipulation and beyond, removal of topography cues had the stronger effect. For both skin color distribution and skin surface topography, however, smoothing / removal beyond a magnitude of $50 \%$ did not result in any significant further increase in preference for these faces (Fig. 2).

Table 1 Descriptive statistics for age preferences for female faces varying in the magnitude of smoothing / removal skin color distribution (Set 1) and skin surface topography (Set 2) $(\mathrm{N}=160)$

\begin{tabular}{|c|c|c|}
\hline Magnitude of manipulation (\%) & Mean & SD \\
\hline \multicolumn{3}{|l|}{ Set 1} \\
\hline Original & 1.38 & 0.91 \\
\hline 25 & 2.09 & 1.34 \\
\hline 50 & 2.55 & 1.50 \\
\hline 75 & 2.83 & 1.53 \\
\hline 100 & 2.73 & 1.50 \\
\hline \multicolumn{3}{|l|}{ Set 2} \\
\hline Original & 1.48 & 0.92 \\
\hline 25 & 2.01 & 1.22 \\
\hline 50 & 3.16 & 1.56 \\
\hline 75 & 3.39 & 1.57 \\
\hline 100 & 3.38 & 1.66 \\
\hline
\end{tabular}

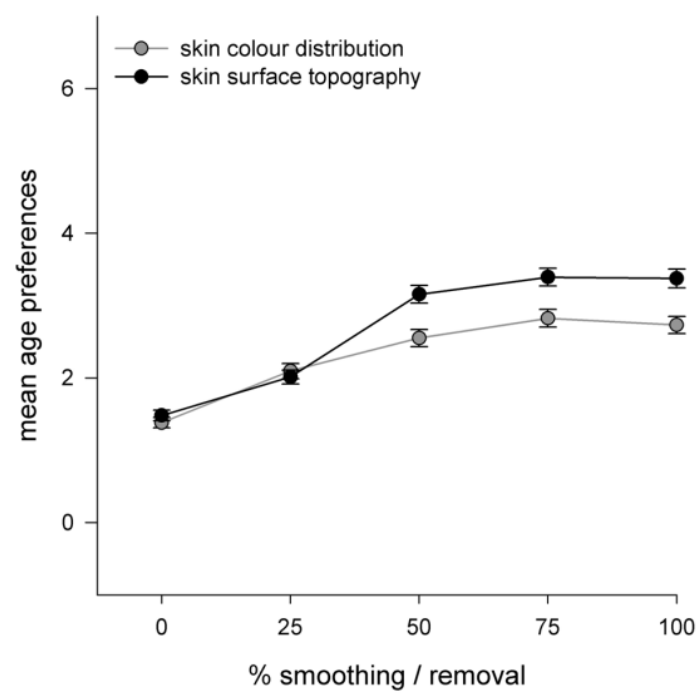

Figure 2 Mean ( \pm SE) age preferences for female faces varying in the magnitude of smoothing / removal of skin color distribution and skin surface topography. 


\section{Health}

Descriptive statistics of facial health perception are provided in Table 2. As with age, there was a significant main effect of each skin feature $\left(\mathrm{F}_{(1,159)}=195.84, \mathrm{P}<0.05\right)$ and the magnitude of its manipulation $\left(\mathrm{F}_{(3,539)}=90.96, \mathrm{P}<0.001\right)$ on perceived facial health. In this instance, smoothing of uneven skin color distribution had a significantly stronger effect on facial health perception than the removal of skin surface topography cues. Also, a significant interaction effect of skin feature $x$ magnitude of manipulation $\left(\mathrm{F}_{(4,569)}=26.02, \mathrm{P}<0.001\right)$ on facial health perception was found, indicating that smoothing of uneven skin color distribution at certain magnitudes had a stronger effect on health perception than skin topography removal alone. Post hoc pairwise comparisons (Bonferroni) showed that the judges' preference for images with smoothed skin color distribution increased particularly up to the magnitude of $50 \%$ of removal but did not increase further at higher magnitudes of smoothing (i.e., $>50 \%$ ) (Fig. 3).

Table 2 Descriptive statistics for health preferences for female faces varying in the magnitude of smoothing / removal skin color distribution (Set 1) and skin surface topography (Set 2) $(\mathrm{N}=160)$

\begin{tabular}{|c|c|c|}
\hline Magnitude of manipulation (\%) & Mean & $\mathrm{SD}$ \\
\hline \multicolumn{3}{|l|}{ Set 1} \\
\hline Original & 2.10 & 0.99 \\
\hline 25 & 3.16 & 1.20 \\
\hline 50 & 3.86 & 1.32 \\
\hline 75 & 3.96 & 1.30 \\
\hline 100 & 3.94 & 1.31 \\
\hline \multicolumn{3}{|l|}{ Set 2} \\
\hline Original & 1.17 & 1.00 \\
\hline 25 & 1.59 & 1.07 \\
\hline 50 & 1.64 & 1.15 \\
\hline 75 & 1.86 & 1.30 \\
\hline 100 & 1.73 & 1.38 \\
\hline
\end{tabular}

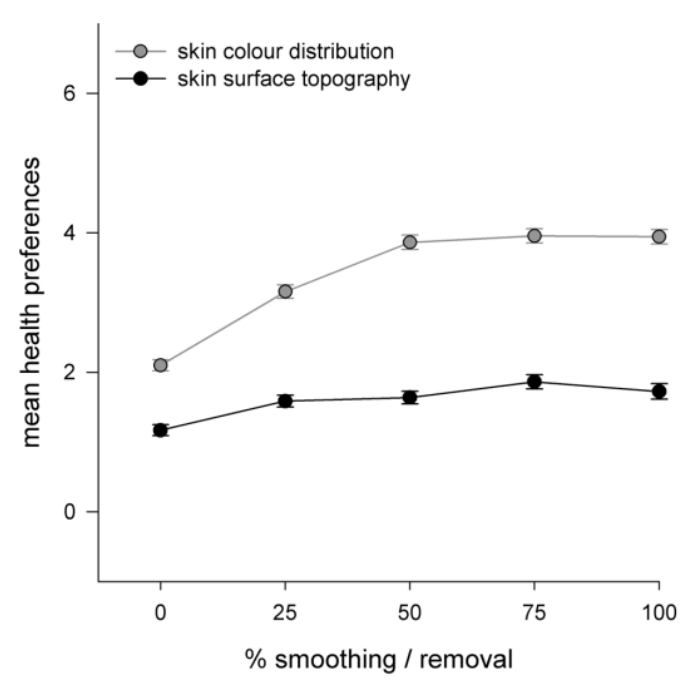

Figure 3 Mean $( \pm S E)$ health preferences for female faces varying in the magnitude of smoothing / removal of skin color distribution and skin surface topography. 


\section{Discussion}

Our results show that while both skin color distribution and skin surface topography cues affect our perceptions of female age, the latter had a significantly stronger effect and this was particularly so for topography removal of 50\% and more. With regard to health perception, it was found that smoothing of uneven skin color distribution had a significantly stronger effect than topography removal. This effect was present after a smoothing of skin color distribution of $25 \%$ or more. The present study, thus, confirms and extends previous findings (Fink \& Matts, 2008) that reported differences in the strengths of signalling provided by skin coloration and surface topography. Importantly, in addition to these findings, which compared only $0 \%$ and $100 \%$ modified images, the present data show that differential age and health information conveyed by skin color distribution and skin surface topography can be perceived readily even after relatively subtle changes in these features. Moreover, it should be noted that while a steady increase in (age) preferences with the magnitude of manipulations of both skin features was detected, such an effect was not found for skin surface topography removal and perception of health. This, once again, supports the particular significance of even skin color distribution in the perception of facial health.

Our sample images comprised variations of color distribution and surface topography in the facial skin of only one woman, which could be of concern in terms of the validity of the study. We chose this image because her face showed expression of both skin features in multiple facial areas. This was essential for the study design as it ensured that manipulations of skin color distribution and skin surface topography (in terms of the magnitude of their expression) resulted in distinct categories. Thus, participants' perception of facial age and health was based on the introduction of systematic variation in skin color distribution and skin surface topography while keeping all other facial characteristics constant - a design that has significant advantages when investigating the impact of subtle changes in visible skin characteristics for the first time. We are aware that future replications of this study could include facial stimuli from a larger number of different women. However, we believe that such studies would benefit from the present design and findings by focusing on smaller increments of change in skin feature and, thus, reducing the number of stimuli in a rating study.

It is generally true that in women aged 40 years and upwards, there is considerable variation in the relative magnitude of expression of skin color distribution and skin surface topography features, consistent with varying pressure from both extrinsic and intrinsic factors, including genetics, cumulative exposure to solar UVR and behaviour and lifestyle choice (Leyden, 1990). This variation of co-expression was modelled systematically in this present 
study. Based on our findings, we hypothesized whether it is this very combination of effects which is able to help make a woman look more or less attractive for her age, depending on the benefit she gains from even skin color distribution. Put another way, if genetic pre-disposition has been kind, or if necessary care has been taken to maintain an even skin color distribution (e.g., through moderating chronic UVR exposure by behaviour or use of sunscreens), our results suggest that the ensuing health signal will contribute positively and significantly to others' overall perception of her facial attractiveness, regardless of her age. Moreover, our new data suggest that an increase in facial attractiveness derived in this manner need not involve extreme measures (such as, for example, chemical peels or laser surgery), as we appear to be able to detect even subtle changes in both skin color distribution and skin surface topography.

Evolutionary psychologists have argued that age-dependent changes in visible skin condition, particularly those of women, could be regarded as visual cues to their reproductive potential (in the form of health and fertility) by men (e.g., Ref. Fink, Grammer, \& Thornhill, 2001). Recent studies support this assertion as they have shown that variation in the evenness of (Caucasian) female skin color distribution can alter the perception of facial age and health (Fink, Grammer, \& Matts, 2006; Fink et al., 2008; but see Gunn et al., 2009; Nkengne et al., 2008). In addition, a recent study reported an influence of overall basal skin coloration on the perception of facial health (Stephen et al., 2009). This result, however, is not readily comparable to our present data as the stimuli images in this study were taken from a sample of young (18 to 22 year old) men and women. In young, healthy skin, both constitutive and facultative melanin expression is uniform and synchronous, resulting in a homogeneous distribution of the melanin chromophore in both basal and sun-exposed sites. Likewise, dermal vasculature in young, healthy skin is delicate and fine, resulting in a homogeneous "bloom" of color. While we do not question that overall skin color also signals aspects of health, we think that these effects need to be distinguished from the process of photoageing, which produces localised concentration and increasingly uneven distribution of melanin and haemoglobin, with increased visible contrast (only this was manipulated in this present study). The likely interaction effect of overall basal skin color and color contrast on facial perception will provide another extremely interesting research focus in future studies.

In conclusion, we have modelled systematically the differential expression of skin color distribution and skin surface topography in the facial skin of a 61-year-old woman and both confirmed and extended our previous results - that not only is wrinkling a predominant cue for ageing and color evenness, in particular, a strong cue for health, but also that relatively small changes in each are sufficient to be noticed. We have identified this "balance" of feature 
previously and associated it with the term found in many cultures, "growing old gracefully"; these data add further depth to this notion.

\section{Acknowledgement}

This project was funded by The Procter \& Gamble Company, the German Science Foundation (DFG), grant number FI 1450-4-1, awarded to Bernhard Fink as well as through the Institutional Strategy of the University of Goettingen. 


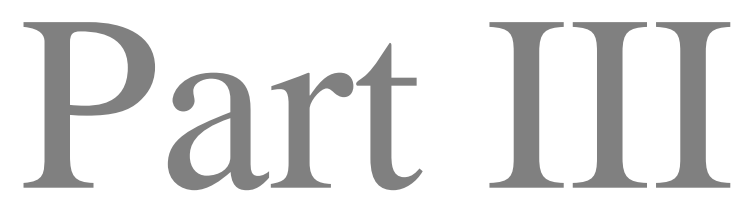

Facial skin as an indicator of female fertility 


\section{ChAPTER 5}

\section{DOES A WOMAN'S SKIN COLOUR INDICATE HER FERTILITY LEVEL? PRELIMinary FindingS.}

Nadine Samson*, Bernhard Fink* \& Paul J. Matts ${ }^{\dagger}$

* Department of Sociobiology / Anthropology, University of Goettigen, Germany

† The Procter \& Gamble Company, Rusham Park Technical Centre, Whitehall Lane, Egham, Surrey TW20 9NW, UK

Swiss Journal of Psychology, in review 


\begin{abstract}
Roberts et al. (2004) showed that perceived facial attractiveness of women is higher in the fertile phase of the menstrual cycle than in the luteal phase, suggesting the existence of visible cues of ovulation. However, the nature of such cues remains speculative. Here we test the hypothesis that changes in female facial skin colouration across the menstrual cycle could be one of the signals that men have adapted to in order to assess female fertility. Spectrophotometric measurements of facial skin colour of normally ovulating Caucasian women (aged $24-29$ years) were collected in the late follicular and mid-luteal phase of their menstrual cycle. Facial images were also taken in both sessions and judged for attractiveness and health by a panel of German men (aged 16 - 37 years). In line with Roberts et al. (2004) our results show that men perceive women in the late follicular phase to be significantly more attractive and healthier than those in the mid-luteal phase. However, we did not detect any significant differences in objective measurements of skin colour between the two phases. We conclude that the increase in male perception of female facial attractiveness and health in the fertile phase of the menstrual cycle is not caused by a change in overall skin colour and / or lightness.
\end{abstract}

Keywords: skin colour, women, face, menstrual cycle, fertility, spectrophotometer 


\section{Introduction}

The female menstrual cycle is regulated by the endocrine system with oestrogen and progesterone having a prominent role in the on- and offset of the follicular and luteal phases. Cyclical changes of these hormones are known to influence both female emotional status and behaviour (Farage, Neill, \& MacLean, 2009), and male perception of female olfactory (Kuukäsjarvi et al., 2004) and vocal cues (Pipitone \& Gallup, 2008). Roberts et al. (2004) have argued that female facial appearance might also be subject to cyclical variation, which may be perceptible to potential mates. They showed that men do indeed consider female faces in the peri-ovulatory phase of their menstrual cycle as being more attractive when compared to the same faces in the luteal phase. However, as the authors admit, there are other potential candidates, which could drive the differences noted in male perception of female appearance across the menstrual cycle (such as lip colour and size, pupillary dilation, and skin colour and tone. Findings by Law Smith et al. (2006) also show that facial skin condition could be a source of information about female fertility. Men judged images of female faces without make-up most feminine, attractive, and healthy when taken in the peri-ovulatory phase, but this effect was absent in women with make-up. Thus, in this present study, we tested the possibility that overall skin colour and lightness (Van den Berghe \& Frost, 1986) is among the cues that drive male perception of female attractiveness and health at different stages of the menstrual cycle.

Given that cyclical fluctuations of plasma oestrogen and progesterone concentrations have been shown to influence various skin characteristics, such as surface lipid secretion, sebum production (Thiboutot, 2001), vasodilation (Charkoudian et al., 1999) and pigmentation (Farage, Neill, \& MacLean, 2009; Thornton, 2002), it is likely that visible skin condition is another cue to female fertility. The few existing studies investigating skin pigmentation in relation to the menstrual cycle have shown a premenstrual increase in skin pigmentation around the eyes, followed by the forehead and the cheeks (McGuiness, 1961; Snell \& Turner, 1966) accompanied by an increase in skin lightness around ovulation - a cue which is thought to be associated with fertility (Van den Berghe \& Frost, 1986). However, these findings were based mainly on self-assessments. Studies are needed, therefore, in which both female reproductive state and skin colouration is quantified more objectively.

In this present pilot study, therefore, we measured female subjects' skin colouration during high (late follicular phase) and low (mid-luteal phase) fertility using spectrophotometric measurements, and related it to male judgement of corresponding facial images. 


\section{Methods}

Spectrophotometric measurements and image capture were performed from February to April 2010 to minimize the potentially confounding effects of increased insolation in the summer months. We collected data from 14 healthy Caucasian women at the late follicular phase (19 - 15 days before the onset of next menstruation - the period of highest probability of conception) and the mid-luteal phase (5 - 10 days before the onset of next menstruation). Menstrual cycle day was calculated by the "Reverse Cycle Day" (RCD) method, which takes individual cycle length into account and controls for the variation of the follicular phase of the cycle (Haselton \& Gangestad, 2006). Women were asked to report the date of onset of the next menstrual bleeding (i.e. after completing both sessions of the study) via email to the principal investigator.

Women were not breast feeding nor pregnant, and were not using hormonal contraceptives nor had been for the 90 days preceding the study (cf. Law Smith et al., 2006). Subjects also had a regular cycle (variance of \pm 2 days), and did not suffer from any visible skin disease. Two women had to be excluded due to cycle irregularities, another two women due to sudden illness, and one woman because of poor image quality. Thus, nine women of ages from 24 to 29 years (mean age 26.4 years, $\mathrm{SD}=2.3$ ), and with a cycle length ranging from 22 to 30 days (mean cycle length: 27.1 days, $\mathrm{SD}=2.42$ ), completed data collection. They were debriefed fully about the purpose of the study and received $15 €$ for participation at the end of data collection.

At the beginning of each session, women were asked to tie back their hair, using a black hair-band, and to remove their make-up and any facial adornments (e.g., jewellery, etc.). Skin colour and lightness was measured in terms of $\mathrm{L}^{*} \mathrm{a} * \mathrm{~b} *$ coordinates, according to the definitions of the CIELab colour space (Commission Internationale de l'Eclairage) on predefined areas (i.e. regions have been marked on a digital facial image) on the forehead and both cheeks using a calibrated spectrophotometer (Spectrophotometer, CM-600d, Konica Minolta Sensing Inc., Singapore). Each skin area was measured in triplicate, and the calculated arithmetical mean of each area was used in the statistical analyses (Figure 1).

Facial images were taken with neutral expression and in frontal view (Figure 1) using a Fuji S2 Pro 6.2 megapixel single lens reflex camera equipped with a Nikon AF Micro Nikkor $105 \mathrm{~mm} \mathrm{1:28} \mathrm{lens} \mathrm{(Nikon} \mathrm{Corporation,} \mathrm{Japan)} \mathrm{and} \mathrm{two} \mathrm{slave} \mathrm{studio} \mathrm{flash} \mathrm{lights} \mathrm{(Portaflash}$ 336, Jessops, UK). Camera Auto settings were disabled to allow Manual control over all camera function, to ensure constancy of exposure between imaging sessions (Matts et al., 2006). Positioning of the head was maintained using a chin rest. Images were saved in an uncom- 
pressed TIFF format at a resolution of 1276 x 1559 pixels and 72 dpi. Neither colour correction nor spatial filtering was applied. Digital images of faces were standardized for interpupillary distance and a facial mask was applied in order to minimise the potentially confounding cues of hair colour and style (see Figure 1).

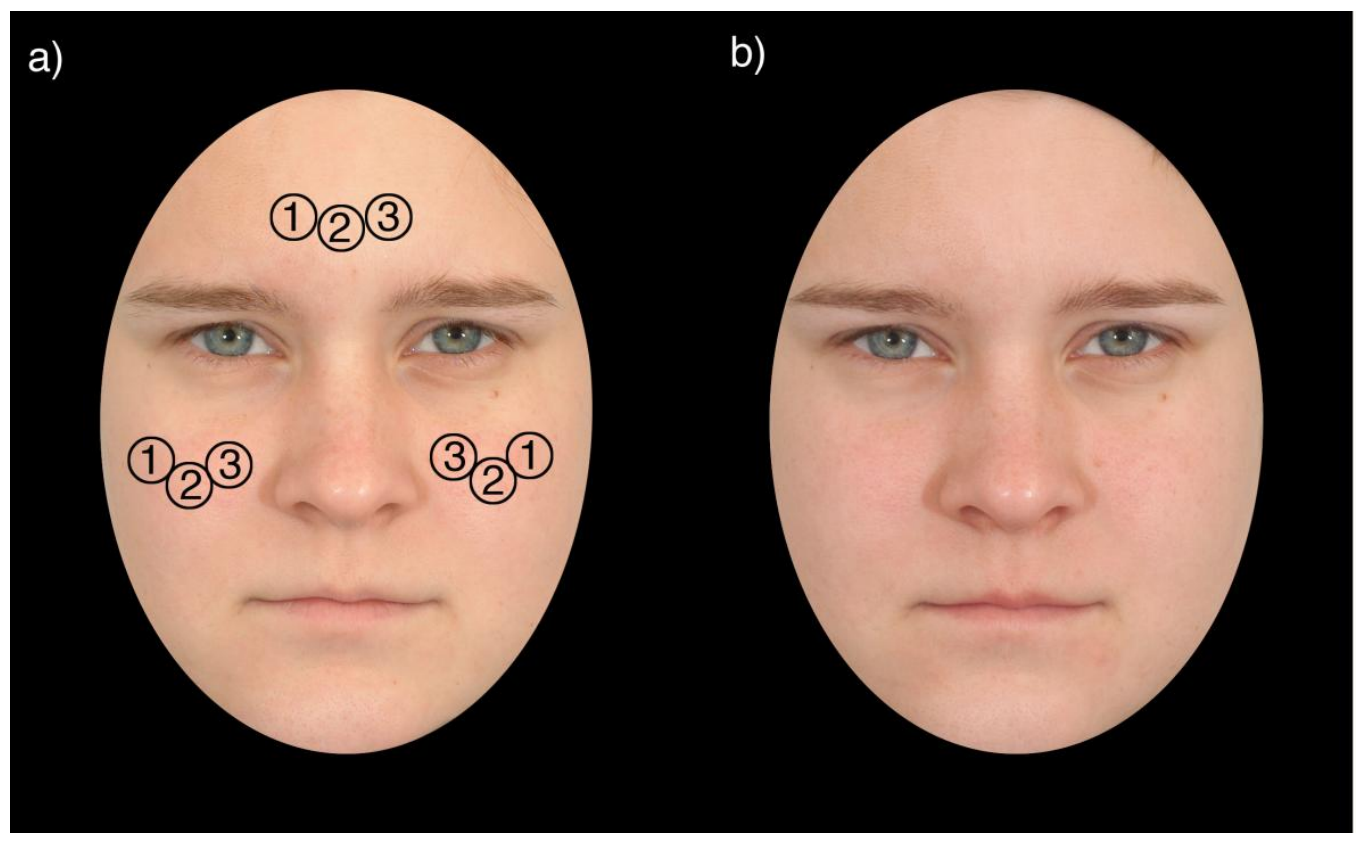

Figure 1 Female facial images captured in (a) the late follicular phase and (b) the mid-luteal phase of the menstrual cycle. Circles indicate regions measured with the spectrophotometer.

\section{Rating study}

Images of the subjects were presented pair-wise with MediaLab software (Empirisoft Inc., NY, USA) by combining one image taken in the late follicular phase with one image (of the same subject) taken in the mid-luteal phase. The side of presentation (left / right) and order of pairs was randomised. A total of 80 men (aged 16 - 37 years, mean age 22.7 years, $\mathrm{SD}=3.3$ ), rated the stimuli at the University of Goettingen on colour-corrected TFT monitors (LaCie 324, LaCie Inc, Portland, USA, Paris, France) set to a resolution of 1920 x 1200 pixels at 32-bit ("true colour") colour depth. The rating study was split into two parts. In the first part, men were asked to select the facial image which they considered to be healthier and, in the second part, as more attractive. Participants were debriefed fully and received a payment of $5 €$ at the end of the experiment.

\section{Results}

Male preference of attractiveness and health for female faces in the follicular phase was significantly higher than that for the same subjects in mid-luteal phase (Wilcoxon signed-rank 
test; health: $\mathrm{Z}=-5.2, \mathrm{P}<0.001$; attractiveness: $\mathrm{Z}=-3.5, \mathrm{P}<0.001$ ) (Figure 2). However, the results of a $2 \times 3$ (reproductive state * facial region) repeated measures analysis of variance (ANOVA) revealed neither a significant main effect of fertility status on the $\mathrm{L}^{*} \mathrm{a}^{*} \mathrm{~b}^{*}$ values, nor a significant main effect of the facial region or the interaction of fertility status and facial region (see Table 1a,b).

Table 1a Mean CIELab values \pm SD for skin within female forehead and cheek areas at different reproductive states of the menstrual cycle.

\begin{tabular}{cccc}
\hline & & \multicolumn{2}{c}{ menstrual cycle phase } \\
\cline { 3 - 4 } & & follicular & luteal \\
\hline forehead & $\mathrm{L}^{*}$ & $65.39 \pm 1.89$ & $65.16 \pm 2.72$ \\
& $\mathrm{a}^{*}$ & $10.48 \pm 1.59$ & $10.95 \pm 1.29$ \\
& $\mathrm{~b}^{*}$ & $16.49 \pm 1.63$ & $16.33 \pm 1.58$ \\
right cheek & & & \\
& $\mathrm{L}^{*}$ & $66.04 \pm 1.84$ & $65.24 \pm 2.18$ \\
& $\mathrm{a}^{*}$ & $11.78 \pm 1.96$ & $11.96 \pm 1.90$ \\
& $\mathrm{~b}^{*}$ & $16.56 \pm 1.81$ & \\
& & & $66.31 \pm 2.25$ \\
& $\mathrm{~L}^{*}$ & $66.47 \pm 1.88$ & $11.12 \pm 1.82$ \\
& $\mathrm{a}^{*}$ & $10.77 \pm 1.37$ & $16.71 \pm 1.26$ \\
\hline
\end{tabular}

Table 1b Main and interaction effects of facial region and fertility status on CIELab skin colour values.

\begin{tabular}{ccccc} 
coordinate & factor & $\mathrm{df}$ & $\mathrm{F}$ & $\mathrm{p}$ \\
\hline \multirow{2}{*}{$\mathrm{L}^{*}$} & region & 2,16 & 3.32 & 0.06 \\
& fertility & 1,8 & 1.21 & 0.30 \\
& region * fertility & 2,16 & 2.70 & 0.10 \\
\hline \multirow{2}{*}{$\mathrm{a}^{*}$} & region & 2,16 & 2.87 & 0.09 \\
& fertility & 1,8 & 1.16 & 0.31 \\
& region * fertility & 2,16 & 0.21 & 0.81 \\
\hline $\mathrm{b}^{*}$ & region & 2,16 & 0.78 & 0.48 \\
& fertility & 1,8 & 0.01 & 0.94 \\
& region * fertility & 2,16 & 0.44 & 0.66
\end{tabular}

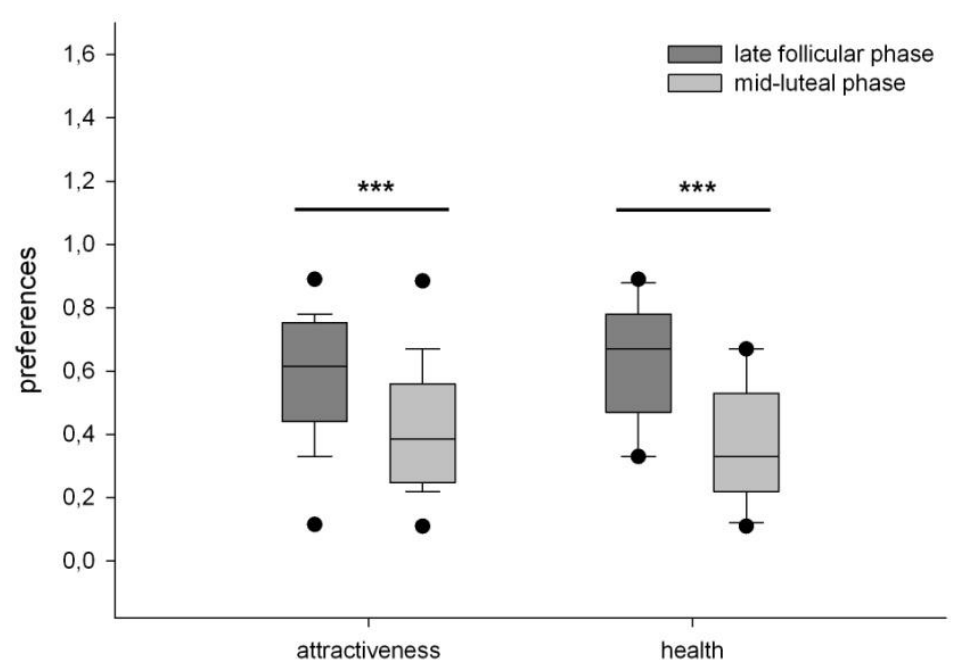

Figure 2 Frequencies of male attractiveness and health preferences. Values represent medians with their $5^{\text {th }} / 95^{\text {th }}$ percentiles. $\mathrm{N}=80, * * * \mathrm{P}<0.001$. 


\section{Discussion}

Our results show that - as in the study of Roberts et al. (2004) - men perceived female facial images in the late follicular phase of the menstrual cycle as significantly more attractive and healthier than those taken in the mid-luteal phase. However, in this study, we found that these perceptual differences were not driven by changes in overall skin colouration or lightness, as we did not detect any differences in these objective measures between the two cycle phases.

Roberts et al. (2004) note that hairstyle and / or condition could provide additional information relating to menstrual cycle stage as, in their study, hairstyle was not always constant across the two sample images. While it has been shown that women give more attention to their looks (including hairstyle) in their fertile phase (see Roeder, Brewer, \& Fink, 2009), this could not have affected our results as we masked these features in digital images before presentation to male judges. Another effect that has been reported concerns soft-tissue changes across the menstrual cycle, with women becoming more symmetrical around ovulation (Manning et al., 1996). While Manning et al. report fluctuating asymmetry in ears across the menstrual cycle, these features have been masked in the present study (see Figure 1). Furthermore, we can find no evidence present in the literature of fluctuating asymmetry in other facial shape-related features. Bearing in mind, therefore, the standardised nature of the imaging methods employed in the present study, we believe that differences in perception over the menstrual cycle is attributable to changes in visible skin condition.

We conclude, therefore, that the remaining main variable in our study is the effect of visible skin condition, which appears to have some signalling quality, as male judgement of attractiveness and health of facial images taken in the fertile phase was higher than that of images taken in the mid-luteal phase. However, rather than a difference in overall skin colour and / or lightness, it is possible that (male) perceptual differences reflect changes in patterns of (female) skin colour distribution. It is known that an even skin colouration (i.e., lower contrast) plays an important role in the perception of age, health and attractiveness (Fink, Grammer, \& Matts, 2006) and that these perceptions correlate with objective measures of skin colour evenness (Matts et al., 2007). This is particularly true for pre-menopausal women and those at college age who comprise the majority of subjects in attractiveness research (as in our study), as undesirable skin changes in skin surface topography usually become visible only later in life.

Skin colouration is determined largely by the two chromophores melanin and haemoglobin (Matts \& Fink, 2010). The visible expression of both these chromophores undergoes 
dramatic change due to the influence of so-called extrinsic ageing, the vast majority of which is associated with chronic photodamage (cumulative lifetime exposure to solar ultraviolet radiation). This results in a progressive visible heterogeneity of chromophore distribution, commensurate with age (Griffiths, 1992). In terms of possible variation in these chromophores during the much shorter time-frame of the menstrual cycle, we hypothesise that, whereas we have shown that overall skin colour does not appear to change, monthly variation in female physiology may drive varying patterns of evenness of visible distribution. We have already shown that relatively minor variation in the distribution of these chromophores (as a function of chronic photodamage) can drive profound differences in judgement of age, health and attractiveness (Fink, Grammer, \& Matts, 2006; Matts et al., 2007). It is possible that subtle, localised variation in haemoglobin and melanin volume fraction driven by circulating sex hormones (Charkoudian et al., 1999; Farage, Neill, \& MacLean, 2009; Hall, 1969; McLeod, Ranson, \& Mason, 1994; Thornton, 2002) affects male perception of female facial attractiveness and health - although this needs further research.

\section{Acknowledgements}

This project was funded by The Procter \& Gamble Company, Cincinnati, USA and the German Science Foundation (DFG), grant number FI 1450-4-1, awarded to Bernhard Fink as well as through the Institutional Strategy of the University of Goettingen. 


\section{Chapter 6}

\section{GENERAL DisCUSSION}

The face has been of paramount interest in human attractiveness research over the past 15 years (Roberts, 2008) because of its contribution to perception of overall physical attractiveness (Peters, Rhodes, \& Simmons, 2007; Thornhill \& Grammer, 1999) and its significance in social perceptions and interactions (Haxby, Hoffman, \& Gobbini, 2002; Langlois et al., 2000). In addition to body morphology and movement, facial appearance provides the first visual information about an individual. Particularly the appearance of facial skin seems to be indicative to age and health (Jones et al., 2004; Matts \& Fink, 2010). There is some evidence that female skin condition may 'leak' information about women's fertility as well (Johnston et al., 2005; Law Smith et al., 2006), yet empirical evidence is lacking. Thus, facial skin appearance may affect the process of rejecting potential mates and accepting or soliciting others. The present thesis focused on the influence of variations in the appearance of female visible facial skin on people's age, health, and attractiveness perception with regard to the evolutionary psychology framework.

In summary, results demonstrated a high sensitivity of both male and female participants to even subtle changes in cutaneous facial age cues of postmenopausal women, i.e. they were able to detect at least a $20 \%$ visual change in surface topography (Chapter 3) and a 25\% visual change in skin colour homogeneity (Chapter 4) within female faces. Age and attractiveness perception was particularly influenced by topographical changes in the skin surface of the forehead and the (sub-) orbital region (Chapter 3). In contrast to surface topography, facial skin colour characteristics had a strong effect on both human age and health perception. Furthermore, the thesis provided additional evidence for men being sensitive to cyclically fluctuating changes in women's facial skin condition across their menstrual cycles. Spectrophotometric changes in skin colour and / or lightness have not been found, suggesting that changes in basal skin colouration (at least on the forehead and the cheeks) are not among the facial cues that may indicate a female's probability to conceive. Additional studies are required to prove the validity of these preliminary findings (Chapter 5). 
The present chapter integrates results from the previous chapters and discusses facial skin as an indicator of a woman's age, health, and fertility, as well as possible implication for male mate selection and female intrasexual competition. Finally, areas of future research are suggested.

\section{Facial skin as an indicator of female age, health, and fertility}

Previous studies have shown that skin wrinkling due to cutaneous aging significantly influences perceived age (Gunn et al., 2009; Nkengne et al., 2008), health (Fink \& Matts, 2008), and attractiveness (Fink, Grammer, \& Thornhill, 2001) of female facial images. Results of the present thesis additionally revealed that not all parts of the face received equal attention. Changes in surface topography on the forehead and underneath the eyes had the strongest effect on age and attractiveness perception, followed by the crow's feet area / the upper lip, and the cheeks (in descending order). This suggests a hierarchy among different facial regions as to their informational value about a woman's age (Chapter 3).

Given that recent studies suggest that measures of visual attention reflect the relative importance of stimuli including specific facial regions (Nguyen, Isaacowitz, \& Rubin, 2009), a simultaneous eye-tracking study using the same stimuli faces was conducted in the course of a diploma thesis. This study investigated visual attention relative to different facial regions and whether this corresponded to topographical changes in facial regions. Results confirmed that the forehead and eye-region are preferentially treated by humans, since they received the highest amount of visual attention (Wisser, 2009). These findings are additionally in line with various eye-tracking studies reporting a visual preference for the eye-region (Hsiao \& Cottrell, 2008; Janik et al., 1978; Nguyen, Isaacowitz, \& Rubin, 2009), even in infants younger than eleven weeks (Haith, Bergman, \& Moore, 1977). Considering the relevance of eyes in human communication (Argyle \& Dean, 1965; Kleinke, 1986; Senju \& Johnson, 2009), the strong impact of the eye's surrounding skin on human's perception is not surprising. In an investigation of age discrimination in preschool children, Jones and Smith (1984) revealed that children may obtain more reliable age information from the eye-region than from other facial areas, since the eye-region is particularly prone to develop wrinkles with increasing age. Firstly, the lower eyelid's skin is merely $0.4-0.5 \mathrm{~mm}$ thick, which is thinner than at any other body site, and secondly, it's dermis contains the lowest amounts of collagen, elastin, and glycosaminoglycan (see Ohshima \& Takiwaki, 2008). It is therefore likely that humans are sensitive to characteristics of the eye-region when assessing an individual's age. The strong influence of the forehead region on age and attractiveness perception found in the 
present thesis may derive from the fact that the forehead is the largest continuous facial area when viewed from the front. Another reason might be the skin's tendency to develop pronounced long linear wrinkles (“expression lines”) in this area (Quatresooz et al., 2006). Consequently, forehead wrinkles may be particularly noticeable when removed and informative about an individual's age.

Male and female participants' significant sensitivity to even subtle $(20-25 \%)$ variations in skin colour characteristics and surface topography (Chapter $\mathbf{3}$ and 4) suggests that humans may notice fine lines and changes in skin colour distribution within faces of younger subjects as well. More precisely, subtle cutaneous age cues may influence age, health, and attractiveness perception in the same way as they did in postmenopausal women. By investigating human noticeability of variations in facial skin topography and colour, this thesis thus provides an important basis for future research on the influence of female facial skin aging on sexual selection. In this context, women aged $30+$ might be of particular interest for two reasons: First, wrinkles do not become persistent before entering the third decade of age (Hatzis, 2004; Quatresooz et al., 2006). Hence, studies with adolescent women would be rather uninformative. Second, at least in Western societies, men and women are having children at increasing age (Sobotka, 2010). Facial cutaneous age cues in women of childbearing age might therefore be an important source of information important in male mate selection.

While in comparison with skin colour distribution, surface topography cues generally seemed to be the stronger indicators to female facial age (Fink \& Matts, 2008; Gunn et al., 2009), in the present thesis, they had only marginal effects on health perception, despite the fact that health condition declines with age (Gibson et al., 2009; Gray, 1994). In contrast, facial skin colour characteristics appeared to provide information about both female age and health (Chapter 4). These results therewith emphasised the particular significance of an even skin colour distribution in the perception of facial health, i.e. even in the presence of surface topography cues, humans were sensitive to variations in skin colour distribution and relate them to physical health. Changes in colour evenness are obvious signs of photoageing, since cumulative life-time exposure to UVR causes dilation and twisting of blood vessels and also drives a variety of pigmentation disorders, resulting in a hyper- and hypo-expression of melanin (Dayan, 2008; Matts \& Fink, 2010). Pigment disorders such as actinic keratosis and melanocyte naevi, however, are precancerous and may eventually become malignant due to the carcinogenic effect of UVR (Atillasoy et al., 1998; Kennedy et al., 2003; Riley, 2003; Yaar \& Gilchrest, 2001). 
Skin cancer has become a major public health concern (Jemal et al., 2008). Scenariobased modelling predicts an increase of $5-10 \%$ in the incidence of skin cancer in Europe and the United States during the middle decades of this century (McMichael \& Beaglehole, 2000). In the Western world, tanned skin is commonly believed to be more attractive and to look healthier than untanned skin, although Banerjee et al. (2008) showed that only $18 \%$ believed that a tanned person is actually healthier. Despite data showing an association between sun bed usage and the occurrence of skin cancer, sun bed use to enhance attractiveness is increasing, especially among teenagers and young adult women (Banerjee, Campo, \& Greene, 2008; Kemp \& Eagle, 2009; Schulman \& Fisher, 2009). Because the present thesis shows a negative effect of cumulative UV exposure on attractiveness and health perception (Chapter 4), tanned skin might be viewed as attractive for a short while, however, UV exposure has detrimental effects on both health and perceived attractiveness in the long-term. Since sun protective behaviour such as sun avoidance, adequate clothing, and appropriate use of sunscreen products can reduce lifetime exposure by at least $50 \%$ and thus chronic photodamage (Nole \& Johnson, 2004), responsible sun exposure may not only have health benefits, but also improve facial health appearance and therewith attractiveness. Results of the present thesis could thus motivate the public to decrease sun exposure, which has been rather unsuccessful by pointing out the health detriments of tanning, by stressing the negative effects on attractiveness.

Recent research suggests that men are sensitive to female facial cues, which are indicating their fertility (Johnston et al., 2005; Law Smith et al., 2006; Roberts et al., 2004). The present thesis supported this notion. In line with Roberts et al. (Roberts et al., 2004), men perceived female facial images taken in the late follicular phase of the menstrual cycle as significantly more attractive and healthier than those taken in the mid-luteal phase. Men's judgments, however, appeared not to be influenced by measurable changes in overall skin colour and / or lightness (at least on the forehead and the cheeks) (Chapter 5). This stands in contrast to various studies based on self-reports that quoted a slight lightning during ovulation (Van den Berghe \& Frost, 1986), and an increase in skin pigmentation in the luteal-phase (McGuiness, 1961; Snell \& Turner, 1966), but also to findings in primate studies. In some species of Old World monkeys, for instance in macaques (Waitt et al., 2006) and baboons (Dubuc et al., 2009; Higham et al., 2008), female perineal skin swells during oestrus due to an excessive accumulation of extracellular fluid. Because this area is rich in blood vessels, the skin simultaneously reddens due to an oestrogen-induced increase in vascular blood flow (Jablonski, 2006; Waitt et al., 2006). Likewise, women's cheeks have been reported to slightly redden around ovulation (Buss, 2008). Although blood vessel density is high in this 
facial region (Huzaira et al., 2001), spectrophotometric measurements failed to detect differences in skin colour and lightness between the late follicular and mid-luteal phase of the menstrual cycle. A potential source of this inconsistency between reported colour changes in primates and the spectrophotometric measures of the present thesis could be the small female sample size. Future research will expand the sample size to prove the validity of these preliminary results. Moreover, the large size of the spectrophotometer's target mask precludes from colour measurements in the sub-orbital region, in which altered skin pigmentation has most commonly been reported in humans (McGuiness, 1961; Snell \& Turner, 1966). Furthermore, although the target-mask itself was large-sized, its opening was only eight millimetres in diameter, which may have been too small a specimen port to measure the differences that human males can detect. As yet spectrophotometers with an opening size bigger than six to eight millimetres are unavailable.

Another reason could be differences in the applied measurement techniques itself (Stevens, Caswell Stoddard, \& Higham, 2009). Various studies in non-human primates determined skin colouration using digital imaging (e.g. Dubuc et al., 2009; Setchell et al., 2009; Setchell, Wickings, \& Knapp, 2006) or colour charts (e.g. Gauthier, 1999; Setchell \& Dixson, 2001) while I obtained colour information using direct (contact) spectrophotometry (Chapter 5). This method allowed me to reduce the influence of changing light conditions which is a common measurement problem with animals in the field (Dubuc et al., 2009; Stevens, Caswell Stoddard, \& Higham, 2009). Moreover, by giving colour values in the CIELab space I obtained precise information about the intensity of light reflected over the entire visible spectrum, i.e. each colour was defined unambiguously in terms of its Cartesian coordinates with respect to the $\mathrm{L}^{*}, \mathrm{a}^{*}$, and $\mathrm{b}^{*}$ axes (Weatherall \& Coombs, 1992). Colour rendering did not depend on the sensitivity and settings of individual devices, since CIELab is the only device independent colour space (Stevens \& Cuthill, 2005a). Finally, CIELab corresponds well to human colour perception and is thus most appropriate for recording colour values for humans and other trichromatic primates (Stevens, Caswell Stoddard, \& Higham, 2009). A substantial work in human skin reflectance spectrophotometry relies on data given in the conventional tricolour red-green-blue (RGB) colour space (Angelopoulou, 2001). Since RGB values have a fixed lightness, they cannot reproduce the entire colour range. It is therefore a common misconception that this colour space is identical to human colour vision. Moreover, the RGB colour space is not uniform, i.e. distances in the coordinate system do not equal perceived colour difference by the observer. Thus, measured differences do not necessarily reflect differences in human perception of these colours. If possible, spectrophotometric measurement 
techniques should be therefore preferred for colour measurements (Stevens \& Cuthill, 2005b; Stevens \& Merilaita, 2009).

By masking the facial stimuli, confounding effects of, for instance, hairstyle (Roberts et al., 2004) or variations in soft tissue symmetry (Manning et al., 1996) could be excluded. Thus, differences in men's perception over the menstrual cycle had to be due to changes in visible skin condition. Alterations in facial skin colour, however, could perhaps be rather irregular (e.g., by altered melanin production or vasodilation), making it necessary to study changes in skin colour distribution, rather than focussing on overall skin colouration (e.g., Stephen et al., 2009). Full-face non-contact SIAscope chromophore maps (Matts, 2008), for instance, could provide information about facial changes in melanin, haemoglobin, and collagen distribution across the menstrual cycle (cf. Chapter 2). Moreover, not only melanin pigmentation and vasodilation may influence the perception of female facial skin colour, but also hormone-mediated skin blemishes such as pimples, which were commonly caused by clogged or infected pores due to hyperactivation of sebaceous glands (Thiboutot, 2007; Turkington \& Dover, 2007). Although only healthy women without any skin disorders were allowed to participate in the present study, occurrence of (a few) isolated pimples could not be excluded, and thus, may impair skin colour evenness. Because oestrogens (directly or indirectly) reduce sebum production (Thiboutot, 2001, 2007), women's skin is reported to be clearest of any blemishes around ovulation (Johnston et al., 2005). More precisely, while skin condition improves through the follicular phase of the female menstrual cycle (Khanna \& Pandhi, 1991), it deteriorates throughout the luteal phase (Lucky, 2004; Stoll et al., 2001). To note, in addition to an increase in skin colour homogeneity, blemishes cause changes in the appearance of surface topography. In case of visible (non-) inflammatory pimples, the present thesis could thus not exclude an effect of surface topography on the perception of female's health and attractiveness.

To conclude, there is good evidence that the appearance of female visible facial skin could provide information about her health, age, and fertility, as relatively small variations influenced people's age and health judgments, as well as perception of attractiveness.

\section{Consequences for male mate selection and female intrasexual competition}

People's sensitivity to certain facial regions may be especially pronounced in the context of mate attraction (Mulhern et al., 2003). Female efforts to enhance physical appearance have played an important role in historical and contemporary societies. During the Elizabethan era, for instance, women of the upper class used make-up called ceruse, a compound of 
poisonous white lead, to acquire the desired pale appearance and cover cues of aging (Parish $\&$ Crissey, 1988; Romm, 1989). Moreover, in the $17^{\text {th }}$ and $18^{\text {th }}$ century, women covered pockmarks and wrinkles with wax patches or used full face masks (Parish \& Crissey, 1988). Nowadays, cosmetic products are increasingly important to women (Cash \& Cash, 1982; Korichi et al., 2011; Parish \& Crissey, 1988), and are suggested to be systematically used in situations in which physical appearance may influence social outcomes (Cash, Rissi, \& Chapman, 1985). As a result, women reported to spend about 14 minutes per day applying their make-up (Cash \& Cash, 1982). Besides regular make-up, there is also a rise in permanent cosmetic procedures that apply tattoos (permanent pigmentation of the dermis) to mimic eye, lip, or eyebrow liner ('permanent make-up', Saunders \& Armstrong, 2005). The market for anti-aging cosmetic products is rising, and is predicted to account for about one-quarter of the global skin care market by 2012 (Challener, 2008, April). Although plastic surgery is still frequently used for facial rejuvenation, especially the application of less invasive procedures such as biodegradable dermal fillers and botulinum toxin has grown rapidly in the last years (De Boulle et al., 2010; De Maio, 2004; Fagien \& Carruthers, 2008). According to the American Association of Plastic Surgeons (ASPS, 2009) face-lifts decreased by 16\% from 2000 to 2008 , yet the use of soft tissue fillers increased by $144 \%$. In the same period, the application of botulinum toxin increased by $537 \%$. Double-blind, placebo-controlled studies with botulinum toxin injections into the forehead (corrugator supercilli and procerus) and periorbital (orbicularis oculi, which is responsible for the formation of 'crow's feet') muscles confirmed a significant improvement in the severity of wrinkles (Ascher, Rzany, \& Grover, 2009; Keen et al., 1994). Furthermore, facial images of female patients who received botulinum toxin injections in the forehead were perceived to be more attractive and thought to have higher dating and athletic success (Dayan et al., 2008). The strong influence of forehead wrinkles on perception of attractiveness is consistent with the present thesis in which the surface topography of the forehead had the strongest impact on perceived age and attractiveness (Chapter 3). However, since formation of 'crow's feet' while smiling is associated with happiness (Knoll, Attkiss, \& Persing, 2008), trustworthiness, and cooperativeness (Johnston, Miles, \& Macrae, 2010), it is reasonable to assume that patients treated with botulinum toxin in this facial area might be perceived to be less attractive than patients that have been treated in other facial areas. In comparison to the forehead and sub-orbital region, removal of skin surface topography in the crow's feet area had indeed a relatively low effect on age and attractiveness perception in this thesis (Chapter 3). This effect might be even stronger in dy- 
namic faces, as crow's feet are more pronounced when smiling (Hillebrand \& Myamoto, 2007, September-October).

From an evolutionary psychology perspective, the quality of appearance enhancement techniques depends upon the extent to which they achieve a more fertile appearance (Gallup Jr. \& Frederick, 2010). Correspondingly, middle-aged women (40 - 54 years) who have passed the peak of fertility make up the largest proportion of plastic surgery patients (ASPS, 2009; Slevec \& Tiggemann, 2010). Because of a negative ageing stereotype in Western Societies (Ebner, 2008), facial rejuvenation procedures might also improve women's mental well-being and social interactions, and thus their quality of life (Finn, Cox, \& Earl, 2003; Kinnunen, 2010; Sommer et al., 2003). Interestingly, the use of soft tissue fillers increased by $7 \%$ in women aged $20-29$ years from 2007 to 2008 (ASPS, 2009). Given that persistent wrinkles are usually not to be expressed before the age of 30 years (Hatzis, 2004; Quatresooz et al., 2006), this rise may emphasise a strong desire for a youthful appearance even in young women, suggesting high intrasexual competition. Since youth is a powerful indicator of female fertility, a youthful appearance is a valuable asset for women in obtaining a high-quality mate, in terms of a high status and economic resources (Lozano \& George, 2008). The Moroccan emperor Moulay Ismail the Bloodthirsty, for instance, banished women reaching the age of 30 years from his harem and sent them to those of lower-level leaders. In doing so, he may have significantly increased his reproductive success, as he was acknowledged to sire 888 children (Buss, 2008). Grammer (1992) provides another example for a positive correlation between female youth and male economic resources. Analysis of advertisements of 1,048 German men and 1,590 German women in computer dating services demonstrated that men with increasing income seek younger partners (reported in Buss, 2008).

This thesis might provide additional evidence for high female intrasexual competition in that women were more sensitive to small variations in the skin surface topography of female faces than men (Chapter 3). Because women reported that they feel to have relatively less control over traits relevant to their desirability (e.g. youth, attractiveness) than men (Ben Hamida, Mineka, \& Bailey, 1998), Little and Mannion (2006) suggest them to have sophisticated mechanisms to estimate their relative 'market value' within a population. One of these mechanisms might be their heightened sensitivity to cutaneous age cues in comparison to men. Perhaps, women being highly sensitive to facial age cues are more accurate in estimating their relative attractiveness in comparison with other women. Female mate choice has been shown to be condition-dependent, i.e. a woman's preference for male quality varies with the attractiveness of her competitors as females of different mate values may have differing 
costs and benefits of mating with high-quality males (Little \& Mannion, 2006). Since highquality males are most likely to provide paternal investment to likewise high-quality mates (Buss \& Schmitt, 1993; Singh, 2004), less attractive women would benefit from mating with males of lower mate quality, but that are willing to invest in progeny. This 'market-valuedependent mate choice' has been also observed in females of other species, e.g. zebra finches (Taeniopygia guttata, Burley, 1986) and three-spined sticklebacks (Gasterosteus aculeatus, Bakker, Künzler, \& Mazzi, 1999). Besides estimating the relative attractiveness of female competitors, assessing another woman's fertility status could be important, since highly fertile women may present a bigger competition than less fertile ones. Findings by Roberts et al. (2004) suggest that women can estimate another female's probability of conception, since they preferred facial images of women in the late follicular phase over facial images of women in the mid-luteal phase. Especially, women in heterosexual long-term relationships would benefit from the ability to assess the fertility of other females, since unfaithful men may leave them and / or channel their investment and resources to extra-pair copulation partners and offspring (Buss, 2000, 2002).

As revealed by the present thesis, men's health and attractiveness perception of female images seems to be not only influenced by cutaneous age cues within women's faces, but also facial cues to their fertility (Chapter 6). Findings of this thesis are consistent with studies showing a male preference for body odours (Kuukäsjarvi et al., 2004; Singh \& Bronstad, 2001), voices (Bryant \& Haselton, 2009; Pipitone \& Gallup, 2008), and lap dances (Miller, 1998) of women being in the fertile phase of their menstrual cycle over those being in their non-fertile phase (reviewed in Haselton \& Gildersleeve, 2011). More importantly, they confirmed Roberts and colleagues (Roberts et al., 2004) suggestions of the existence of visible cues to ovulation in female faces. While these authors were not able to attribute men's preferences to changes in certain facial characteristics, the present thesis indicates that visible skin condition could be one cue to female fertility. This assertion is supported by Law Smith et al. (2006), who reported a positive correlation between late follicular oestrogens and ratings of facial femininity, attractiveness, and apparent health in women without make-up, but not in women using make-up. Yet, it is very unlikely that the physical changes accompanied with ovulation represent signals to communicate female fertility, since this would presuppose that (ancestral) women benefit(ed) by detecting them (cf. Gangestad \& Thornhill, 2008). Kuukasjärvi and colleagues (2004) study on sexual attractiveness of women's body odours with respect to the day of the menstrual cycle demonstrated that men are sensitive to the days in which ovulation is most likely to occur, but cannot pinpoint the time (at least by olfactory 
cues). Similar observations with respect to the male's sensitivity to female fertility cues have been made in some Old World monkeys, such as Hanuman langurs (Heistermann et al., 2001; Ostner et al., 2006) and longtailed macaques (Engelhardt et al., 2004). These findings are concordant with a sexually antagonistic co-evolution of an increasing sensitivity to physical cues of ovulation in males in response to the reduction in the intensity of fertility cues in females (Tarin \& Gomez-Piquer, 2002). Given the influence of female skin condition on perception of fertility, facial foundation and make-up might not only be used to improve female visible skin appearance and thus attractiveness, but also help to conceal ovulation by 'masking' one source of information about women's current fertility.

\section{Conclusion}

In conclusion, this thesis has demonstrated a significant influence of relatively small variations in female visible skin condition on the perception of female facial age, health, and attractiveness. This high public awareness towards the appearance of women's facial skin is congruent with the evolutionary psychology framework, which states that a woman's desirability as a mate depends in particular on her health and fertility, which are both negatively correlated with age. Hence, there is a positive selection pressure on women to maintain a youthful appearance (e.g. through the application of cosmetic products or surgery) even beyond the age of highest fertility, and thus, to increase their attractiveness.

\section{Future prospects}

This thesis has raised several questions that should be investigated in future research. While this thesis has concentrated on the perception of facial skin of Caucasian females, facial skin of women from different ethnic groups has not been considered. Yet, ethnic differences in the cutaneous aging process have been reported (Querleux et al., 2009; Tschachler \& Morizot, 2006) and seem to influence age and attractiveness perception. Asian facial skin, for instance, is generally seen to age more gracefully than Caucasian skin due to a good skin turgor and an apparent "baby-like" physiognomy of the face (Shirakabe, Suzuki, \& Lam, 2003). Cross-cultural studies will inform us about whether the perception and noticeability of cutaneous age cues influence people from different ethnic groups in a similar way or whether perception is culture-bound. In addition to visible changes in skin topography and colour, aging causes certain facial areas to undergo fat atrophy and other areas a persistence of hypertrophy fat (Donofrio, 2000). Because these changes in soft tissue symmetry may interact with cuta- 
neous age cues, it could be of interest to include them when investigating facial age and health perception. Given the apparent significance of expression lines in human communication, it might be timely not only to examine people's health, age, and attractiveness preferences for static stimuli (i.e. facial images), but also for dynamic ones (i.e. videotapes). Rubenstein (2005) demonstrated that dynamic and static faces are judged by different evaluative standards, e.g. facial structure or emotions. Since expression lines in particular are more prominent in dynamic faces, it is possible that the suborbital region is then no longer one of the two facial regions that influence age and attractiveness perception the most.

Moreover, future researchers will explore the influence of male facial skin on female age, health, and attractiveness perception. Because women were sensitive to variations in skin appearance of young adult men (aged 20 - 25 years, Jones et al., 2004), they might notice different magnitudes of facial age cues in adult men aged 30+ as well. Previous findings suggest that facial age cues in men may influence perception of attractiveness similar to those in women (Adams \& Huston, 1975; Cross \& Cross, 1971). Techniques applied in the present thesis to manipulate digital images could help to investigate the effect of age-dependent changes in skin surface topography and skin colour distribution on women's perception of age, health, and attractiveness of male facial images in more detail. However, independent component analysis (ICA) of skin colour images might be an alternative to the colour manipulation of digital images in Photoshop CS (Adobe Systems, San Jose, CA, USA). In order to separate the spatial distribution of melanin and haemoglobin, Tsumura et al. (1999) applied ICA to identify those vectors in the RGB colour space, which correspond to changes in the concentration of both chromophores. By changing the parameters that correspond to chromophore concentrations, the authors were able to simulate specific changes in skin colour, e.g. tanning, reddening, and enhancement of skin blemishes (Preece et al., 2004; Tsumura et al., 2003). This technique would facilitate a more accurate manipulation of skin colour distribution when generating stimuli varying in skin colour homogeneity for perception studies. Moreover, it would allow for disentangling the influence of melanin pigmentation and haemoglobin on human age, health, and attractiveness perception.

I further suggest additional measurements to determine possible variations in facial melanin and haemoglobin distribution and concentrations across the menstrual cycle. While Tsumara and colleagues' (1999) technique might be the best choice for image manipulation, it might be insufficient to determine chromophore concentrations. Cotton and Claridge (1996) note that because Tsumara et al. (1999) did not consider light scattering by collagen, their technique may not necessarily give accurate values. For the analysis of chromophore concen- 
trations, I therefore recommend full-face non-contact SIAscopy (Matts, 2008), which has been described in the present thesis. 


\section{SUMMARY}

Evolutionary psychologists argue that humans have evolved preferences for those facial features that signal health and fertility and thus facilitate mate selection. While there is ample evidence for the influence of facial form in the perception of attractiveness, only few studies have addressed the significance of visible skin condition in mate selection, even though humans attach great importance to a beautiful, unblemished skin, especially in women. The present thesis focusses on the influence of facial skin appearance on the perception of a woman's age, health, and attractiveness with regard to the evolutionary psychology framework. Therefore, by progressively removing cutaneous age cues from digital facial images of women (aged $47-61$ years), human noticeability of age related changes in skin colour distribution (e.g. melanin pigmentation, dilated blood vessels) and surface topography (e.g. wrinkles, fine lines) was determined, as well as the relative effect of both skin features on age and health perception. Moreover, it was investigated whether men differ in their health and attractiveness perception between young adult women (aged $24-29$ years) being in their fertile and nonfertile phase of the menstrual cycle as a function of spectrophotometric measurable alterations in basal skin colour of the face.

Confirming previous studies, cutaneous age cues exerted a negative influence on the perception of female facial age, health, and attractiveness. Age and attractiveness perception were driven mainly by topographical changes in the forehead and (sub-) orbital region, while health perception was influenced particularly by changes in the evenness of facial skin colour. Importantly, even relatively small changes $(20-25 \%)$ effected participants' age, health, and attractiveness perception. Since men perceived women being in the late follicular phase of the menstrual cycle healthier and more attractive compared to women in the mid-luteal phase, this thesis provides evidence for facial skin condition being indicative of female fertility. Their preferences, however, appeared not to be driven by changes in basal skin colour, as no changes in spectrophotometric measurements were found.

In conclusion, the present thesis provides good evidence that even subtle variations in facial skin condition provide information about a woman's age, health, and fertility, and thus demonstrated a relatively high public awareness towards the appearance of female facial skin. 


\section{ZUSAMMENFASSUNG}

Evolutionspsychologen zufolge haben Menschen Präferenzen für jene Gesichtsmerkmale entwickelt, die Gesundheit und Fertilität signalisieren und somit die Partnerwahl erleichtern. Während es zahlreiche Beweise für den Einfluss der Gesichtsform auf die Attraktivitätswahrnehmung gibt, haben sich nur wenige Studien mit der Bedeutung des äußeren Erscheinungsbildes der sichtbaren Haut für die Partnerwahl befasst, wenngleich besonders bei Frauen ein hoher Wert auf eine schöne und makellose Haut gelegt wird.

Die vorliegende Arbeit fokussiert den Einfluss des Erscheinungsbilds der Gesichtshaut auf die Wahrnehmung von Alter, Gesundheit und Attraktivität einer Frau im Hinblick auf die evolutionspsychologischen Rahmenbedingungen. Hierzu wurde durch progressives Entfernen von Hautalterungszeichen in digitalen Frauengesichtern (47 - 61 Jahre alt) die Wahrnehmung altersbedingter Veränderungen in der Farbhomogenität der Gesichtshaut (z.B. Melaninpigmentierung, erweiterte Blutgefäße) und Oberflächentopographie (z.B. Gesichtsfalten, feine Linien) bestimmt sowie der relative Einfluss beider Hautmerkmale auf die Altersund Gesundheitswahrnehmung erforscht. Zudem wurde untersucht, ob Männer in ihrer Gesundheits- und Attraktivitätswahrnehmung zwischen jungen Frauen (24 - 29 Jahre alt) in der fertilen und nicht-fertilen Phase des Menstruationszyklus differenzieren und ob diese Unterschiede in spektrophotometrisch messbaren Veränderungen der basalen Gesichtsfarbe begründet sind.

Die Ergebnisse früherer Studien bestätigend, übten Zeichen der Hautalterung einen negativen Einfluss auf die Wahrnehmung weiblicher Gesichter aus. Die Alters- und Attraktivitätswahrnehmung wurde hauptsächlich durch topographische Veränderungen in der Stirn- und (Sub-)Orbitalregion bedingt, während die Gesundheitswahrnehmung vor allem durch Veränderungen in der Farbhomogenität der Gesichtshaut beeinflusst wurde. Hierbei übten schon relativ geringe Veränderungen $(20-25 \%)$ des Hautbildes einen Einfluss auf die Alters-, Gesundheits- und Attraktivitätswahrnehmung der Probanden aus. Da Männer Frauen in der späten Follikelphase des Menstruationszyklus als gesünder und attraktiver wahrnahmen als Frauen in der Mittlutealphase, belegt diese Studie ferner, dass die Beschaffenheit der Gesichtshaut auf die Fertilität einer Frau schließen lässt. Diese Präferenzen schienen jedoch nicht in Veränderungen der basalen Hautfarbe begründet, da spektrophotometrische Messungen keine Unterschiede ergaben. 
Zusammenfassend konnte gezeigt werden, dass selbst subtile Variationen der Gesichtshaut Informationen über Alter, Gesundheitszustand und Fertilität einer Frau vermitteln. Dies demonstriert eine relativ hohe Sensibilisierung der Öffentlichkeit gegenüber dem Erscheinungsbild weiblicher Gesichtshaut. 


\section{BIBLIOGRAPHY}

Adams GR, \& Huston TL (1975) Social perception of middle-aged persons varying in physical attractiveness. Develop Psychol 11: 657-658.

Agache P, \& Humbert P (2004) Measuring the skin. Berlin: Springer-Verlag.

Aizen E, \& Gilhar A (2001) Smoking effect on skin wrinkling in the aged population. Int J Dermatol 40 (7): 431-433.

Alaluf S, Atkins D, Barrett K, Blount M, Carter N, \& Heath A (2002) Ethnic variation in melanin content and composition in photoexposed and photoprotected human skin. Pigment Cell Res 15 (2): 112-118.

Alley TR, \& Cunningham MR (1991) Averaged faces are attractive, but very attractive faces are not average. Psychol Sci 2 (2): 123-126.

Anastasi JS, \& Rhodes MG (2005) An own-age bias in face recognition for children and older adults. Psychon Bull Rev 12 (6): 1043-1047.

Anastasi JS, \& Rhodes MG (2006) Evidence for an own-age bias in face recognition. N Am J Psychol 8 (2): 237-252.

Anderson RR, John BS, \& Parrish MD (1981) The optics of human skin. J Invest Dermatol 77: 13-19.

Andersson M (1994) Sexual selection. Princeton: Princeton University Press.

Angelopoulou E (2001) Understanding the color of human skin. Proc SPIE 4299: 243-251.

Aoki K (2002) Sexual selection as a cause of human skin colour variation: Darwin's hypothesis revisited. Ann Hum Biol 29 (6): 589-608.

Argyle M, \& Dean J (1965) Eye-Contact, Distance and Affiliation. Sociometry 28: 289-304.

Ascher B, Rzany BJ, \& Grover R (2009) Efficacy and safety of botulinum toxin type A in the treatment of lateral crow's feet: double-blind, placebo-controlled, dose-ranging study. Dermatol Surg 35 (10): 14781486.

ASPS (2009). 2009 report of the 2008 statistics: National Clearinghouse of Plastic Surgery Statistics. From http://www.plasticsurgery.org/Media/stats/2008-cosmetic-minimally-invasive-surgery-over-20-39.pdf

Atillasoy ES, Seykora JT, Soballe PW, Elenitsas R, Nesbit M, Elder DE, Montone KT, Sauter E, \& Herlyn M (1998) UVB induces atypical melanocytic lesions and melanoma in human skin. Am J Pathol 152 (5): 1179-1186.

Aznar-Casanova J, Torro-Alves N, \& Fukusima S (2010) How much older do you get when a wrinkle appears on your face? Modifying age estimates by number of wrinkles. Neuropsychol Dev Cogn B Aging Neuropsychol Cogn 17 (4): 406-421.

Bakker TCM, Künzler R, \& Mazzi D (1999) Condition-related mate choice in sticklebacks. Nature 401: 234.

Banerjee SC, Campo S, \& Greene K (2008) Fact or wishful thinking? Biased expectations in "I think I look better when I'm tanned". Am J Health Behav 32 (3): 243-252.

Barankin B, \& DeKoven J (2002) Psychosocial effect of common skin diseases. Can Fam Physician 48: 712 716. 
Barber N (1995) The evolutionary psychology of physical attractiveness: Sexual selection and human morphology. Ethol Sociobiol 16: 395-307.

Battistutta D, Pandeya N, Strutton GM, Fourtanier A, Tison S, \& Green AC (2006) Skin surface topography grading is a valid measure of skin photoaging. Photodermatol Photoimmunol Photomed 22 (1): 3945 .

Beals RL, \& Hoijer H (1965) An introduction to anthropology (3rd ed.). New York: The Macmillian Co.

Beattie PE, \& Lewis-Jones MS (2006) A comparative study of impairment of quality of life in children with skin diseases and children with other chronic childhood diseases. Br J Dermatol 155 (1): 145-151.

Ben Hamida S, Mineka S, \& Bailey JM (1998) Sex differences in perceived controllability of mate value: An evolutionary perspective. J Pers Soc Psychol 75 (4): 953-966.

Bennett MF, Robinson MK, Baron ED, \& Cooper KD (2008) Skin immune systems and inflammation: Protector of the skin or promoter of aging? J Investig Dermatol Symp Proc 13 (1): 15-19.

Bereczkei T, \& Csanaky A (1996) Mate choice, marital success, and reproduction in a modern society. Ethol Sociobiol 17: 17-35.

Boehncke WH, Ochsendorf F, Paeslack I, Kaufmann R, \& Zollner TM (2002) Decorative cosmetics improve the quality of life in patients with disfiguring skin diseases. Eur J Dermatol 12 (6): 577-580.

Bond S, \& Cash TF (1992) Black beauty: Skin colour and body images among African-Amerian college women. J Appl Soc Psychol 22: 874-888.

Boomsma CM, Fauser BC, \& Macklon NS (2008) Pregnancy complications in women with polycystic ovary syndrome. Semin Reprod Med 26 (1): 72-84.

Brincat M, Moniz CJ, Studd JW, Darby A, Magos A, Emburey G, \& Versi E (1985) Long-term effects of the menopause and sex hormones on skin thickness. Br J Obstet Gynaecol 92 (3): 256-259.

Broniarczyk-Dyla G, \& Joss-Wichman E (2001) Ageing of the skin during menopause. J Eur Acad Dermatol Venereol 15 (5): 494-495.

Bryant GA, \& Haselton MG (2009) Vocal cues of ovulation in human females. Biol Lett 5 (1): 12-15.

Bunker CB, Newton JA, Kilborn J, Patel A, Conway GS, Jacobs HS, Greaves MW, \& Dowd PM (1989) Most women with acne have polycystic ovaries. Br J Dermatol 121: 675-680.

Burley N (1986) Sexual selection for aesthetic traits in species with biparental care. Am Nat 127: 415-445.

Buss DM (2000) Desires in human mating. Ann N Y Acad Sci 907: 39-49.

Buss DM (2002) Human mate guarding. Neuro Endocrinol Lett 23 Suppl 4: 23-29.

Buss DM (2008) Evolutionary psychology: The new science of the mind (3rd ed.). Boston: Pearson Education Inc.

Buss DM, \& Schmitt DP (1993) Sexual strategies theory: An evolutionary perspective on human mating. Psychol Rev 100: 204-232.

Buston PM, \& Emlen ST (2003) Cognitive processes underlying human mate choice: The relationship between self-perception and mate preference in Western society. Proc Natl Acad Sci U S A 100 (15): 8805-8810.

Byard PJ (1981) Quantitative genetics of human skin color. Yrbk Phys Anthropol 24: 123-137.

Carter C, Daly R, \& Ramani P (2007) Clinical pathology (Oxford core texts) (1st ed.). New York: Oxford University Press, Inc. 
Cash TF, \& Cash DW (1982) Women's use of cosmetics: Psychosocial correlates and consequences. Int J Cosmet Sci 4: 1-14.

Cash TF, Dawson K, Davis P, Bowen M, \& Galumbeck C (1989) Effects of cosmetic use on the physical attractiveness and body image of American college women. J Soc Pschol 129 (3): 349-355.

Cash TF, Rissi J, \& Chapman R (1985) Not just another pretty face: Sex roles, locus of control and cosmetic use. Pers Soc Psychol Bull 11: 246-257.

Challener C (2008, April). Strong growth for antiaging active incredients: High demand for antiaging consumer products is driving a growing market for effective active ingredients. ICIS Chemical Business Retrieved 2011, April 23rd, From http://www.icis.com/Articles/2008/04/07/9113160/strong-growth-forantiaging-active-ingredients.html

Charkoudian N, Stephens DP, Pirkle KC, Kosiba WA, \& Johnson JM (1999) Influence of female reproductive hormones on local thermal control of skin blood flow. J Appl Physiol 87 (5): 1719-1723.

Cooper PA, \& Hosey GR (2003) Sexual dichromatism and female preference in Eulemur fulvus subspecies. Int J Primatol 24 (6): 1177-1188.

Cotterill J (1988) What is really true about the cosmetic industry? Int J Dermatol 27 (10): 682-683.

Cotterill JA, \& Cunliffe WJ (1997) Suicide in dermatological patients. Br J Dermatol 137 (2): 246-250.

Cotton SD, \& Claridge E (1996) Developing a predictive model of human skin colouring. Proc Soc Photo Opt Instrum Eng 2708: 814-825.

Cross JF, \& Cross J (1971) Age, sex, race, and the percetion of facial beauty. Dev Psychol 5 (3): 433-439.

Crozier WR (2007) In praise of blushing. J Cosmet Dermatol 6 (1): 68-71.

Czaja JA, Robinson JA, Eisele SG, Scheffler G, \& Goy RW (1977) Relationship between sexual skin colour of female rhesus monkeys and midcycle plasma levels of oestradiol and progesterone. J Reprod Fertil 49 (1): $147-150$.

Dancey CP, \& Reidy J (2004) Statistics without maths for psychology: Using SPSS for WindowsTM (3rd ed.). Edinburgh Gate: Pearson Education Limited.

Dayan N (2008) Skin aging handbook: An integrated approach to biochemistry and product development. Norwich: William Andrew Inc.

Dayan SH, Lieberman ED, Thakkar NN, Larimer KA, \& Anstead A (2008) Botulinum toxin a can positively impact first impression. Dermatol Surg 34 Suppl 1: S40-47.

De Boulle K, Fagien S, Sommer B, \& Glogau R (2010) Treating glabellar lines with botulinum toxin type Ahemagglutinin complex: A review of the science, the clinical data, and patient satisfaction. Clin Interv Aging 5: 101-118.

De Maio M (2004) The minimal approach: An innovation in facial cosmetic procedures. Aesthetic Plast Surg 28 (5): 295-300.

Dicanio D, Sparacio R, Declercq L, Corstjens H, Muizzuddin N, Hidalgo J, Giacomoni PU, Jorgensen L, \& Maes D (2009) Calculation of apparent age by linear combination of facial skin parameters: A predictive tool to evaluate the efficacy of cosmetic treatments and to assess the predisposition to accelerated aging. Biogerontology 10 (6): 757-772.

Dion K, Berscheid E, \& Walster E (1972) What is beautiful is good. J Pers Soc Psychol 24: 285-290.

Dixson AF (1983) Observations on the evolution and behavioral significance of "sexual skin" in female primates. Adv Study Behav 13: 63-106. 
Dixson BJ, Dixson AF, Li B, \& Anderson MJ (2007) Studies of human physique and sexual attractiveness: Sexual preferences of men and women in China. Am J Hum Biol 19 (1): 88-95.

Donofrio LM (2000) Fat distribution: A morphologic study of the aging face. Dermatol Surg 26 (12): 1107 1112.

Dubose J, \& Pratt JW (2004) Victim of fashion: Endocarditis after oral piercing. Curr Surg 61 (5): $474-477$.

Dubuc C, Brent LJ, Accamando AK, Gerald MS, MacLarnon A, Semple S, Heistermann M, \& Engelhardt A (2009) Sexual skin color contains information about the timing of the fertile phase in freeranging Macaca mulatta. Int J Primatol 30: 777-789.

Dufva R, \& Allander K (1995) Intraspecific variation in plumage coloration reflects immune-response in great tit (Parus major) males. Funct Ecol 9 (5): 785-789.

Ebner NC (2008) Age of face matters: Age-group differences in ratings of young and old faces. Behav Res Methods 40 (1): 130-136.

Edwards EA, \& Duntley SQ (1939) The pigments and color of living human skin. Am J Anat 65 (1): 1-33.

Ekman P (2003) Darwin, deception, and facial expression. Ann N Y Acad Sci 1000: 205-221.

Engelhardt A, Pfeifer JB, Heistermann M, Niemitz C, van Hooff JARAM, \& Hodges JK (2004) Assessment of female reproductive status by male longtailed macaques, Macaca fascicularis, under natural conditions. Anim Behav 67 (5): 915-924.

Ernster VL, Grady D, Miike R, Black D, Selby J, \& Kerlikowske K (1995) Facial wrinkling in men and women, by smoking status. Am J Public Health 85 (1): 78-82.

Fagien S, \& Carruthers JD (2008) A comprehensive review of patient-reported satisfaction with botulinum toxin type a for aesthetic procedures. Plast Reconstr Surg 122 (6): 1915-1925.

Farage MA, Miller KW, Elsner P, \& Maibach HI (2008) Intrinsic and extrinsic factors in skin ageing: A review. Int J Cosmet Sci 30: 87-95.

Farage MA, Neill S, \& MacLean AB (2009) Physiological changes associated with the menstrual cycle: A review. Obstet Gynecol Surv 64 (1): 58-72.

Fedok FG (1996) The aging face. Facial Plast Surg 12: 107-115.

Fink B, Grammer K, \& Matts PJ (2006) Visible skin color distribution plays a role in the perception of age, attractiveness, and health in female faces. Evol Hum Behav 27: 433-442.

Fink B, Grammer K, \& Thornhill R (2001) Human (Homo sapiens) facial attractiveness in relation to skin texture and color. J Comp Psychol 115 (1): 92-99.

Fink B, \& Matts PJ (2008) The effects of skin colour distribution and topography cues on the perception of female facial age and health. J Eur Acad Dermatol Venereol 22 (4): 493-498.

Fink B, Matts PJ, Klingenberg H, Kuntze S, Weege B, \& Grammer K (2008) Visual attention to variation in female facial skin colour distribution. J Cosmet Dermatol 7 (2): 155-161.

Fink B, Matts PJ, Roeder S, Johnston A, \& Burquest M (2011) Differences in visual perception of age and attractiveness of female facial and body skin. Int J Cosmet Sci 33 (2): 126-131.

Fink B, \& Neave N (2005) The biology of facial beauty. Int J Cosmet Sci 27: 317-325.

Fink B, \& Penton-Voak IS (2002) Evolutionary psychology of facial attractiveness. Curr Dir Psychol Sci 11: 154-158. 
Finn JC, Cox SE, \& Earl ML (2003) Social implications of hyperfunctional facial lines. Dermatol Surg 29 (5): $450-455$.

Fisher GJ, Wang ZQ, Datta SC, Varani J, Kang S, \& Voorhees JJ (1997) Pathophysiology of premature skin aging induced by ultraviolet light. New Engl J Med 337: 1419-1428.

Folstad I, \& Karter AJ (1992) Parasites, bright males, and the immunocompetence handicap. Am Nat 139 (3): 603-622.

Friedman O (2005) Changes associated with the aging face. Facial Plast Surg Clin North Am 13 (3): 371-380.

Frost P (1988) Human skin color: A possible relationship between its sexual dimorphism and its social perception. Perspect Biol Med 32 (1): 38-58.

Frost P (1989) Human skin color: The sexual differentiation of its social perception. Mankind Q 30: 3-16.

Frost P (1994a) Geographic distribution of human skin colour: A selective compromise between natural selection and sexual selection? Hum Evol 9: 141-153.

Frost P (1994b) Preference for darker faces in photographs at different phases of the menstrual cycle: Preliminary Assessment of evidence for a hormonal relationship. Percept Mot Skills 79: 507-514.

Furnham A, Mistry D, \& McClelland A (2004) The influence of age of the face and the waist to hip ratio on judgments of female attractiveness and traits. Pers Individ Diff 36 (5): 1171-1185.

Gallup Jr. GG, \& Frederick DA (2010) The science of sex appeal: An evolutionary perspective. Rev Gen Psychol 14 (3): 240-250.

Galton F (1907) Inquiries into human faculty and its development (2nd ed.). London: J. M. Dent \& Co. (Everyman).

Gangestad SW, \& Scheyd GJ (2005) The evolution of human physical attractiveness. Annu Rev Anthropol 34: 523-548.

Gangestad SW, \& Thornhill R (2008) Human oestrus. Proc Biol Sci 275 (1638): 991-1000.

Gantz I, \& Fong TM (2003) The melanocortin system. Am J Physiol Endocrinol Metab 284 (3): $468-474$.

Gauthier CA (1999) Reproductive parameters and paracallosal skin color changes in captive female guinea baboons, Papio papio. Am J Primatol 47 (1): 67-74.

Gerald MS, Waitt C, Little AC, \& Kraiselburd E (2007) Females pay attention to female secondary sexual color: An experimental study in Macaca mulatta. Int J Primatol 28 (1): 1-7.

Ghadially R, Brown BE, Sequeira-Martin SM, Feingold KR, \& Elias PM (1995) The aged epidermal permeability barrier. Structural, functional, and lipid biochemical abnormalities in humans and a senescent murine model. J Clin Invest 95 (5): 2281-2290.

Gibson KL, Wu YC, Barnett Y, Duggan O, Vaughan R, Kondeatis E, Nilsson BO, Wikby A, Kipling D, \& Dunn-Walters DK (2009) B-cell diversity decreases in old age and is correlated with poor health status. Aging Cell 8 (1): 18-25.

Gilchrest BA, \& Krutman J (2006) Skin Aging. Berlin Heidelberg: Springer-Verlag.

Goldenberg N, \& Glueck C (2008) Medical therapy in women with polycystic ovarian syndrome before and during pregnancy and lactation. Minerva Ginecol 60 (1): 63-75.

Grabmeier B, Landthaler M, \& Hohenleutner S (2005) Menstruationszyklus und Haut. J Dtsch Dermatol Ges 3: $52-65$. 
Grammer K (1992) Variations on a theme: Age dependent mate selection in humans. Behav Brain Sci 15: 100102.

Gray DP (1994) Health in old age. J R Soc Med 87 (8): 474-476.

Griffiths CE (1992) The clinical identification and quantification of photodamage. Br J Dermatol 127 Suppl 41: $37-42$.

Gunn DA, Murray PG, Tomlin CC, Rexbye H, Christensen K, \& Mayes AE (2008) Perceived age as a biomarker of ageing: A clinical methodology. Biogerontology 9 (5): 357-364.

Gunn DA, Rexbye H, Griffiths CE, Murray PG, Fereday A, Catt SD, Tomlin CC, Strongitharm BH, Perrett DI, Catt M, Mayes AE, Messenger AG, Green MR, van der Ouderaa F, Vaupel JW, \& Christensen K (2009) Why some women look young for their age. PLoS One 4 (12): e8021.

Gupta MA, Schork NJ, Gupta AK, Kirkby S, \& Ellis CN (1993) Suicidal ideation in psoriasis. Int J Dermatol 32 (3): 188-190.

Guthrie RD (1970) Evolution of human threat display organs. Evol Biol 4: 257-302.

Haith MM, Bergman T, \& Moore MJ (1977) Eye contact and face scanning in early infancy. Science 198 (4319): 853-855.

Hall PN, Hunter JE, Walter FM, \& Norris P (2008) Use of spectrophotometric intracutaneous analysis device in the real-time diagnosis of melanoma. Br J Dermatol 158: 405-433.

Hamilton WD, \& Zuk M (1982) Heritable true fitness and bright birds: A role for parasites? Science 218 (4570): 384-387.

Haselton MG, \& Gangestad SW (2006) Conditional expression of women's desires and men's mate guarding across the ovulatory cycle. Horm Behav 49 (4): 509-518.

Haselton MG, \& Gildersleeve K (2011) Can men detect ovulation? Curr Dir Psychol Sci 20 (2): 87-92.

Hatzis J (2004) The wrinkle and its measurement: A skin surface profilometric method. Micron 35 (3): 201-219.

Havlicek J, Roberts SC, \& Flegr J (2005) Women's preference for dominant male odour: Effects of menstrual cycle and relationship status. Biol Lett 1 (3): 256-259.

Haxby JV, Hoffman EA, \& Gobbini MI (2000) The distributed human neural system for face perception. Trends Cogn Sci 4 (6): 223-233.

Haxby JV, Hoffman EA, \& Gobbini MI (2002) Human neural systems for face recognition and social communication. Biol Psychiatry 51 (1): 59-67.

Hayashi N, Imori M, Yanagisawa M, Seto Y, Nagata O, \& Kawashima M (2005) Make-up improves the quality of life of acne patients without aggravating acne eruptions during treatments. Eur J Dermatol 15 (4): 284-287.

Heistermann M, Ziegler T, van Schaik CP, Launhardt K, Winkler P, \& Hodges JK (2001) Loss of oestrus, concealed ovulation and paternity confusion in free-ranging Hanuman langurs. Proc Biol Sci 268 (1484): 2445-2451.

Held BL, Nader S, Rodriguez-Rigau LJ, Smith KD, \& Steinberger E (1984) Acne and hyperandrogenism. $J$ Am Acad Dermatol 10 (2): 223-226.

Hellstrom WJ, Overstreet JW, Sikka SC, Denne J, Ahuja S, Hoover AM, Sides GD, Cordell WH, Harrison LM, \& Whitaker JS (2006) Semen and sperm reference ranges for men 45 years of age and older. J Androl 27 (3): 421-428. 
Herz RS, \& Inzlicht M (2002) Sex differences in response to physical and social factors involved in human mate selection: The importance of smell for women. Evol Hum Behav 23: 359-364.

Higham JP, MacLarnon AM, Ross C, Heistermann M, \& Semle S (2008) Baboon sexual swelling: Information content of size and color. Horm Behav 53: 452-462.

Hillebrand GG, \& Myamoto K (2007, September-October) The influence of facial expression on the agedependent changes in facial wrinkling. Paper presented at the 21 st World Congress of Dermatology, Buenos Aires, AR.

Hong J, Koo B, \& Koo J (2008) The psychosocial and occupational impact of chronic skin disease. Dermatol Ther 21 (1): 54-59.

Hoss RA, Ramsey JL, Griffin AM, \& Langlois JH (2005) The role of facial attractiveness and facial masculinity/femininity in sex classification of faces. Perception 34 (12): 1459-1474.

Hsiao JH, \& Cottrell G (2008) Two fixations suffice in face recognition. Psychol Sci 19 (10): 998-1006.

Hulse FS (1967) Selection for skin color among Japanese. Am J Phys Anthropol 27: 143-156.

Hunter ML (2002) "If you're light you're alright": Light skin color as social capital for women of color. Gend Soc 16 (2): 175-193.

Huzaira M, Rius F, Rajadhyaksha M, Anderson RR, \& Gonzalez S (2001) Topographic variations in normal skin, as viewed by in vivo reflectance confocal microscopy. J Invest Dermatol 116 (6): 846-852.

Ito S, \& Wakamatsu K (2003) Quantitative analysis of eumelanin and pheomelanin in humans, mice, and other animals: A comparative review. Pigment Cell Res 16 (5): 523-531.

Jablonski NG (2006) Skin: A natural history. Berkeley: University of California Press.

Jablonski NG, \& Chaplin G (2000) The evolution of human skin coloration. J Hum Evol 39 (1): 57-106.

Janik SW, Wellens AR, Goldberg ML, \& Dell'Osso LF (1978) Eyes as the center of focus in the visual examination of human faces. Percept Motor Skills 47 (3): 857-858.

Jemal A, Siegel R, Ward E, Hao Y, Xu J, Murray T, \& Thun MJ (2008) Cancer statistics, 2008. CA Cancer J Clin $\mathbf{5 8}$ (2): 71-96.

Jenkins G (2002) Molecular mechanisms of skin ageing. Mech Ageing Dev 123 (7): 801-810.

Jimbow K, Quevedo WC, Jr., Fitzpatrick TB, \& Szabo G (1976) Some aspects of melanin biology: 19501975. J Invest Dermatol 67 (1): 72-89.

Jobanputra R, \& Bachmann M (2000) The effect of skin diseases on quality of life in patients from different social and ethnic groups in Cape Town, South Africa. Int J Dermatol 39 (11): 826-831.

Jobling R, \& Naldi L (2006) Assessing the impact of psoriasis and the relevance of qualitative research. J Invest Dermatol 126 (7): 1438-1440.

Johnston L, Miles L, Carter C, \& Macrae CN (2005) Menstrual influences on person perception: Male sensitivity to fluctuating female fertility. Soc $\operatorname{Cog} 23$ (3): 279-290.

Johnston L, Miles L, \& Macrae CN (2010) Why are you smiling at me? Social functions of enjoyment and non-enjoyment smiles. Br J Soc Psychol 49 (1): 107-127.

Jones BC (1997) An evolutionary perspective on physical attractiveness. Evol Anthropol 5 (3): 87-109.

Jones BC, Little AC, Burt DM, \& Perrett DI (2004) When facial attractiveness is only skin deep. Perception 33: $569-576$ 
Jones G, \& Smith PK (1984) The eyes have it: Young children's discrimination of age in masked and unmasked facial photographs. J Exp Child Psychol 38: 328-337.

Kalick SM, Zebrowitz LA, Langlois JH, \& Johnson RM (1998) Does human facial attractiveness honestly advertise health? Longitudinal data on an evolutionary question. Psychol Sci 9: 8-18.

Keen M, Blitzer A, Aviv J, Binder W, Prystowsky J, Smith H, \& Brin M (1994) Botulinum toxin A for hyperkinetic facial lines: Results of a double-blind, placebo-controlled study. Plast Reconstr Surg 94 (1): 94-99.

Kemp G, \& Eagle L (2009) The bronze debate: Looking gold versus getting old (16): 1-12.

Kennedy C, Bajdik CD, Willemze R, De Gruijl FR, \& Bouwes Bavinck JN (2003) The influence of painful sunburns and lifetime sun exposure on the risk of actinic keratoses, seborrheic warts, melanocytic nevi, atypical nevi, and skin cancer. J Invest Dermatol 120 (6): 1087-1093.

Khanna VN, \& Pandhi K (1991) Relationship of acne with menstrual period. Indian J Dermatol Venereol Leprol 57: 138-140.

Kimyai-Asadi A, \& Usman A (2001) The role of psychological stress in skin disease. J Cutan Med Surg 5 (2): $140-145$.

Kinnunen T (2010) 'A second youth': pursuing happiness and respectability through cosmetic surgery in Finland. Sociol Health Illn 32 (2): 258-271.

Kittles R (1995) Nature, origin, and variation of human pigmentation. J Black Stud 26: 36-61.

Kleinke CL (1986) Gaze and eye contact: A research review. Psychol Bull 100 (1): 78-100.

Kligman AM, \& Graham JA (1986) The psychology of appearance in the elderly. Dermatol Clin 4 (3): 501 507.

Knoll BI, Attkiss KJ, \& Persing JA (2008) The influence of forehead, brow, and periorbital aesthetics on perceived expression in the youthful face. Plast Reconstr Surg 121 (5): 1793-1802.

Korichi R, Pelle-de-Queral D, Gazano G, \& Aubert A (2011) Relation between facial morphology, personality and the functions of facial make-up in women. Int J Cosmet Sci 33 (2): 1-8.

Koscinski K (2007) Facial attractiveness: General patterns of facial preferences. Annu Rev Anthropol 70: 45-79.

Krutman J (2003) Vorzeitige Hautalterung durch ultraviolette Strahlung und andere Umweltnoxen. Der Hautarzt 54 (3): 300-301.

Krutman J, \& Gilchrest BA (2006) Photoaging of skin. In BA Gilchrest \& J Krutman (Eds.), Skin aging (pp. 33-43). Berlin Springer-Verlag.

Kuukäsjarvi S, Eriksson CJP, Koskela E, Mappes T, Nissinen K, \& Rantala MJ (2004) Attractiveness of women's body odors over the menstrual cycle: The role of oral contraceptives and receiver sex. Behav Ecol 15 (4): 579-584.

Langlois JH, Kalakanis L, Rubenstein AJ, Larson A, Hallam M, \& Smoot M (2000) Maxims and myths of beauty? A meta-analytic and theoretical review. Psychol Bull 126 (3): 390-423.

Langlois JH, Ritter JM, Roggman LA, \& Vaughn LS (1991) Facial diversity and infant preferences for attractive faces. Dev Psychol 27: 79-84.

Langlois JH, \& Roggman LA (1990) Attractive faces are only average. Psychol Sci 1: 115-121.

Langlois JH, Roggman LA, Casey RJ, Ritter JM, Rieser-Danner LA, \& Jenkins VY (1987) Infant preferences for attractive faces: Rudiments of a stereotype? Dev Psychol 23 (3): 363-369. 
Law Smith MJ, Perrett DI, Jones BC, Cornwell RE, Moore FR, Feinberg DR, Boothroyd LG, Durrani SJ, Stirrat MR, Whiten S, Pitman RM, \& Hillier SG (2006) Facial appearance is a cue to oestrogen levels in women. Proc R Soc Lond B Biol Sci 273: 135-140.

Lee MM, \& Lasker GW (1959) The sun-tanning potential of human skin. Hum Biol 31: 252-260.

Leung WC, \& Harvey I (2002) Is skin ageing in the elderly caused by sun exposure or smoking? Br J Dermatol 147 (6): 1187-1191.

Leyden JJ (1990) Clinical features of ageing skin. Br J Dermatol 122 Suppl 35: 1-3.

Little AC, Jones BC, De Bruine LM, \& Feinberg DR (2008) Symmetry and sexual dimorphism in human faces: Interrelated preferences suggest both signal quality. Behav Ecol 19 (4): 902-908.

Little AC, Jones BC, Penton-Voak IS, Burt DM, \& Perrett DI (2002) Partnership status and the temporal context of relationships influence human female preferences for sexual dimorphism in male face shape. Proc Biol Sci 269 (1496): 1095-1100.

Little AC, \& Mannion H (2006) Viewing attractive or unattractive same-sex individuals changes self-rated attractiveness and face preferences in women. Anim Behav 72: 981-987.

Lock-Andersen J, Drzewiecki KT, \& Wulf HC (1998) The measurement of constitutive and facultative skin pigmentation and estimation of sun exposure in Caucasians with basal cell carcinoma and cutaneous malignant melanoma. Br J Dermatol 139 (4): 610-617.

Loomis WF (1967) Skin-pigment regulation of vitamin-D biosynthesis in man. Science 157 (788): 501-506.

Lozano, \& George A (2008) Obesity and sexually selected anorexia nervosa (Vol. 71). Kidlington, ROYAUME-UNI: Elsevier.

Lu SY, \& Wu HC (2004) Initial diagnosis of anemia from sore mouth and improved classification of anemias by MCV and RDW in 30 patients. Oral Surg Oral Med Oral Pathol Oral Radiol Endod 98 (6): 679685.

Lucky AW (2004) Quantitative documentation of a premenstrual flare of facial acne in adult women. Arch Dermatol 140 (4): 423-424.

Luna M, Barritt J, Bar-Chama N, Copperman AB, Mukherjee T, \& Grunfeld L (2007) A negative correlation identified between paternal age and art outcome: Is there a male biological clock ticking? Fertil Steril 88: 114.

Luxen MF, \& Van de Vijver FJR (2006) Facial attractiveness, sexual selection, and personnel selection: When evolved preferences matter. J Organiz Behav 27: 241-255.

Madrigal L, \& Kelly W (2007) Human skin-color sexual dimorphism: A test of the sexual selection hypothesis. Am J Phys Anthropol 132: 470-482.

Madsen V, Valkiunas G, Iezhova TA, Mercade C, Sanchez M, \& Osorno JL (2007) Testosterone levels and gular pouch coloration in courting magnificent frigatebird (Fregata magnificens): Variation with ageclass, visited status and blood parasite infection. Horm Behav 51 (1): 156-163.

Mah K, \& Binik YM (2001) The nature of human orgasm: A critical review of major trends. Clin Psychol Rev 21 (6): 823-856.

Maner JK, Kenrick DT, Becker DV, Delton AW, Hofer B, Wilbur CJ, \& Neuberg SL (2003) Sexually selective cognition: Beauty captures the mind of the beholder. J Pers Soc Psychol 85 (6): 1107-1120.

Manning JT (1985) Choosy females and correlates of male age. J Theor Biol 116: 349-354. 
Manning JT, Bundred PE, \& Mather FM (2004) Second to fourth digit ratio, sexual selection, and skin colour. Evol Hum Behav 25: 38-50.

Manning JT, Scutt D, Whitehouse GH, Leinster SJ, \& Walton JM (1996) Asymmetry and the menstrual cycle in women. Ethol Sociobiol 17 (2): 129-143.

Manuskiatti W, Schwindt DA, \& Maibach HI (1998) Influence of age, anatomic site and race on skin roughness and scaliness. Dermatology 196 (4): 401-407.

Matts PJ (2008) New insights into skin appearance and measurement. J Investig Dermatol Symp Proc 13 (1): 69.

Matts PJ, Dykes PJ, \& Marks R (2007) The distribution of melanin in skin determined in vivo. Br J Dermatol 156 (4): 620-628.

Matts PJ, \& Fink B (2010) Chronic sun damage and the perception of age, health and attractiveness. Photochem Photobiol Sci 9 (4): 421-431.

Matts PJ, Fink B, Grammer K, \& Burquest M (2007) Color homogeneity and visual perception of age, health, and attractiveness of female facial skin. J Am Acad Dermatol 57 (6): 977-984.

McGuiness BW (1961) Skin pigmentation and the menstrual cycle. Br Med J 2: 563-565.

McMichael AJ, \& Beaglehole R (2000) The changing global context of public health. Lancet 356 (9228): 495499.

Michalska M, Chodorowska G, \& Krasowska D (2004) SIAscopy: A new non-invasive technique of melanoma diagnosis. Ann Univ Mariae Curie Sklodowska Med 59 (2): 421-431.

Miller GF (1998) A review of sexual selection and human evolution: How mate choice shaped human nature. In C Crawford \& D Krebs (Eds.), Evolution and Human Behavior: Ideas, Issues, and Applications.: Lawrence Erlbaum.

Mobius MM, \& Rosenblat TS (2006) Why beauty matters. J Econom 93 (3): 267-291.

Morrone A (2007) Anthropology of skin colors. In E Berardesca, JL Lévêque \& HI Maibach (Eds.), Ethnic skin and hair (pp. 1-12). New York: Informa Healthcare USA, Inc.

Moskovtsev SI, Willis J, \& Mullen JB (2006) Age-related decline in sperm desoxyribonucleic acid integrity in patients evaluated for male infertility. Fertil Steril 85 (2): 496-499.

Mulhern R, Fieldman G, Hussey T, Lévêque JL, \& Pineau P (2003) Do cosmetics enhance female Caucasian facial attractiveness? Int J Cosmet Sci 25: 199-205.

Nakagawa H, Imokawa G, Etoh T, \& Ishiabashi Y (1989) Melanogenesis in normal human epidermal melanocytes. Am J Clin Dermatol 92: 488.

Nash R, Fieldman G, Hussey T, Lévêque JL, \& Pineau P (2006) Cosmetics: They influence more than Caucasian female facial attractiveness. J Appl Soc Psychol 36 (2): 493-504.

Nelson RJ (2000) An introduction in behavioral endocrinology. Sunderland, MA, US: Sinauer Associates, Inc. Publishers.

Nguyen HT, Isaacowitz DM, \& Rubin PA (2009) Age- and fatigue-related markers of human faces: An eyetracking study. Ophthalmology 116 (2): 355-360.

Nieuwenhuijsen K, de Neef KJ, \& Slob AK (1986) Sexual behaviour during ovarian cycles, pregnancy and lactation in group-living stumptail macaques (Macaca arctoides). Hum Reprod 1 (3): 159-169. 
Nkengne A, Bertin C, Stamatas GN, Giron A, Rossi A, Issachar N, \& Fertil B (2008) Influence of facial skin attributes on the perceived age of Caucasian women. J Eur Acad Dermatol Venereol 22 (8): 982-991.

Nole G, \& Johnson AW (2004) An analysis of cumulative lifetime solar ultraviolet radiation exposure and the benefits of daily sun protection. Dermatol Ther 17 Suppl 1: 57-62.

Nordlund JJ (2009) Cutaneous ectoparasites. Dermatol Ther 22 (6): 503-517.

Norton HL, Kittles RA, Parra E, McKeigue P, Mao X, Cheng K, Canfield VA, Bradley DG, McEvoy B, \& Shriver MD (2007) Genetic evidence for the convergent evolution of light skin in Europeans and East Asians. Mol Biol Evol 24 (3): 710-722.

Ohshima H, \& Takiwaki H (2008) Evaluation of dark circles of the lower eyelid: Comparison between reflectance meters and image processing and involvement of dermal thickness in appearance. Skin Res Technol 14 (2): 135-141.

Ortonne JP, \& Bissett DL (2008) Latest insights into skin hyperpigmentation. J Investig Dermatol Symp Proc 13 (1): 10-14.

Ostner J, Chalise MK, Koenig A, Launhardt K, Nikolei J, Podzuweit D, \& Borries C (2006) What Hanuman langur males know about female reproductive status. Am J Primatol 68 (7): 701-712.

Özener B, \& Fink B (2010) Facial symmetry in young girls and boys from a slum and a control area of Ankara, Turkey. Evol Hum Behav 31: 436-441.

Parish LC, \& Crissey JT (1988) Cosmetics: A historical review. Clin Dermatol 6 (3): 1-4.

Parra EJ (2007) Human pigmentation variation: Evolution, genetic basis, and implications for public health. Am J Phys Anthropol 45: 85-105.

Pawlowski B, \& Dunbar RI (1999) Impact of market value on human mate choice decisions. Proc Biol Sci 266 (1416): 281-285.

Penton-Voak IS, \& Perrett DI (2001) Male facial attractiveness: Perceived personality and shifting female preferences for male traits across the menstrual cycle. Adv Study Behav 30: 219-259.

Perrett DI, Penton-Voak IS, Little AC, Tiddeman BP, Burt DM, Schmidt N, Oxley R, Kinloch N, \& Barrett L (2002) Facial attractiveness judgements reflect learning of parental age characteristics. Proc Biol Sci 269 (1494): 873-880.

Peters A, Rhodes G, \& Simmons LW (2007) Contributions of the face and body to overall attractiveness. Anim Behav 73: 937-942.

Piérard GE (1998) EEMCO guidance for the assessment of skin colour. J Eur Acad Dermatol Venereol 10: 111.

Piérard GE, Uhoda I, \& Pierard-Franchimont C (2003) From skin microrelief to wrinkles. An area ripe for investigation. J Cosmet Dermatol 2 (1): 21-28.

Pipitone RN, \& Gallup GG (2008) Women's voice attractiveness varies across the menstrual cycle. Evol Hum Behav 29 (4): 268-274.

Preece, Stephen J, Claridge, \& Ela (2004) Spectral filter optimization for the recovery of parameters which describe human skin. IEEE Trans Pattern Anal Mach Intell 26 (7): 913-922.

Quatresooz P, Thirion L, Pierard-Franchimont C, \& Piérard GE (2006) The riddle of genuine skin microrelief and wrinkles. Int J Cosmet Sci 28 (6): 389-395. 
Querleux B, Baldeweck T, Diridollou S, de Rigal J, Huguet E, Leroy F, \& Barbosa VH (2009) Skin from various ethnic origins and aging: An in vivo cross-sectional multimodality imaging study. Skin Res Technol 15 (3): 306-313.

Quiroga RM (2005) Anti-aging medicine as it relates to dermatology. In CM Burgess (Ed.), Cosmetic Dermatology (1st ed., pp. 1-16). Berlin Springer-Verlag.

Rawlings AV, \& Matts PJ (2005) Stratum corneum moisturization at the molecular level: An update in relation to the dry skin cycle. J Invest Dermatol 124 (6): 1099-1110.

Rees JL (2004) The genetics of sun sensitivity in humans. Am J Hum Genet 75: 739-751.

Reichert KE, Heistermann M, Hodges JK, Boesh C, \& Hohmann G (2002) What females tell males about their reproductive status: Are morphological and behavioural cues reliable signals of ovulation in bonobos (Pan paniscus)? Ethology 108: 583-600.

Rhodes G (2006) The evolutionary psychology of facial beauty. Annu Rev Psychol 57: 199-226.

Rhodes G, Simmons LW, \& Peters A (2005) Attractiveness and sexual behavior: Does attractiveness enhance mating success? Evol Hum Behav 26: 186-201.

Rhodes G, Yoshikawa S, Palermo R, Simmons LW, Peters M, Lee K, Halberstadt J, \& Crawford JR (2007) Perceived health contributes to the attractiveness of facial symmetry, averageness, and sexual dimorphism. Perception 36 (8): 1244-1252.

Rigters-Aris CAE (1972) A reflectometric study of the skin in Dutch families. J Hum Evol 2 (4): 123-136.

Riley PA (2003) Melanogenesis and melanoma. Pigment Cell Res 16 (5): 548-552.

Robert C, \& Kupper TS (1999) Inflammatory skin diseases, T cells, and immune surveillance. N Engl J Med 341 (24): 1817-1828.

Roberts SC (2008) Communication of mate quality in humans. In P D'Ettorre \& DP Hughes (Eds.), Sociobiology of communication and interdisciplinary perspective (pp. 157-170). Copenhagen: Oxford Scholarship Online.

Roberts SC, Havlicek J, Flegr J, Hruskova M, Little AC, Jones BC, Perrett DI, \& Petrie M (2004) Female facial attractiveness increases during the fertile phase of the menstrual cycle. Proc R Soc Lond B Biol Sci 271: 270-S272.

Roberts SC, Little AC, Gosling LM, Perrett DI, Carter V, Jones BC, Penton-Voak IS, \& Petrie M (2005) MHC-heterozygosity and human facial attractiveness. Evol Hum Behav 26: 213-226.

Robins AH (1991) Biological perspetives on human pigmentation. Cambridge New York: Cambridge University Press.

Romm S (1989) The changing face of beauty. Aesthetic Plast Surg 13 (2): 91-98.

Roulin A, Almasi B, Rossi-Pedruzzi A, Ducrest A-D, Wakamatsu K, Miksik I, Blount JD, Jenni-Eiermann S, \& Jenni L (2008) Corticosterone mediates the condition-dependent component of melanin-based coloration. Anim Behav 75: 1351-1358.

Roulin A, \& Dijkstra C (2003) Genetic and environmental components of variation in eumelanin and phaeomelanin sex-traits in the barn owl. Heredity 90 (5): 359-364.

Rubenstein AJ (2005) Variation in perceived attractiveness: Differences between dynamic and static faces. Psychol Sci 16 (10): 759-762.

Samson N, Fink B, \& Matts PJ (2010) Visible skin condition and perception of human facial appearance. Int J Cosmet Sci 32: 167-184. 
Samson N, Fink B, Matts PJ, Dawes NC, \& Weitz S (2010) Visible changes of female facial skin surface topography in relation to age and attractiveness perception. J Cosmet Dermatol 9 (2): 79-88.

Saunders JC, \& Armstrong ML (2005) Experiences and influences of women with cosmetic tattooing. Dermatol Nurs 17 (1): 23-28, 31.

Schaefer K, Lauc T, Mitteroecker P, Gunz P, \& Bookstein FL (2006) Dental arch asymmetry in an isolated Adriatic community. Am J Phys Anthropol 129 (1): 132-142.

Schieke SM (2003) Lichtalterung und Infrarotstrahlung. Der Hautarzt 54: 822-824.

Schildkrout E (2004) Inscribing the body. Annu Rev Anthropol 33: 319-344.

Schlessinger J (2007) Skin care for men and its marketing. Dermatol Ther 20 (6): 452-456.

Schneider L-A, Wlaschek M, \& Scharffetter-Kochanek K (2003) Hautalterung - Klinik und Pathogenese. J Dtsch Dermatol Ges 1: 223-233.

Schulman JM, \& Fisher DE (2009) Indoor UV tanning and skin cancer: Health risks and opportunities. Curr Opin Oncol 21 (2): 114-149.

Schürer NY (2003) Anti-aging: Fakten und Visionen. Der Hautarzt 54: 833-838.

Sefcek JA, Brumbach BH, Vasquez G, \& Miller GF (2006) The evolutionary psychology of human mate choice: How ecology, genes, fertility, and fashion influence mating behaviour. J Psychol Human Sex 18: $125-185$.

Senju A, \& Johnson MH (2009) The eye contact effect: Mechanisms and development. Trends Cogn Sci 13 (3): 127-134.

Setchell JM, Charpentier MJE, Abbott KM, Wickings EJ, \& Knapp LA (2009) Is brightest best? Testing the Hamilton-Zuk hypothesis in mandrills. Int J Primatol 30: 825-844.

Setchell JM, \& Dixson AF (2001) Changes in the secondary sexual adornments of male mandrills (Mandrillus sphinx) are associated with gain and loss of alpha status. Horm Behav 39 (3): 177-184.

Setchell JM, Wickings EJ, \& Knapp LA (2006) Signal content of red facial coloration in female mandrills (Mandrillus sphinx). Proc Biol Sci 273 (1599): 2395-2400.

Shaw JC (2002) Acne: Effect of hormones on pathogenesis and management. Am J Clin Dermatol 3 (8): 571 578.

Shirakabe Y, Suzuki Y, \& Lam SM (2003) A new paradigm for the aging Asian face. Aesthetic Plast Surg 27 (5): 397-402.

Singh D (2004) Mating strategies of young women: Role of physical attractiveness. J Sex Res 41 (1): $43-54$.

Singh D, \& Bronstad PM (2001) Female body odour is a potential cue to ovulation. Proc Biol Sci 268 (1469): 797-801.

Slayden SM, Moran C, Sams Jr. WM, Boots LR, \& Azziz R (2001) Hyperandrogenemia in patients presenting with acne. Fertil Steril 75 (5): 889-892.

Slevec J, \& Tiggemann M (2010) Attitudes toward cosmetic surgery in middle-aged women: Body image, aging anxiety, and the media. Psychol Women $Q$ 34: 65-74.

Slominski A, \& Wortsman J (2000) Neuroendocrinology of the skin. Endocr Rev 21 (5): 457-487.

Snell RS, \& Turner R (1966) Skin pigmentation in relation to the menstrual cycle. J Invest Dermatol 47 (2): 147-155. 
Sobotka T (2010) Shifting parenthood to advanced reproductive ages: Trends, causes and consequences. In JC Tremmel (Ed.), A young generation under pressure? (Vol. 2, pp. 129-154). Berlin Heidelberg: Springer-Verlag.

Sommer B, Zschocke I, Bergfeld D, Sattler G, \& Augustin M (2003) Satisfaction of patients after treatment with botulinum toxin for dynamic facial lines. Dermatol Surg 29 (5): 456-460.

Stahl W, Heinrich U, Jungmann H, von Laar J, Schietzel M, Sies H, \& Tronnier H (1998) Increased dermal carotenoid levels assessed by noninvasive reflection spectrophotometry correlate with serum levels in women ingesting Betatene. J Nutr 128 (5): 903-907.

Stamatas GN, Zmudzka BZ, Kollias N, \& Beer JZ (2004) Non-invasive measurements of skin pigmentation in situ. Pigment Cell Res 17 (6): 618-626.

Stanford CB (1998) The social behavior of chimpanzees and bonobos: Empirical evidence and shifting assumptions. Curr Anthropol 39 (4): 399-420.

Stephen ID, Law Smith MJ, Stirrat MR, \& Perrett DI (2009) Facial skin coloration affects perceived health of human faces. Int J Primatol 30 (6): 845-857.

Stevens M, Caswell Stoddard M, \& Higham JP (2009) Studying primate color: Towards visual systemdependent methods. Int J Primatol 30: 893-917.

Stevens M, \& Cuthill IC (2005a) The unsuitability of HTML-based colour charts for estimating animal colours -- a comment on Berggren and Merila (2004). Front Zool 2: 14

Stevens M, \& Cuthill IC (2005b) The unsuitability of HTML-based colour charts for estimating animal colours: A comment on Berggren and Merilä (2004). Front Zool 2: 14

Stevens M, \& Merilaita S (2009) Animal camouflage: Current issues and new perspectives. Philos Trans $R$ Soc Lond B Biol Sci 364 (1516): 423-427.

Stirn A (2003) Body piercing: Medical consequences and psychological motivations. Lancet 361 (9364): 12051215.

Stoll S, Shalita AR, Webster GF, Kaplan R, Danesh S, \& Penstein A (2001) The effect of the menstrual cycle on acne. J Am Acad Dermatol 45 (6): 957-960.

Strum SC, \& Western JD (1982) Variation in fecundity with age and environment in olive baboons (Papio anubis). Am J Primatol 3: 61-76.

Sturm RA (2006) A golden age of human pigmentation genetics. Trends Genet 22 (9): 464-468.

Sulem P, Gudbjartsson DF, Stacey SN, Helgason A, Rafnar T, Magnusson KP, Manolescu A, Karason A, Palsson A, Thorleifsson G, Jakobsdottir M, Steinberg S, Palsson S, Jonasson F, Sigurgeirsson B, Thorisdottir K, Ragnarsson R, Benediktsdottir KR, Aben KK, Kiemeney LA, Olafsson JH, Gulcher J, Kong A, Thorsteinsdottir U, \& Stefansson K (2007) Genetic determinants of hair, eye and skin pigmentation in Europeans. Nat Genet 39 (12): 1443-1452.

Swami V, Furnham A, \& Joshi K (2008) The influence of skin tone, hair length, and hair colour on ratings of women's physical attractiveness, health and fertility. Scand J Psychol 49 (5): 429-437.

Symons D (1995) Beauty is the adaptation of the beholder: The evolutionary psychology of human female sexual attractiveness. In PR Abramson \& SD Pinkerton (Eds.), Sexual nature, sexual culture (pp. 80-118). Chicago: The University of Chicago Press.

Tarin JJ, \& Gomez-Piquer V (2002) Do women have a hidden heat period? Hum Reprod 17 (9): 2243-2248.

Taylor SC (2005) Photoaging and pigmentary changes of the skin. In CM Burgess (Ed.), Cosmetic Dermatology (1st ed., pp. 29-52). Berlin Heidelberg: Springer-Verlag. 
Thacker PD (2004) Biological clock ticks for men, too: Genetic defects linked to sperm of older fathers. JAMA 291 (14): 1683-1685.

Thiboutot D (2001) Hormones and acne: Pathophysiology, clinical evaluation, and therapies. Semin Cutan Med Surg 20 (3): 144-153.

Thiboutot D (2007) Hormonal influences in acne. In GF Webster \& AV Rawlings (Eds.), Acne and its therapy (pp. 83-93). New York: Informa Healthcare USA, Inc.

Thornhill R, \& Gangestad SW (1993) Human facial beauty: Averageness, symmetry and parasite resistance. Hum Nat 4 (3): 237-269.

Thornhill R, \& Grammer K (1999) The body and face of woman: One ornament that signals quality? Evol Hum Behav 20: 105-120.

Thornhill R, \& Moller AP (1997) Developmental stability, disease and medicine. Biol Rev Camb Philos Soc 72 (4): 497-548.

Thornton MJ (2002) The biological actions of estrogens on skin. Exp Dermatol 11 (6): 487-502.

Trivers R (1972) Parental investment and sexual selection. In B Campbell (Ed.), Sexual selection and the descent of man 1871-1971 (pp. 136-179). Chicago: Aldine-Atherton.

Tschachler E, \& Morizot F (2006) Ethnic differences in skin aging. In BA Gilchrest \& J Krutman (Eds.), Skin aging (pp. 23-31). Berlin: Springer-Verlag.

Tsumura N, Haneishi H, \& Miyake Y (1999) Independent-component analysis of skin color image. J Opt Soc Am A Opt Image Sci Vis 16 (9): 2169-2176.

Tsumura N, Ojima N, Sato K, Shiraishi M, Shimizu H, Nabeshima H, Akazaki S, Hori K, \& Miyake Y (2003) Image-based skin color and texture analysis/synthesis by extracting hemoglobin and melanin information in the skin. Paper presented at the ACM SIGGRAPH 2003 Papers.

Turkington C, \& Dover JS (2007) The encyclopedia of skin and skin disorders. (3rd ed.). New York: Facts on File.

Uebing A, Gatzoulis MA, von Kaisenberg C, Kramer H, \& Strauss A (2008) Congenital heart disease in pregnancy. Dtsch Arztebl Int 105 (19): 347-354.

UNESCO (1969) Four statements on the race question. Paris: UNESCO.

Van den Berghe PL, \& Frost P (1986) Skin color preference, sexual dimorphism and sexual selection: A case of gene culture evolution? Ethn Racial Stud 9 (1): 87-113.

Wagatsuma H (1967) The social perception of skin color in Japan. Daedalus 96: 407-443.

Waitt C, Gerald MS, Little AC, \& Kraiselburd E (2006) Selective attention toward female secondary sexual color in male rhesus macaques. Am J Primatol 68 (7): 738-744.

Wallen K (1990) Desire and ability: Hormones and the regulation of female sexual behavior. Neurosci Biobehav Rev 14 (2): 233-241.

Watson PJ, \& Thornhill R (1994) Fluctuating asymmetry and sexual selection. Trends Evol Ecol 9: 21-25.

Weatherall IL, \& Coombs BD (1992) Skin color measurements in terms of CIELAB color space values. $J$ Invest Dermatol 99 (4): 468-473.

Wernick M, \& Manaster GJ (1984) Age and the perception of age and attractiveness. Gerontologist 24 (4): 408-414. 
Wilcox AJ, Dunson D, \& Baird DD (2000) The timing of the "fertile window" in the menstrual cycle: Day specific estimates from a prospective study. BMJ 321 (7271): 1259-1262.

Wisser O (2009) Visuelle Wahrnehmung von Frauengesichtern in Abhängigkeit von Variationen der Hauttopographie. Unpublished Diploma thesis, University of Goettingen, Goettingen.

Yaar M (2006) Clinical and histological features of intrinsic versus extrinsic skin aging. In BA Gilchrest \& J Krutman (Eds.), Skin aging (pp. 9-22). Berlin: Springer Verlag.

Yaar M, Eller MS, \& Gilchrest BA (2002) Fifty years of skin aging. J Investig Dermatol Symp Proc 7 (1): 5158.

Yaar M, \& Gilchrest BA (2001) Ageing and photoageing of keratinocytes and melanocytes. Clin Exp Dermatol 26 (7): 583-591.

Zahavi A (1975) Mate selection: A selection for a handicap. J Theor Biol 53 (1): 205-214.

Zonios G, Bykowski J, \& Kollias N (2001) Skin melanin, hemoglobin, and light scattering properties can be quantitatively assessed in vivo using diffuse reflectance spectroscopy. J Invest Dermatol 117 (6): 14521457.

Zouboulis CC (2000) Human skin: An independent peripheral endocrine organ. Horm Res 54 (5-6): 230-242.

Zouboulis CC (2003) Intrinsische Hautalterung. Der Hautarzt 54: 825-832. 


\section{APPENDIX}

\section{Appendix to Part II}

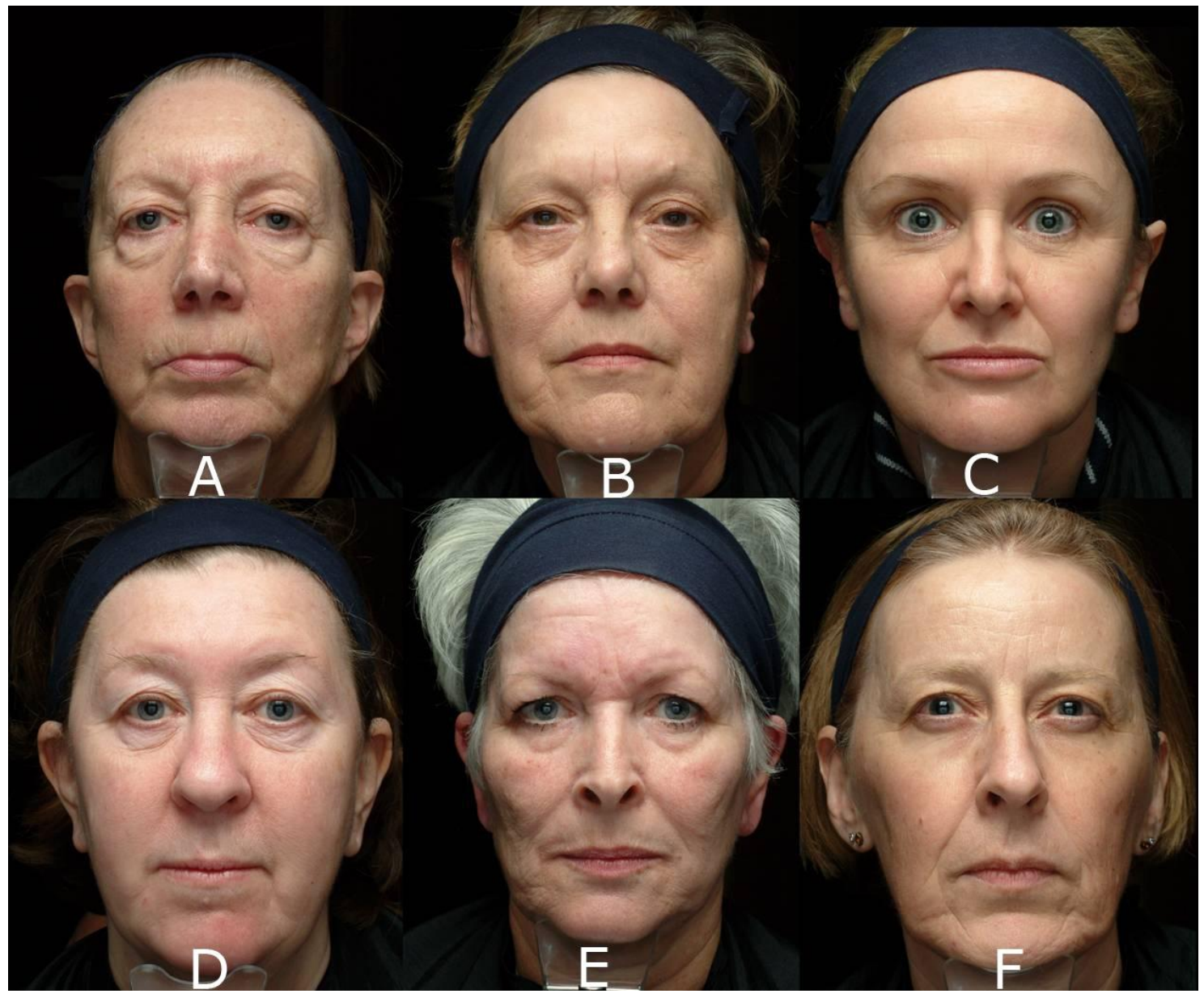

Appendix 1 Female facial images used for stimuli generation.

Appendix 2 Chronological age of female subjects whose images have been used for stimuli generation.

\begin{tabular}{cc} 
subject & chronological age $[\mathrm{yr}]$ \\
\hline A & 61 \\
B & 61 \\
C & 47 \\
D & 50 \\
E & 61 \\
F & 52
\end{tabular}




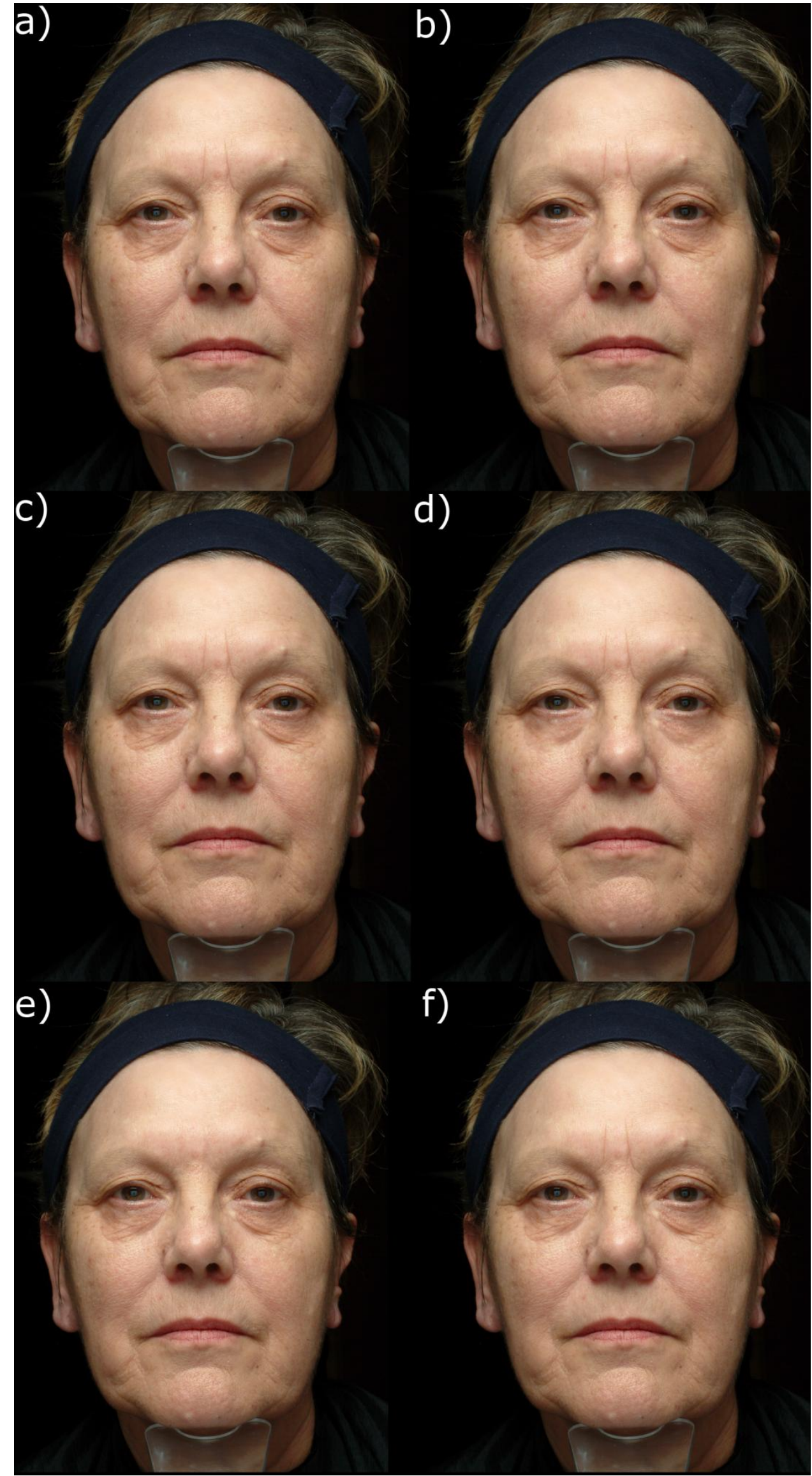

Appendix 3 Examples for facial stimuli varying in the magnitude of skin surface topography in different facial areas. Presented is the (a) original image as well as images with removed surface topography (b) on the cheeks, (c) the crow's feet area, (d) underneath the eyes, (e) the forehead, and (f) above the upper lip. 


\section{Appendix to Part III}

Appendix 4 Descriptive statistics for female participants. Presented are women's age, length of menstrual cycle, and the day relative to the estimated ovulation when photographed in the estimated late follicular phase (session 1) and mid-luteal phase (session 2).

\begin{tabular}{|c|c|c|c|c|c|}
\hline Women & Age & Cycle length & Session 1 & Session 2 & $\begin{array}{l}\text { Excluded from data } \\
\text { analysis because of }\end{array}$ \\
\hline 501 & 29 & 28 & -1 & 11 & \\
\hline 502 & 30 & 27 & -1 & 11 & image quality \\
\hline 503 & 29 & 22 & -3 & 8 & \\
\hline 504 & 25 & 26 & -3 & 6 & \\
\hline 505 & 24 & 27 & 3 & 7 & cycle irregularities \\
\hline 506 & 28 & 26 & -1 & 8 & \\
\hline 507 & 29 & 28 & 3 & 9 & cycle irregularities \\
\hline 508 & 26 & 30 & -3 & 8 & \\
\hline 509 & 25 & 30 & -3 & 5 & \\
\hline 510 & 24 & 28 & -2 & 6 & \\
\hline 511 & 24 & 29 & 0 & 8 & \\
\hline 512 & 29 & 27 & -3 & 5 & \\
\hline 513 & 26 & $\mathrm{x}$ & 0 & $\mathrm{x}$ & illness \\
\hline 514 & 23 & $\mathrm{x}$ & -3 & $\mathrm{x}$ & illness \\
\hline
\end{tabular}
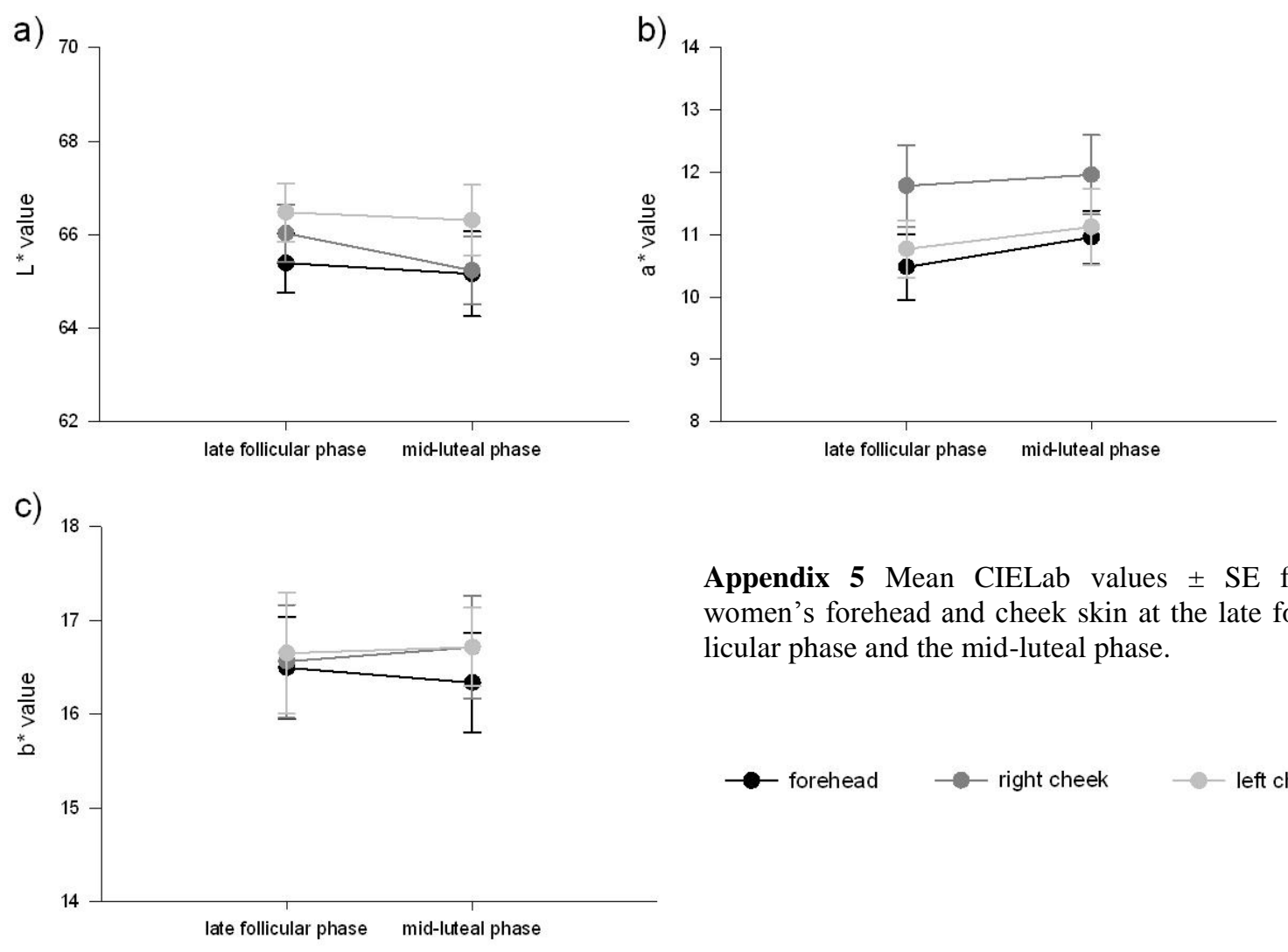

Appendix 5 Mean CIELab values \pm SE for women's forehead and cheek skin at the late follicular phase and the mid-luteal phase.

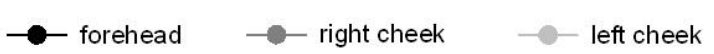




\section{AfFiliations OF CO-AUThORS*}

Bernhard Fink

Nancy C. Dawes

Paul J. Matts

Shannon Mc Arthur-Weitz
Department of Sociobiology / Anthropology, University of Goettingen, Goettingen, Germany

The Procter \& Gamble Company, Sharon Woods Technical Centre, Cincinnati, Ohio, The United States

The Procter \& Gamble Company, Rusham Park Technical Centre, Whitehall Lane, Egham, Surrey, United Kingdom

The Procter \& Gamble Company, Sharon Woods Technical Centre, Cincinnati, Ohio, The United States 


\section{ACKNOWLEDGEMENTS}

I wish to thank all the many nice people who contributed to this thesis in various ways. First, I would like to gratefully thank Prof. Dr. Peter M. Kappeler for providing the possibility to work on human primates, a subject that is rather uncommon in his department. Most of all I have to thank my supervisor Dr. Bernhard Fink who gave me the opportunity to join his team as a non-evolutionary psychologist and to work on this exciting, yet little-studied topic. $\mathrm{He}$ offered his precious advice and knowledge on human skin many times during appealing discussions and was always interested in the progress of my thesis. Thank you very much.

My special thanks go out to my Co-Authors from Procter and Gamble, Dr. Paul J. Matts, Nancy C. Daws, and Shannon Weitz, who additionally organised and conducted the perception studies in Cincinnati. Not to forget, many thanks for the financial funding by the "Deutsche Förderungsgesellschaft" (FI 1450-4-1). In this context, I would also like to express my gratitude for the opportunity to participate in the DFG Science TV project. Although the project was pretty time consuming, it helped me to view my own work from a different perspective and to express scientific research in more simple terms. Lots of thanks to Dr. EvaMaria Streier, Andreas Szelenyi, Anndrea Reichmut, and Alexander Koch.

I am also grateful to Yvonne Laferè, Tobias Kahland, Kathrin Rieck, Anika Saul, Naema Schlagowski, Karina and Andrea Schell, Femke Pflüger, and Anika Weydinger who collected the perception data for the first study in Goettingen. Many thanks also to Tamara Prentzell for assisting in the course of her internship. Furthermore, I would like express my deepest gratitude to Nadine Hugill for her constructive criticism on my thesis and Laurel Bunse for polishing up my English in some parts of the thesis. I also owe thanks to Jeanette Freynik, Benjamin Meyer, Livia Schäffler, Frederick Wehrle, and Oliver Wisser, not only for scientific but also physical support by helping me move house. Jeanette and Olli, thank you for all the fun during the DFG Science TV project. My special thanks to Livia who not only shared an office with me during my first year, but also the many ups and downs of my thesis. Thank you for your friendship. I am also thankful to Susanne Röder for being my office mate the last $1 \frac{1}{2} 2$ years. I will never forget our co-working on most of the DFG Science TV storyboards and the many long walks home through the snow. Not to forget, many thanks to all the other nice people who I met in the course of my PhD: Anna Besson, Wiebke Groer, Anke Gutman, Silja Köchy, Sebastian Kuntze, Kathrin Schlange, Christiane Venjacob, Bettina Weege, and many many more. 
With all my heart I would like to thank Nina Kossack, Katja Peplinski, and Martin Windoffer. Thank you for being always there for me. I also owe thanks to my family, especially to my mum, who encouraged me in my career as long as I can remember. Without her, I wouldn't be where I am now. Thank you so much. My deepest thanks, however, go to Benedikt Schäffler, who truly kept me from going insane while working on this thesis. I can't thank you enough for all your immense understanding, patience, and support.

Last but definitely not least, many thanks to all the volunteers who participated in the experiments of my thesis. Without you, the thesis would not have been possible. 


\section{EIDESSTATTLICHE ERKLÄRUNG}

Hiermit erkläre ich, dass ich die vorliegende Doktorarbeit selbständig verfasst und keine anderen als die angegebenen Quellen und Hilfsmittel benutzt habe. Alle Stellen der Arbeit, die anderen Werken dem Wortlaut oder Sinn nach entnommen wurden, habe ich in jedem Fall unter Angabe der Quelle als Entlehnung kenntlich gemacht. Ich versichere weiterhin, dass diese Arbeit in gleicher oder ähnlicher Form noch keiner anderen Prüfungskommission vorgelegt wurde.

Eigene Beiträge im Verhältnis zu denen von Koautoren bei bereits publizierten oder zur Publikation einzureichenden Teilen dieser Arbeit sind wie folgt:

Kapitel 2 Nadine Samson führte die Literaturrecherche durch und verfasste das Manuskript. Bernhard Fink und Paul J. Matts wirkten als Co-Autoren an der Finalisierung des Manuskriptes mit.

Kapitel 3 Bernhard Fink und Paul J. Matts verfassten das Design der Studie. Nadine Samson generierte die Stimuli, führte die Datenanalyse aus und verfasste das Manuskript. Tobias Kahland, Yvonne Laferè, Femke Pflüger, Kathrin Rieck, Anika Saul, Andrea Schell, Karina Schell, Naema Schlagowski und Anika Weydinger rekrutierten die Probanden für die Beurteilungen der Stimuli in Göttingen, Nancy C. Dawes und Shannon Weitz in Cincinnati. Bernhard Fink, Nancy C. Dawes, Paul Matts und Shannon Weitz wirkten als Co-Autoren an der Finalisierung des Manuskriptes mit.

Kapitel 4 Bernhard Fink und Nadine Samson verfassten das Design der Studie. Nadine Samson generierte die Stimuli, führte die Datenanalyse aus und verfasste das Manuskript. Tamara Prentzell und Nadine Samson rekrutierten die Probanden und führten mit ihnen die Wahrnehmungsstudie durch. Bernhard Fink und Paul Matts wirkten als Co-Autoren an der Finalisierung des Manuskriptes mit.

Kapitel 5 Bernhard Fink und Nadine Samson verfassten das Design der Studie. Nadine Samson generierte die Stimuli, führte die Datenanalyse aus und verfasste das Manuskript. Jeanette Freynik, Susanne Röder und Nadine Samson rekrutierten die Probanden und führten mit ihnen die Wahrnehmungsstudie durch. Bernhard Fink und Paul J. Matts wirkten als Co-Autoren an der Finalisierung des Manuskriptes mit.

Göttingen, den 26.04.2011

Nadine Samson 